\title{
ABSTRACT \\ GEOPHYSICAL INVESTIGATION OF THE ROYAL ARCHES MEADOW ROCK AVALANCHE IN YOSEMITE VALLEY - CA
}

Since the retreat of the Last Glacial Maximum ( 15,000 years ago), rockfalls have been the major force shaping Yosemite Valley, California. Rock avalanches are an especially large rockfall/rock slide that extends far beyond the cliff where they originate. These events are infrequent, but can reach hundreds of meters into the valley, and deposit an extremely large volume of debris when compared with regular rockfall events. Yosemite Valley is home of at least ten rock avalanche deposits, with the Royal Arches Meadow rock avalanche (RAMRA), situated in eastern Yosemite Valley, being the oldest event ( 14,000 yr BP). Because this event occurred shortly after the Last Glacial Maximum (LGM), mapping the interface between this rock avalanche and the underlying valley sediments can give us insights about the valley elevation and overall geomorphic state of Yosemite Valley shortly after the LGM. Holocene aggradation covers parts of the deposit, reducing its surface expression. This represents a challenge for estimating the dimensions of the deposit. To overcome this obstacle, we used a combination of geophysical methods (Electrical Resistivity Tomography (ERT) and Ground Penetrating Radar (GPR)) to image the interface between the RAMRA and underlying valley sediments. The strong dielectric permittivity and electrical resistivity contrast between the rock avalanche and the underlying sediments make both electrical resistivity tomography and ground penetrating radar ideal methods for our purpose. This then allowed us to infer that the surface of the valley underneath the Royal Arches Meadow Rock Avalanche is in average $1209 \mathrm{~m}$ with a variation of $+/-3.2 \mathrm{~m}$.

Marcus Vinicius Azevedo de Oliveira Pacheco May 2019 



\title{
GEOPHYSICAL INVESTIGATION OF THE ROYAL ARCHES MEADOW ROCK AVALANCHE IN YOSEMITE VALLEY - CA
}

\author{
by \\ Marcus Vinicius Azevedo de Oliveira Pacheco
}

\author{
A thesis \\ submitted in partial \\ fulfillment of the requirements for the degree of \\ Master of Science in Geology \\ in the College of Science and Mathematics \\ California State University, Fresno \\ May 2019
}




\section{APPROVED \\ For the Department of Earth and Environmental Sciences:}

We, the undersigned, certify that the thesis of the following student meets the required standards of scholarship, format, and style of the university and the student's graduate degree program for the awarding of the master's degree.

\section{Marcus Vinicius Azevedo de Oliveira Pacheco}

\section{Thesis Author}

Christopher Pluhar (Chair)

Earth and Environmental Sciences

Alain Plattner

Geological Sciences - University of Alabama

Greg Stock

National Park Service - Yosemite National Park

For the University Graduate Committee:

Dean, Division of Graduate Studies 


\section{AUTHORIZATION FOR REPRODUCTION}

\section{OF MASTER'S THESIS}

$\mathrm{X} \quad \mathrm{I}$ grant permission for the reproduction of this thesis in part or in its entirety without further authorization from me, on the condition that the person or agency requesting reproduction absorbs the cost and provides proper acknowledgment of authorship.

Permission to reproduce this thesis in part or in its entirety must be obtained from me.

Signature of thesis author: 


\section{ACKNOWLEDGMENTS}

I am the author of this thesis, but as you read it, it will become clear that this was not a one-person project. Instead, the outcomes reached by me here are the result of an extensive network of collaboration, discussion, mentoring, and financial support provided by multiple people and entities.

I gratefully acknowledge Yosemite National Park Service and Park Geologist Dr.

Greg Stock, for issuing the research permit that allowed us to study and better understand the intriguing and fascinating "rock avalanche laboratory" that is Yosemite Valley.

I am also thankful for the fieldwork force and assistance within the geophysical data acquisition provided by Dr. Alain Plattner, Dr. Guohai Jia, Tina Anderson, Jukya and Ryuya Kimura, Dr. Christopher Pluhar, Dr. Mathieu Richaud, Amalie Larsen, and Jessie Shields.

I would like to express my gratitude to my advisor, Dr. Allain Plattner, for the mentoring, valuable and constant feedback, discussion, and for providing me with an amazing open source GPR processing software (GPRPy). I am also thankful for the insightful advice and feedback provided by the committee members: Dr. Alain Plattner, Dr. Christopher Pluhar, and Dr. Greg Stock.

Moreover, I would not have been able to accomplish this project without the generous financial support provided by the Richard Chambers Memorial scholarship (Northern California Geological Society), the Fresno Gem \& Mineral Society scholarship, and the Graduate Research and Creative Activities award (DRGS).

Lastly, I would like to dedicate this work to my family and friends who supported me in this long journey. 


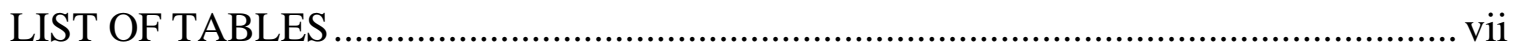

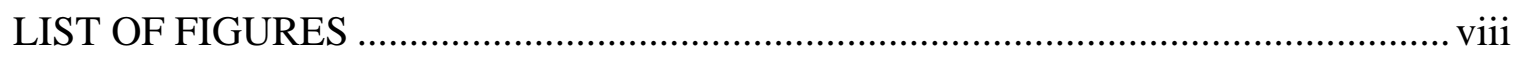

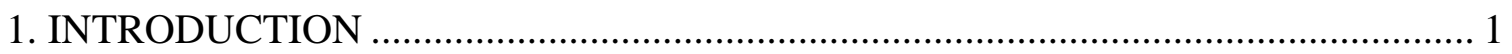

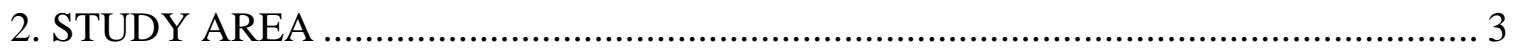

2.1 Physical Setting and Geology of Yosemite Valley ................................................. 4

2.2 Glacial Cycles in Yosemite Valley …………….................................................. 5

2.3 Rockfall and Rock Avalanches in Yosemite Valley ............................................. 5

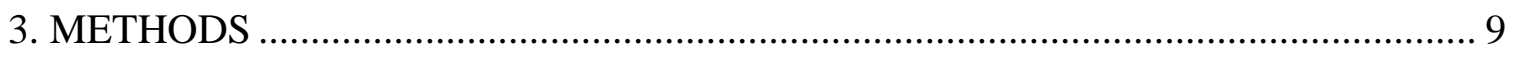

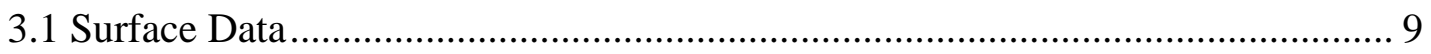

3.2 Ground Penetrating Radar (GPR) ………………….................................... 10

3.3 Electrical Resistivity Tomography (ERT) …………………………………..... 33

3.4 Constraining the ERT data with Selected GPR Reflectors .................................... 39

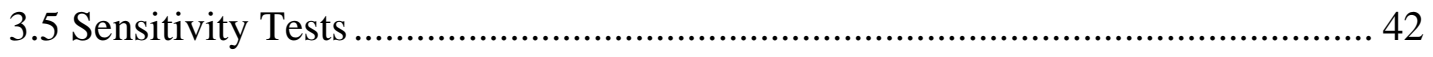

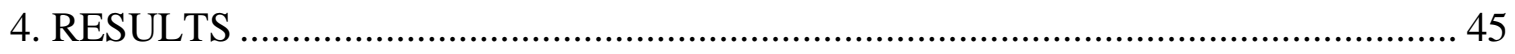

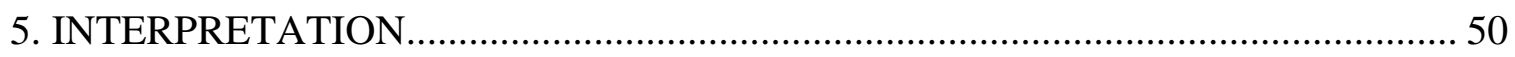

5.1 Estimating the Bottom of the Rock Avalanche................................................. 50

5.2 Estimating the Top of the Rock Avalanche …………………………................. 51

5.3 Distal Extent of the Rock Avalanche in Subsurface ............................................. 55

5.4 Lateral Extent of the Rock Avalanche in Subsurface ......................................... 55

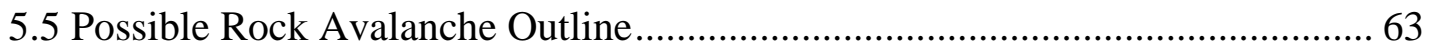

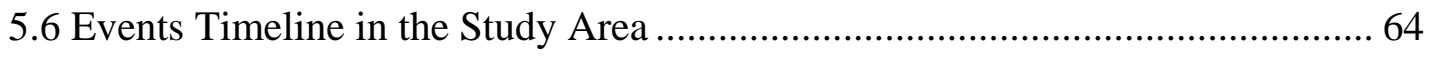

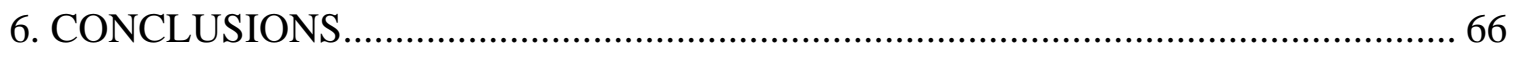

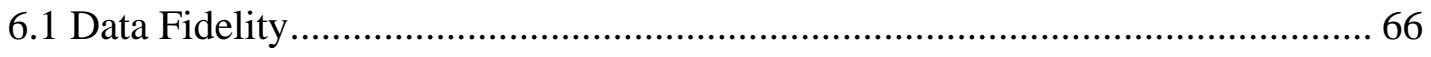




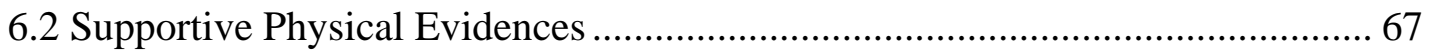

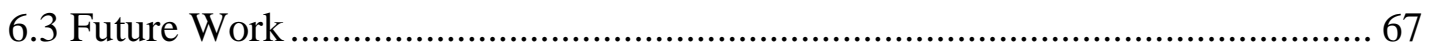

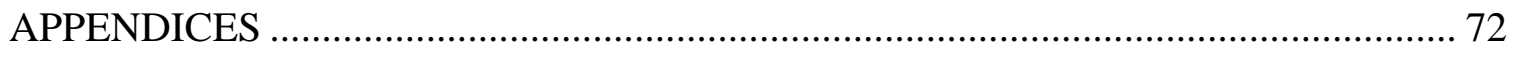

APPENDIX A: GROUND PENETRATIND RADAR MAP AND PROFILES ............ 73

APPENDIX B: ELECTRO RESISTIVITY TOMOGRAPHY PROFILES AND MAP.. 81 


\section{LIST OF TABLES}

Table 1: ERT Acquisition Parameters for profiles shown in Figure 27 ......................... 36

Table 2: Reflector's Average Elevation Along the Profile............................................ 48

Table 3: Reflector's Elevation (m) Across Profiles......................................................... 48 


\section{LIST OF FIGURES}

Page

Figure 1: LiDAR map of Yosemite Valley, CA. Area of study highlighted in red. Modified after Brody et al., (2015) ............................................................... 3

Figure 2: (A) The Lyell Fork of the Tuolumne River, looking southward....................... 4

Figure 3: (A) Exposed section of the Mirror Lake rock avalanche deposit $\sim \mathrm{NE}$ of the study area. (B) and (C) are closer shots of the fine to very fine material. ......... 6

Figure 4: Map view of the study area (A) and surficial expression of the Royal Arches Meadow Rock Avalanche (B-G).

Figure 5: (A) Data acquisition at an individual survey point, showing GPR system components and subsurface reflector configuration. (B) Radar reflection profile resulting from sequential plotting of individual traces from adjacent survey points.

Figure 6: Map view with location of the GPR profiles at the study area....................... 12

Figure 7: GPR data processing workflow used in this investigation........................... 13

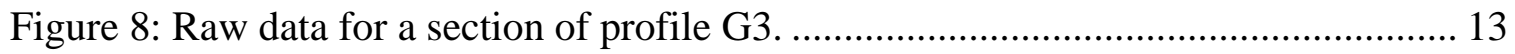

Figure 9: (A) time zero correction for profile G3. (B) zoom at the beginning of the radargram, note the gap between the zero and the subsurface signal (approximately at $3 \mathrm{~ns}$ ). (C) zoom in after time zero correction

Figure 10: Application of dewow filter on a section of profile G3. (A) before dewow.

(B) after dewow.

Figure 11: Profile G3 before (A) and after (B) the removal of the mean trace

Figure 12: Profile G3 before (A) and after (B) the application of t-power gain. Yellow arrows highlight the position of possible reflectors of interest.

Figure 13: WARR plot. (A) recorded waves and (B) colorful lines and hyperbolas highlighting direct and reflected waves.

Figure 14: WARR data acquisition at the Mirror Lake Rock Avalanche.

Figure 15: Reflected wave path (red arrows) given a distance $(\mathrm{X})$ along a profile, a height $(\mathrm{h})$ and three mediums with different velocities $\left(\mathrm{V}_{0}, \mathrm{~V}_{1}\right.$ and $\left.\mathrm{V}_{2}\right)$. 
Figure 16: (A) Raw WARR data. (B) hyperbolic stacked amplitudes velocity semblance (green arrows highlight the best hyperbolic fit). (C) linear stacked amplitudes velocity semblance (brown and blue arrows highlight the best linear fit for ground and air wave respectively), and (D) picked velocities for air, ground and reflected waves.

Figure 17: (A) hyperbola found within profile G6 (highlighted in the dashed black circle) and (B) plotted hyperbola with velocity of $0.125 \mathrm{~m} / \mathrm{ns}$ (blue dashed hyperbola).

Figure 18: Profile G3 Two-way travel time (ns) axis converted into depth (m). 27

Figure 19: On an unmigrated reflection profile, reflector points from a planar, dipping reflector $(\operatorname{dip}=\alpha \mathrm{t})$ have undergone down-dip movement and the resulting record surface has a shallower dip ( $\alpha s)$ 28

Figure 20: (A) before and (B) after the application of the F-k Migration 29

Figure 21: Profile G3: (A) Before and (B) after topographic correction............................ 30

Figure 22: Graph shows the depth error for a velocity shift of $0.012 \mathrm{~m} / \mathrm{ns}$. 31

Figure 23: Terminology to define and describe radar surfaces, radar packages and radar facies .....

Figure 24: ERT field equipment testing at CSU, Fresno campus. (A) field setup. (B) Resistivity meter, power cables, and marine battery. And (C) electrodes...... 33

Figure 25: Explained scheme of the relationship between electrode distance (red triangles), and the depth of collected data (colored circles).......................... 34

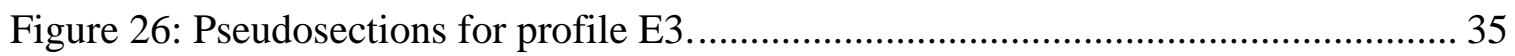

Figure 27: Colored dots illustrate ERT transects at the study area (each individual dot represents an electrode position).

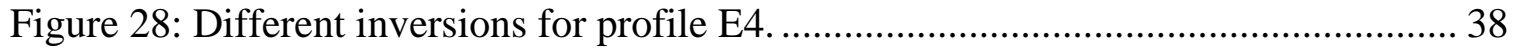

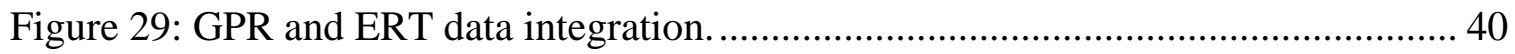

Figure 30: ERT profile E3 data inversion constrain using GPR reflectors..................... 41

Figure 31: ERT profile E3 data inversion constrain using GPR reflectors...................... 42

Figure 32: GPR profile G3 converted to depth/elevation using three different velocities: (A) $0.108 \mathrm{~m} / \mathrm{hs}$, (B) $0.110 \mathrm{~m} / \mathrm{ns}$, and (C) $0.125 \mathrm{~m} / \mathrm{ns}$.

Figure 33: ERT profile E3 inverted using reflector Beta, tracked from radargrams converted with three different velocities: (A) $0.108 \mathrm{~m} / \mathrm{ns}$, (B) $0.110 \mathrm{~m} / \mathrm{ns}$, and $(\mathrm{C}) 0.125 \mathrm{~m} / \mathrm{ns}$. 
Figure 34: Oblique view of the study area with acquired geophysical profiles' position (red lines).

Figure 35: Three-dimensional view of profile G3 crossing profile G6 46

Figure 36: (A) map view showing the position of the GPR profiles, (B) profile G4, (C) section of profile G6 and (D) profile G3

Figure 37: Oblique view (NE) of the GPR profiles with the interpolated reflectors: (A) Kappa, (B) Alpha, (C) Beta, and Gamma.

Figure 38: Inverted result using reflector Beta for profiles: (A) E3, (B) E4 and (C) E5. (D) ERT profiles position in map view, (E) GPR profiles position in map view and $(\mathrm{F})$ oblique view of GPR profiles with Beta Interface.

Figure 39: Beta interface sloping upward in the valley direction (A) ERT profile E3.

(B) GPR profile G3. (C) ERT profile E4. And (D) GPR profile G4

Figure 40: (A) Map view of the study area, green line highlights the position of GPR profile G4 and red dotes highlight the elevation of the Tenaya creek at that position in meters. (B) GPR profile G4, with tracked reflectors highlighted with black lines.

Figure: 41: (A) and (C) are inverted results considering reflector Beta (black line) for profile E3 and E4 respectively. (B) and (D) show the possible distal edge of the RAMRA identified on GPR profiles G3 and G4 respectively. And

(E) Plan view of the identified features in the study area.

Figure 42: Oblique view of the study area with GPR profiles (red lines), highlighting the profiles close to talus deposits (yellow portion of the map. Elevation > 1223).

Figure 43: (A) GPR profile G1 with reflector "X" (black line). (B) ERT profile E1 inverted with reflector " $\mathrm{X}$ " (black line)

Figure 44: (A) ERT profile E1 and (B) inferred western position of the rock avalanche based on ERT profile 1

Figure 45: ERT profile E5 constrained with GPR reflector Beta. (B) section of GPR profile 5.2, yellow line highlights reflector Beta. And (C) map view of morphologies interpreted as edges of the avalanche.

Figure 46: (A) Map view of the study area with the possible extent of the avalanche (dashed yellow line). And (B) zoom in in of the distal most portion of the study area (green dotted line highlights the terrace).

Figure 48: Cartoon illustrating the sequence of events in the study area. (A) Study area during the LGM and Yosemite lake stage. (B) RAMRA event. (C) Modern aggradation in the study area. 


\section{INTRODUCTION}

With the retreat of glaciers in Yosemite Valley, California 15,000 - 20,000 years ago, rockfall has been the major force shaping the valley (Stock et al., 2013). Rock avalanches are an especially large rockfall or rock slide event that extends far beyond the cliff where it was originated. These events are rare, and typically move large masses of material over long distances in a matter of seconds (Stock \& Uhrhammer, 2010). Consequently, these events are an important geomorphic process reshaping the landscape of Yosemite Valley.

While some of the rock avalanche deposits and other mass wasting in Yosemite Valley are well studied and mapped (e.g., Stock, Luco, et al., 2012; Stock \& Uhrhammer, 2010; and Wieczorek, Morrissey, Iovine, \& Godt, 1998), little is known about the Royal Arches Meadow Rock Avalanche (RAMRA). This deposit lies in the eastern Yosemite Valley, and the current understanding of the avalanche extent is mainly based on interpretation of LiDAR (Light Detection and Ranging) images and surface mapping (G. Stock Personal communication). While these techniques provide reliable information of the exposed part of the RAMRA, the depth and extent of this deposit in the subsurface remain uncertain. Also, parts of the rock avalanche that are covered by more recent sedimentary processes are difficult to identify from surface observation.

Cosmogenic ${ }^{10} \mathrm{Be}$ exposure ages demonstrate that the Royal Arches Meadow Rock Avalanche happened 14,030 \pm 340 BP (G. Stock, personal communication). This makes this avalanche deposit not only the oldest dated rock avalanche in Yosemite Valley, but also provides a time stamp of the state of the valley shortly after deglaciation. Therefore, mapping the interface between the rock avalanche deposit and underlying valley floor sediments could give us insight of the state of the valley shortly after the Last Glacial Maximum (15,000 - 20,000 yr B.P.). In addition, mapping the full extent of the 
rock avalanche may provide valuable information for future research related to the dynamics of those events, because the runout extent of an avalanche, along with its associated volume and slope, are typically used to understand the event kinematics, which can also improve risk assessment (e.g., Wieczorek et al., 1999; Guzzetti et al., 2003; Stock, Luco, et al., 2012).

Geophysical methods have been successfully applied to image mass wasting deposits (e.g., Sass, 2006; Otto \& Sass, 2006; Socco et al., 2010; Brody et al. 2015, Liu \& Plattner 2018), allowing researchers to better estimate volume, image internal structures, and to track lateral continuity in depth. In addition, Doetsch, Linde, Pessognelli, Green, \& Günther, (2012), have demonstrated the effectiveness of using Ground Penetrating Radar (GPR) to constrain electrical resistivity tomography (ERT). Inspired by these works, we combined ERT and GPR surveys to image the subsurface of the Royal Arches Meadow rock avalanche. These geophysical methods are highly suited to the area of study because of the conductivity contrast between the underlying valley and local avalanche deposit (e.g., Brody et al. 2015, Liu \& Plattner 2018). 


\section{STUDY AREA}

Yosemite Valley is a $\sim 1 \mathrm{~km}$ deep glacially carved canyon in the Sierra Nevada, California, USA (Matthes, 1930; Huber et al., 1987), home to some of the largest granitic rock faces in the world, with a $\sim 1 \mathrm{~km}$ deep glacially carved canyon in the Sierra Nevada, California, USA (Bateman, 1992). As a consequence of those steep and tall walls, rockfalls and other mass movements are common in Yosemite National Park. From 1857 to 2011, 925 mass wasting events were documented in the park, including rock fall, rock slides, debris flows, etc (Stock et al., 2013). The area of study for this project is the Royal Arches Meadow rock avalanche, which lies in the eastern Yosemite Valley, inside Yosemite National Park in California (Figure 1).

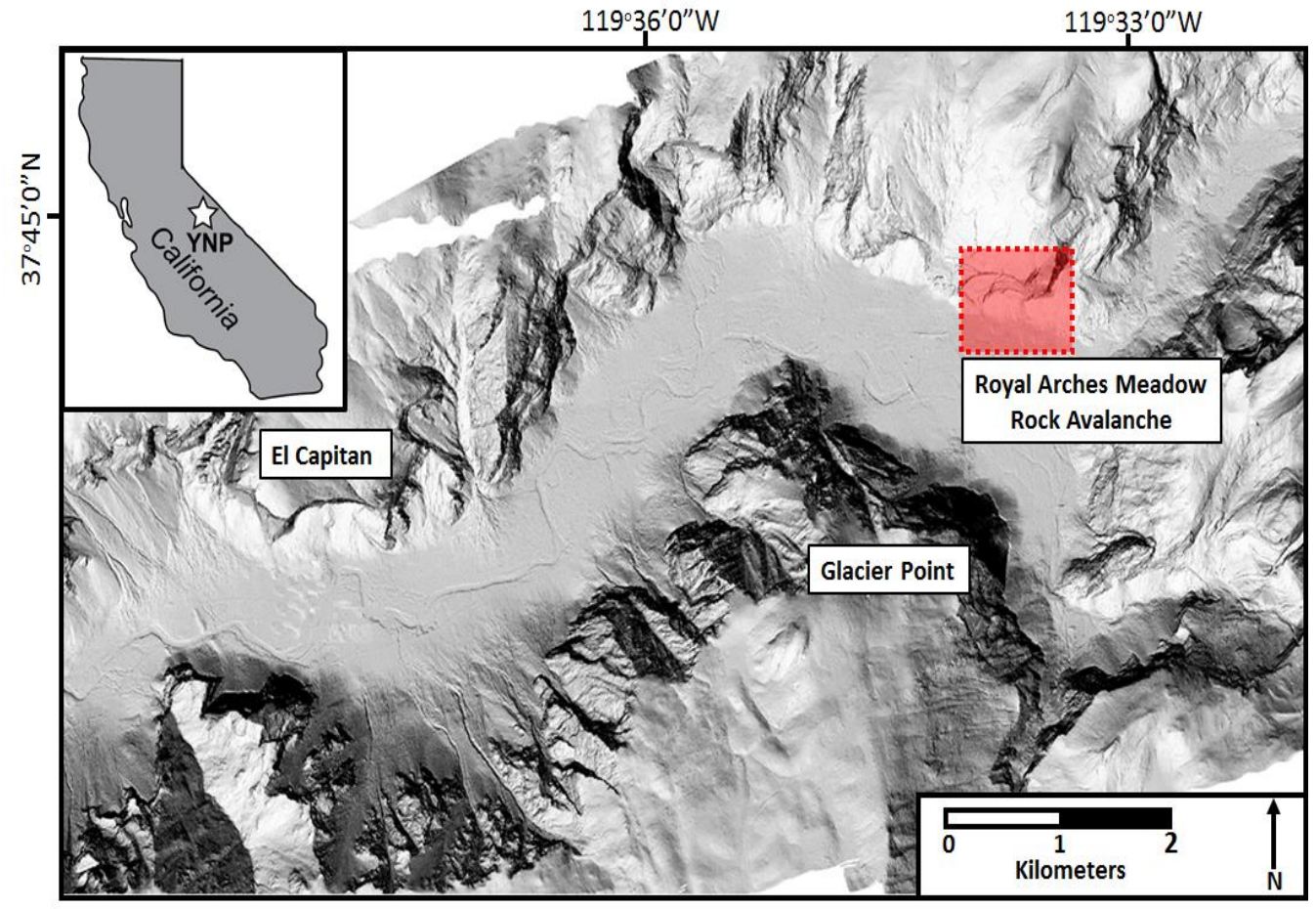

Figure 1: LiDAR map of Yosemite Valley, CA. Area of study highlighted in red. Modified after Brody et al. (2015) 


\subsection{Physical Setting and Geology of Yosemite Valley}

Yosemite Valley, located in Yosemite National Park, lies in the central part of the Sierra Nevada. The Sierra Nevada is an asymmetric mountain range having a western slope broader than the eastern escarpment. During the late Cenozoic, uplift along the faults of the eastern escarpment tilted the western slope into a broad upland surface. Subsequently, glacial and fluvial erosion started incising narrow and steep canyons contributing to create steep cliffs in Yosemite Valley (Matthes, 1930; Huber 1987; Wieczorek \& Jäger, 1996;).

The $\sim 1$ kilometer tall and massive granitic cliffs in Yosemite valley can support extremely steep angles, and even overhanging rock faces such as El Capitan, Half Dome, and Leaning Tower (Stock \& Uhrhammer, 2010). Seismic data collected by Gutenberg, Buwalda, \& Sharp (1956) indicated that the bedrock below the valley floor is as deep as $600 \mathrm{~m}$, and it is filled by glacial, deltaic and lacustrine deposits. The infilling of Yosemite Valley with those sediments explains the relative flat valley surface observed today, which differs from the typical U-shape valley left behind by glaciers. Figure 2 shows a similar example of a U-shape valley filled with sediments.
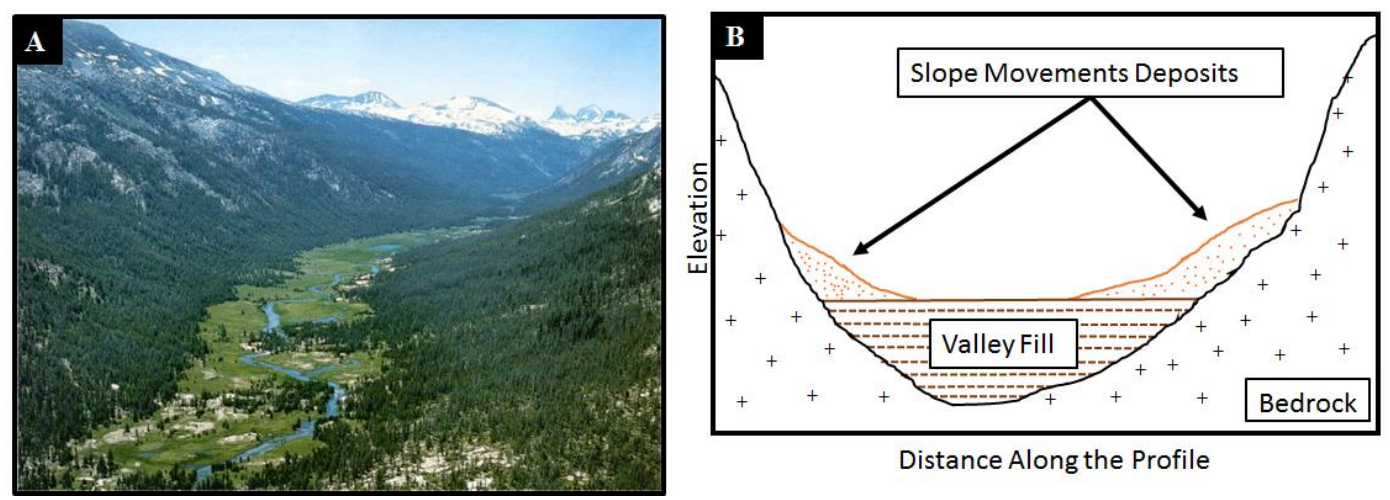

Figure 2: (A) The Lyell Fork of the Tuolumne River, looking southward. This canyon is a typical U-shaped valley formed by glacial erosion (B) Sketch illustrating the physical setting of U-shaped Yosemite Valley. Although eroded by glaciers, the U-shape of Yosemite Valley is related more to talus accumulations on a flat sediment floor. (Source of figure (A): yosemite.ca.us/library/geologic_story_of_yosemite/final_evolution.html 


\subsection{Glacial Cycles in Yosemite Valley}

Yosemite Valley has undergone several glaciation cycles over the past several million years. However, the record of glaciation in Yosemite National Park is very incomplete. The most recent (Tioga) glaciation peaked between 28000 and 17000 year BP and only partially filled Yosemite Valley (Huber, 1987; Guzzetti et al., 2003). Subsequently, Yosemite Valley is thought to have deglaciated by about 15,000 to 17,000 years ago (Huber, 1987; Stock \& Uhrhammer, 2010). And since the last deglaciation, rockfalls along with other mass wasting deposits have been relatively well preserved in Yosemite Valley (Stock, Luco, et al., 2012).

Near the study area (Royal Arches Meadow), Haddon et al., (2016) described a sequence of glacial deposits (Tioga till, 19,000 - 15,000 years B. P.), overlaid by postglacial deposits (fluvial, deltaic and lacustrine). On top of that lies on the Royal Arches Meadow rock avalanche (14,000 \pm 340 years B.P.). Lastly, quaternary fluvial and talus deposits partly cover the Royal Arches Meadow rock avalanche.

\subsection{Rockfall and Rock Avalanches in Yosemite Valley}

Rockfall in Yosemite Valley ranges in size from small individual blocks $\left(<1 \mathrm{~m}^{3)}\right.$ to rock avalanches (up to approximately 11 million $\mathrm{m}^{3}$ ) (Wieczorek, Morrissey, Iovine, \& Godt, 1999; Stock et al., 2011; 2012; 2013). Most Yosemite Valley rockfall debris accumulates at the base of the cliffs, forming a wedge-shaped deposit called a talus deposit (Wieczorek et al., 1999). Infrequently, extremely large rockfalls will extend out further into the valley floor (hundreds of meters scale); these events are termed rock avalanches (Wieczorek et al., 1999). Those massive slope events consist of rock debris and are generally characterized by distinctive morphologies, long runoff distances (relative to their fall heights), velocities of tens of meters per second, and volumes exceeding $1.0 \times 10^{6} \mathrm{~m}^{3}$ (Stock \& Uhrhammer, 2010). 
Northeast of our study area, Tenaya Creek has exposed the interior of the Mirror Lake Rock Avalanche (Figure 3A), revealing the structure and organization of the deposit in a profile. There, we observed a matrix supported deposit, with sediments ranging from large angular clasts (centimeters to meters scale) to fine sediments (millimeter to micrometer scale) (Figure 3B and C).
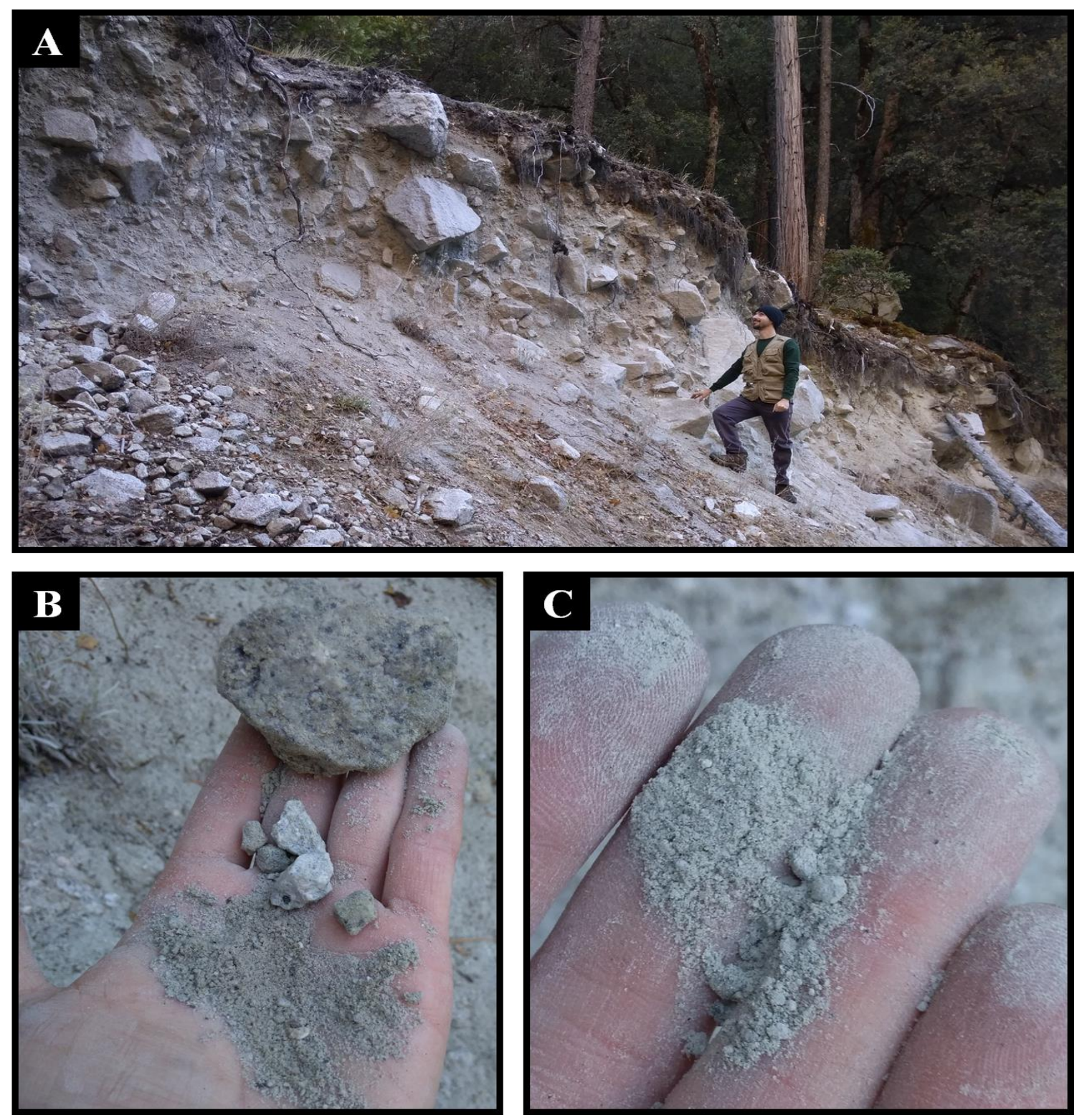

Figure 3: (A) Exposed section of the Mirror Lake rock avalanche deposit $\sim \mathrm{NE}$ of the study area. (B) and (C) are closer shots of the fine to very fine material. 
In the study area, our physical observations are restricted to the portion of the avalanche exposed in the surface (Figure 4). In the proximal part of the deposit, we observed large boulders burriend along with a series of drainages of finer sediments coming from the talus deposits (Figure 4 A-B). As we move towards the distal portion of the avalanche deposit (SW direction), we observed that the bolders decreease in size and surficial expression (from several meters to centimeters scale, and) (Figure 4 D-F), until they complete desapear in the southmost portion (Figure $4 \mathrm{G}$ ). 

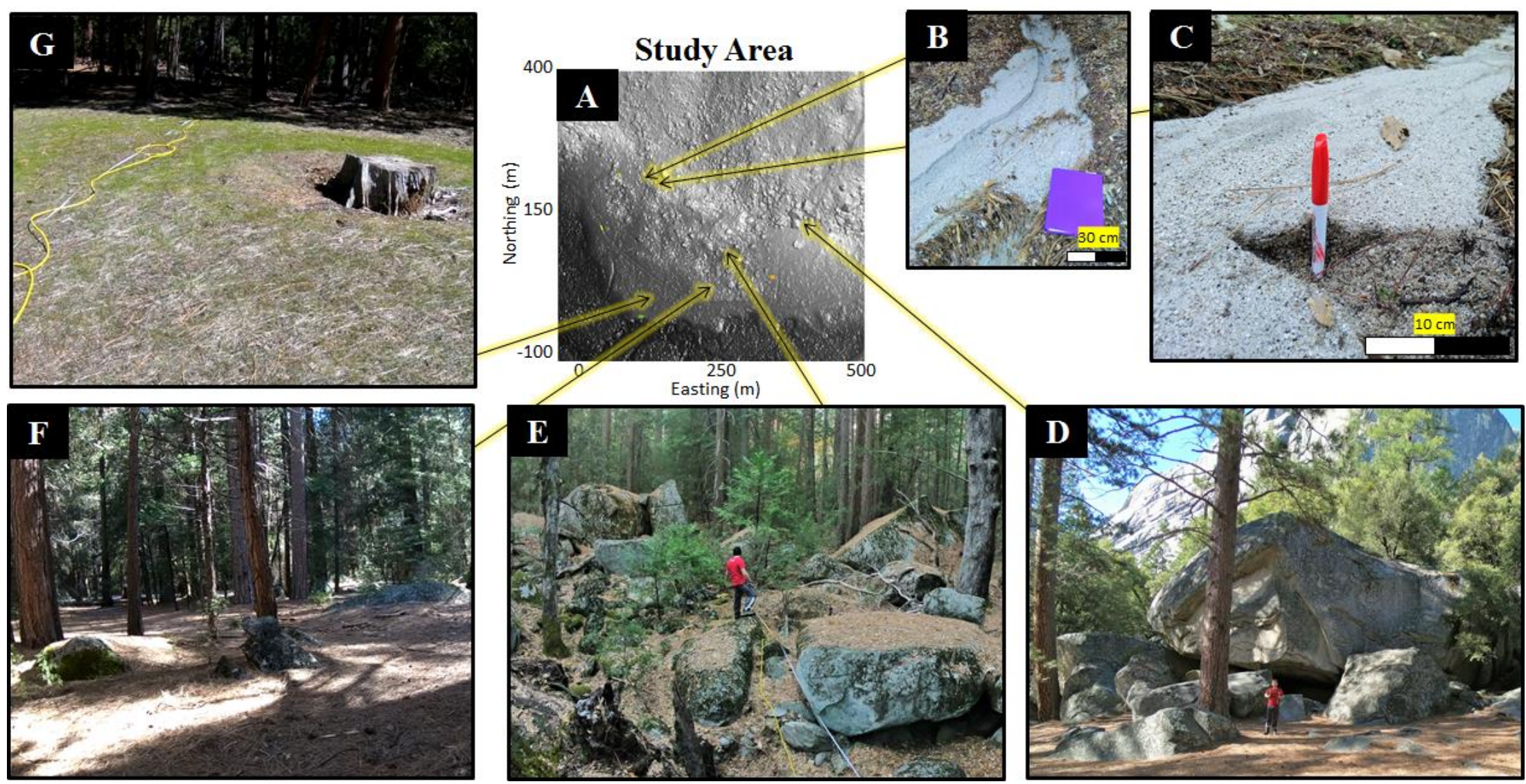

Figure 4: Map view of the study area (A) and surficial expression of the Royal Arches Meadow Rock Avalanche (B-G). 


\section{METHODS}

Most studies related to mass wasting events are limited to surface observations such as surficial geological mapping with the help of LiDAR. This represent a challenge in terms of volume estimation, because the depth of the deposit cannot be easily observed from the surface.

To overcome those limitations, we combined surface information (e.g. LiDAR), Electrical Resistivity Tomography (ERT) and Ground Penetrating Radar (GPR) data to image the internal structure of the Royal Arches Meadow rock avalanche deposit and its interface with the underling valley sediments.

While both methods rely on electrical resistivity contrasts, the way they sense the subsurface is different. Electrical resistivity tomography can detect bulk resistivity values but typically cannot identify the exact location of sharp interfaces. On the other hand, ground penetrating radar is ideally suited for identifying sharp contrasts, but it cannot image the absolute resistivity values. As successfully demonstrated by Sass (2006), Brody et al. (2015), and Liu and Plattner (2018) the strong electrical resistivity contrast between the resistive rock avalanche and the more conductive underlying sediments (valley floor deposits) makes both electrical resistivity tomography and ground penetrating radar ideal methods for our purpose.

\subsection{Surface Data}

We georeferenced our geophysical data using differential GPS measurements acquired with a Trimble Geo 7X GPS. Under ideal conditions (good satellite coverage, no obstruction from trees, mountains), GPS measurements can provide a horizontal standard deviation of less than a few centimeters. The elevation values, on the other hand are much less precise, with standard deviations closer to a meter or more. To overcome the limitations of elevation accuracy, we use the LiDAR topography data available from 
opentopo.sdsc.edu/ to replace the elevation information provided by the GPS with the elevation provided by the LiDAR. We used the Trimble Pathfinder software to conduct the GPS differential correction. This gave us accurate northing and easting locations.

We then used MATLAB to identify and remove outliers, and to interpolate the elevation from the LiDAR topography data at our measurement locations.

Lastly, the maps are displayed using the Universal Transverse Mercator (UTM) coordinate system (zone 11S). To facilitate the visualization of the study area map scale, we used coordinates (zone 11S): Easting $274170 \mathrm{~m}$ and Northing $4180400 \mathrm{~m}$ as a zero referential.

\section{$\underline{3.2 \text { Ground Penetrating Radar (GPR) }}$}

Ground-penetrating radar (GPR) is a noninvasive geophysical technique that detects electrical discontinuities in the shallow subsurface (typically $<50 \mathrm{~m})(\mathrm{Neal}$, 2004). The most common form of GPR measurements keep a transmitter antenna and a receiver antenna at a fixed distance (Figure 5A) and moves them along a profile line on the surface to detect reflections from subsurface features (Jol, 2008). This approach is called "common-offset profiling."

As described by Neal (2004), common-offset profile data are turned into a radargram by plotting the traces recorded at each profile location next to each other (Figure 5B). Each trace results from the GPR system emitting a short pulse of highfrequency electromagnetic energy, typically in the $\mathrm{MHz}$ range into the ground. As the electromagnetic wave propagates downwards it experiences materials of differing electrical properties. If the radar wave is reflected off an obstacle, the reflected signal is detected and recorded by the receiving antenna. 


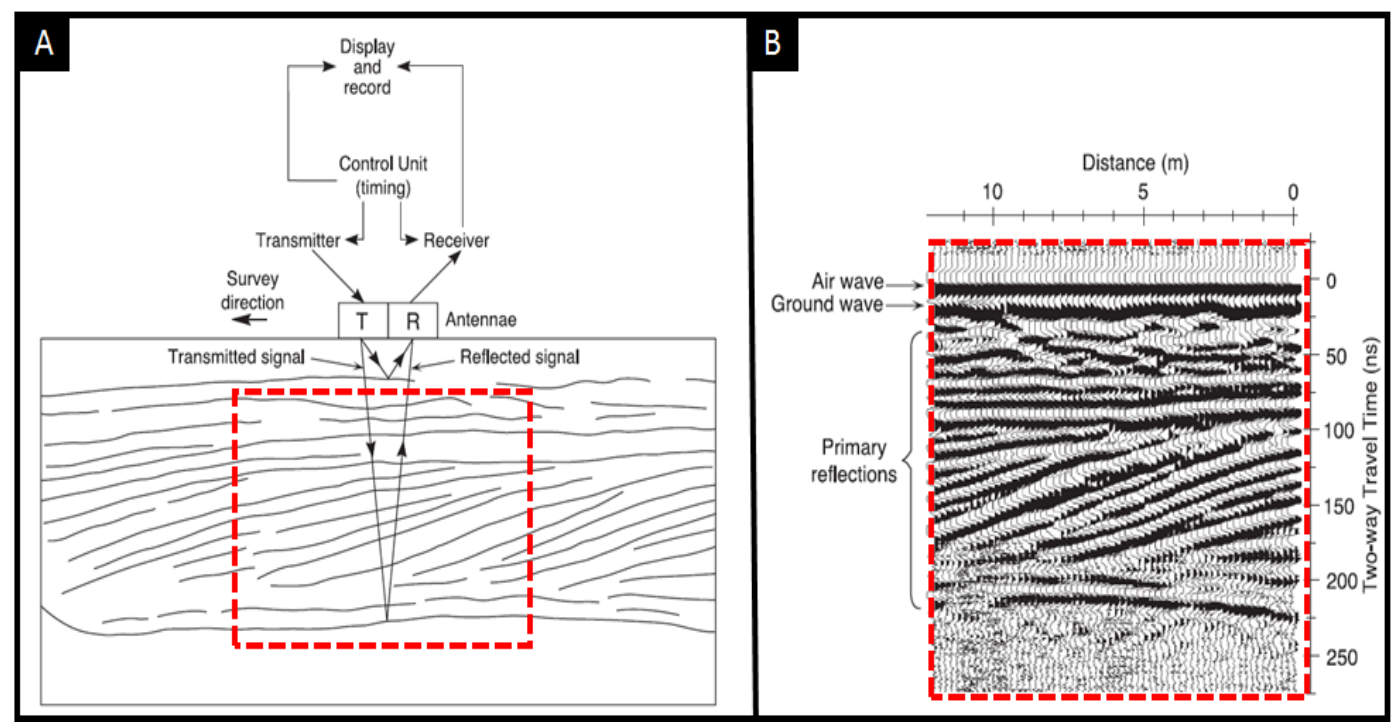

Figure 5: (A) Data acquisition at an individual survey point, showing GPR system components and subsurface reflector configuration. (B) Radar reflection profile resulting from sequential plotting of individual traces from adjacent survey points. Position of the airwave, ground wave and primary reflections are indicated. Source: Neal (2004)

\subsubsection{GPR Data Acquisition}

Eight GPR profiles were collected with a Sensors \& Software PulseEKKO Pro (50 and $100 \mathrm{MHz}$ ) system (Figure 6). Profiles G1, G2, G3, G5, G6, G7 and G8 were collected with the $50 \mathrm{MHz}$ antenna, while profile G4 was collected with the $100 \mathrm{MHz}$ antenna.

Based on LiDAR and surface observations, we acquired profiles along what we believe was the flow direction of the rock avalanche ( NE-SW). We also attempted to acquire profiles perpendicular to the possible path of the rock avalanche. Note that due to obstacles in the field (e.g., boulders and fallen trunks), some of the profiles curve and do not follow the desired path (parallel or perpendicular to the possible rock avalanche flow). 


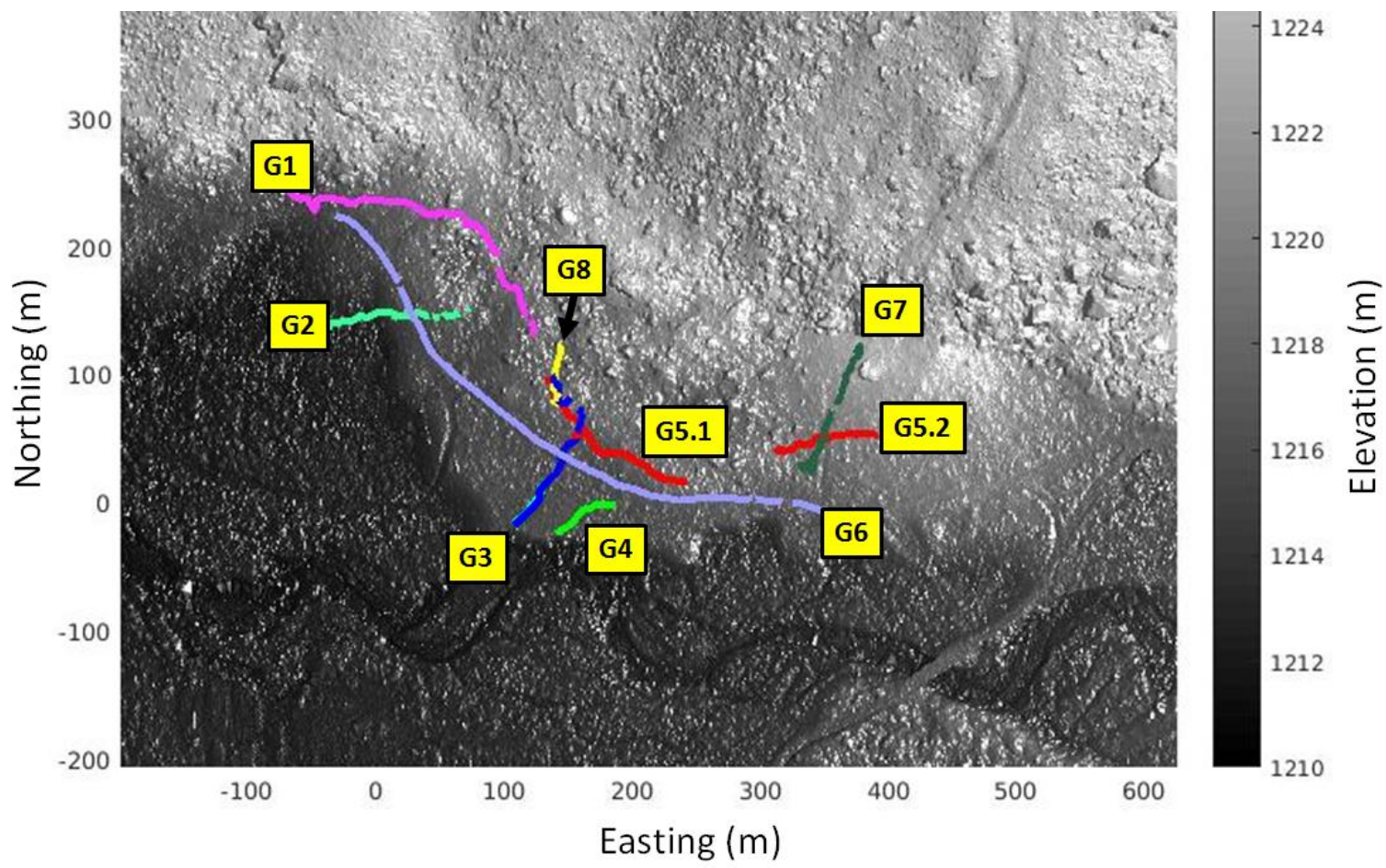

Figure 6: Map view with location of the GPR profiles at the study area. Note that line G5 consists of two section (G5.1 and G5.2). Coordinate 0:0 is centered at zone 11S: Easting $274170 \mathrm{~m}$ and Northing $4180400 \mathrm{~m}$.

\subsubsection{GPR Data Processing and Analysis}

The GPR data was processed using the software GPRPy (A. Plattner, 2019). In GPR investigation, the goal of the data processing is only to facilitate the display and interpretation of structure in the data. However, there is an inherent danger in data processing as it can add structures (artifacts) to the displayed data that are not present in the real geological setting. For that reason, we kept the data processing as minimal as possible. Whenever a processing step is done, we check and compare the new image with the raw data to investigate if any artifacts were added or if any feature of interest has been removed.

The flow chart below illustrates the sequence which those corrections and techniques were applied (Figure 7). 


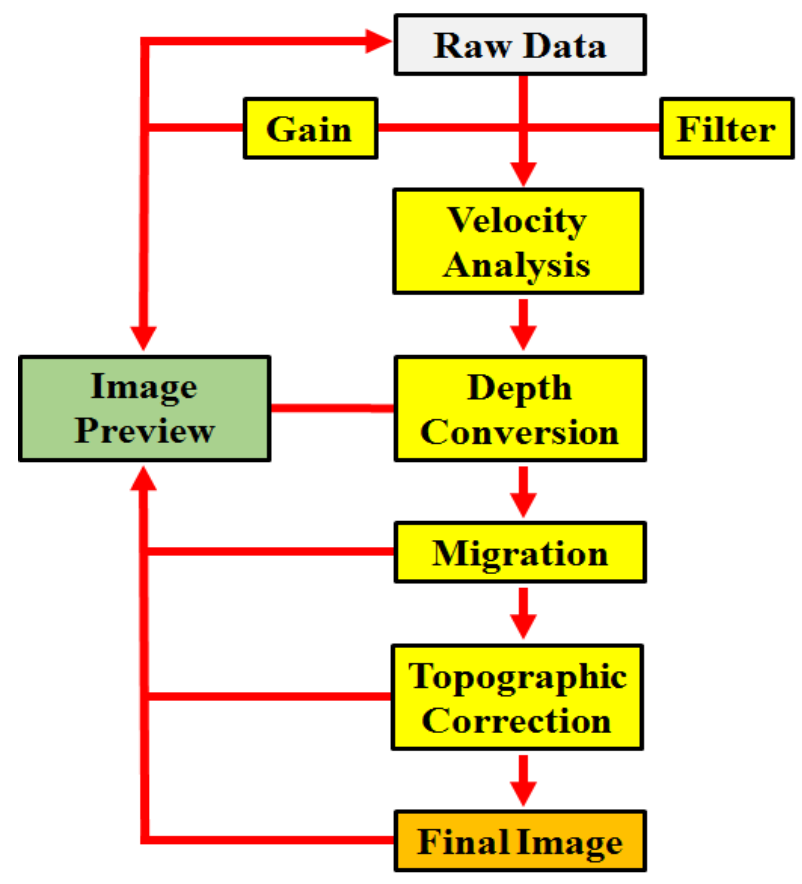

Figure 7: GPR data processing workflow used in this investigation.

Here, we demonstrate the application of those steps by processing and correcting the raw data for a section $(0-55 \mathrm{~m})$ of the GPR profile G3 collected with the $50 \mathrm{MHz}$ antenna (Figure 8).

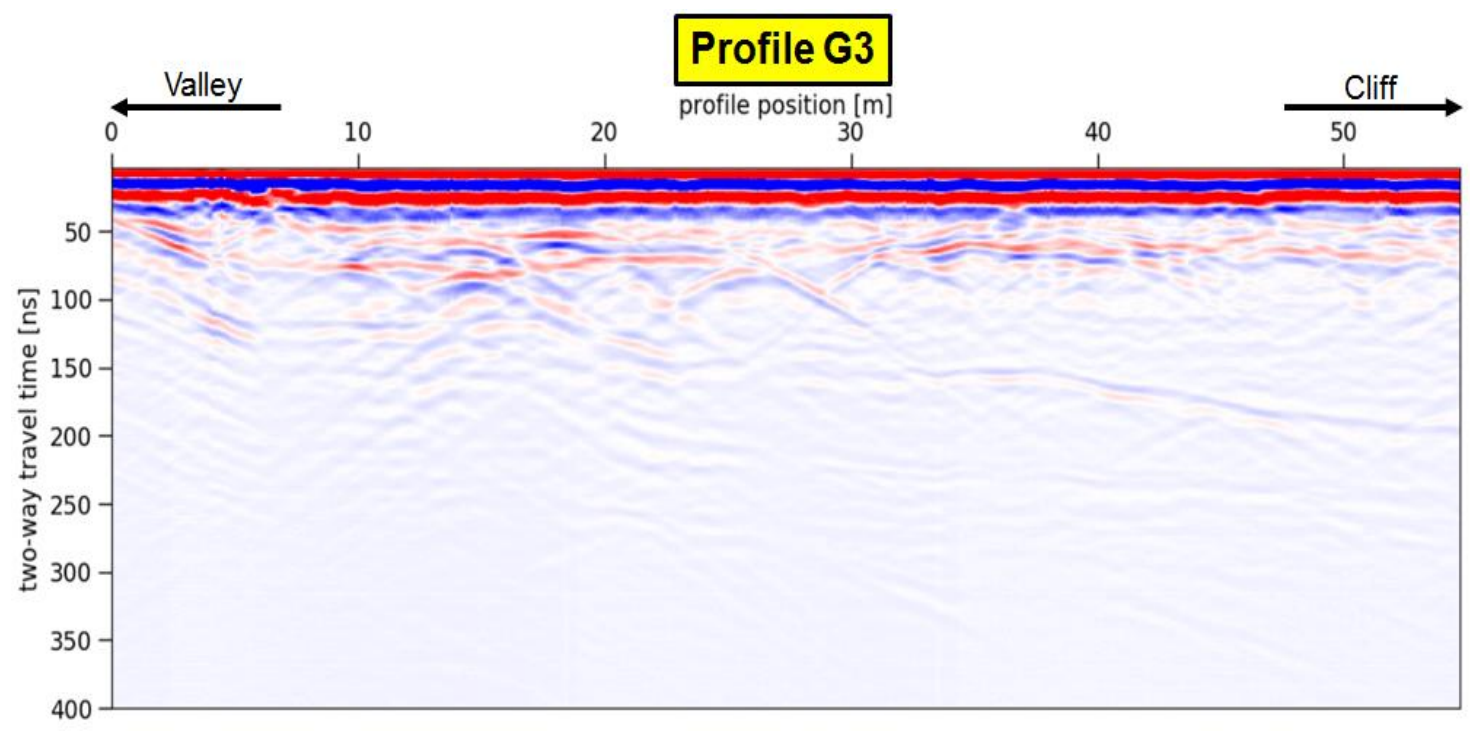

Figure 8: Raw data for a section of profile G3. Air and ground wave are dominating but structures are visible at later arrival times. Arrival time is linearly related to depth. 


\subsubsection{Time Zero Correction}

Because the receiver antenna starts recording a little bit before the arrival of the transmitted signal, a blank in signal will appear at the top most of our radargram at zero nanoseconds (Figure $9 \mathrm{~A}$ and $\mathrm{B}$ ). To correct this effect, we apply a Time Zero Correction, we do it by shifting the arrival time of the transmitted signal (colorful part in Figure 9) to the time-zero position (Figure 9 C).

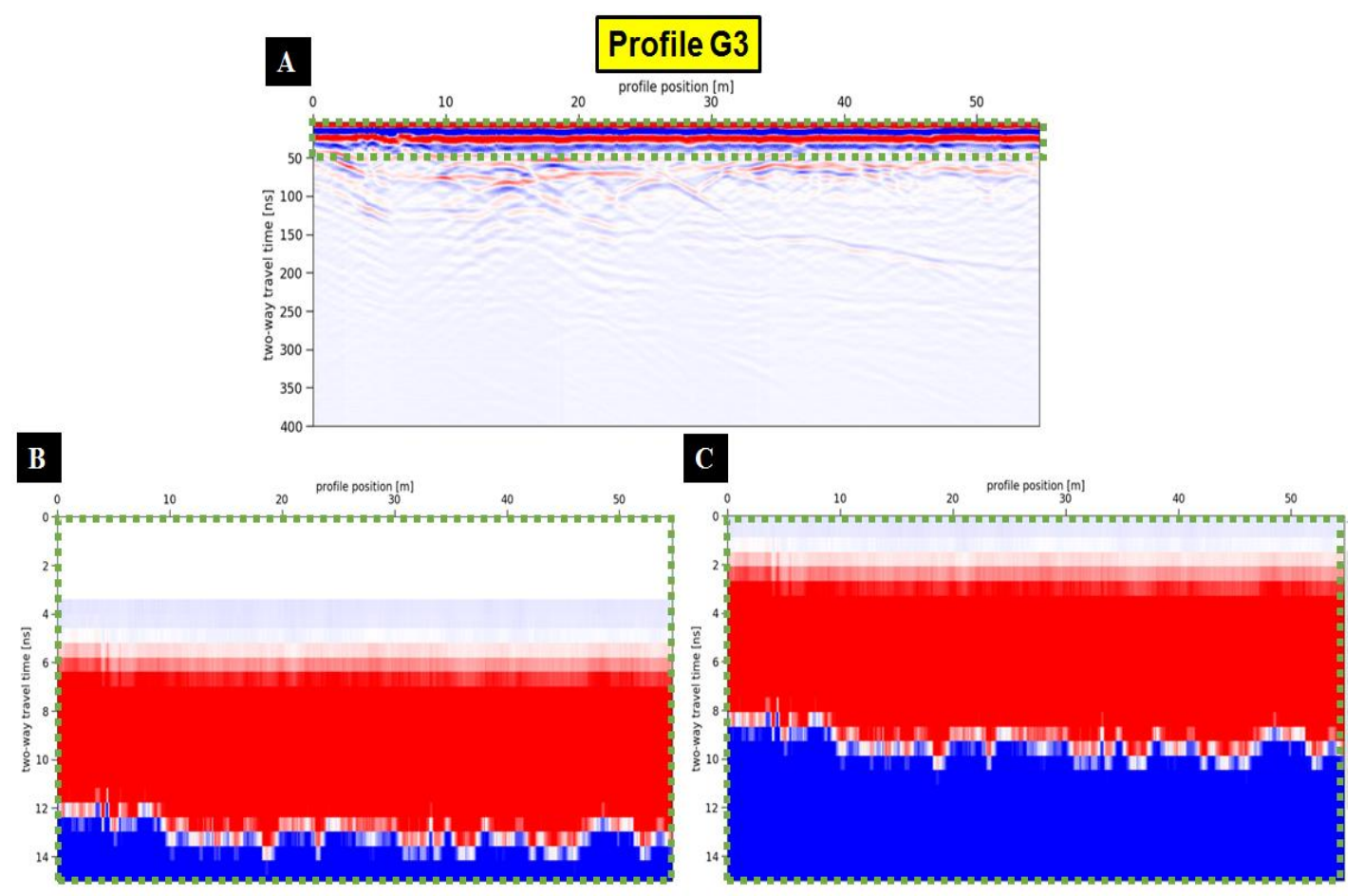

Figure 9: (A) time zero correction for profile G3. (B) zoom at the beginning of the radargram, note the gap between the zero and the subsurface signal (approximately at 3 ns). (C) zoom in after time zero correction.

\subsubsection{Filtering}

When collecting data, the GPR receiver will record electromagnetic waves from a variety of sources. Here, we refer to all undesired data recorded by the receiver as noise. It is desirable to have more signal of interest than noise in our data set. To maximize signal to noise ratio and therefore our ability to visualize the signal of our interest, we can attempt to remove part of the noise by applying digital filters to the recorded data. For 
example, we can remove long wavelengths by subtracting a running mean for a long-time window (dewow) or we can remove short wavelengths by replacing each sample with a running mean for a short time window (smoothing). Similar filters can be applied also along the profile (horizontal).

3.2.4.1 Dewow. As Described in Jol (2008), the fields near the transmitter contain low-frequency energy associated with electrostatic and inductive fields, which decay rapidly with distance. This low frequency energy often yields a slowly time-varying component to the measured field data. And this effect has become known as "wow" (Jol, 2008). The "wow" signal can be eliminated by applying a high-pass temporal filter to the recorded signal (Jol, 2008). This process is referred to as "dewow."

To better visualize the application of dewowing to our data set, we are momentarily setting a high color contrast to profile G3 (Figure 10).

3.2.4.2 Mean trace removal. This filtering technique removes from each trace the average of its surrounding traces. This step is especially important, considering that it can remove the air wave and parts of the ground wave, both of which are dominating in the radargram (black dotted rectangle in Figure 11). The GPR receiver will record signal coming from all directions. This includes the signal coming directly from our transmitter that travels through the air with the speed of light and signal travelling along the groundair interface (called ground wave). These signals will arrive first to the transmitter and therefore will appear very early in our radargram. The presence of airwave and groundwave can be seen in Figure 11 as a strong and horizontally continuous signal along the profile between 0 and $30 \mathrm{~ns}$ (highlighted inside the dotted rectangle). 


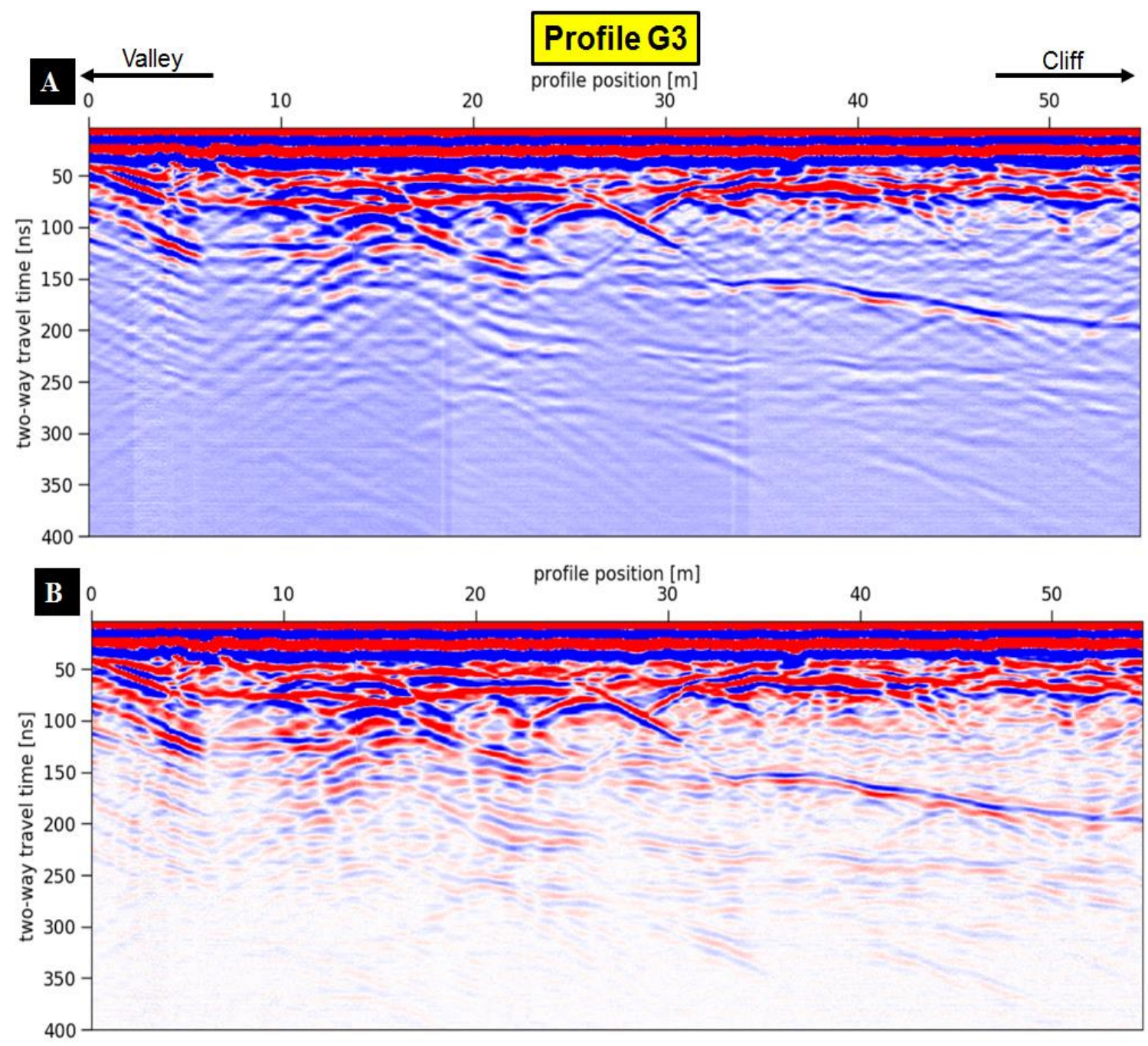

Figure 10: Application of dewow filter on a section of profile G3. (A) before dewow. (B) after dewow. 


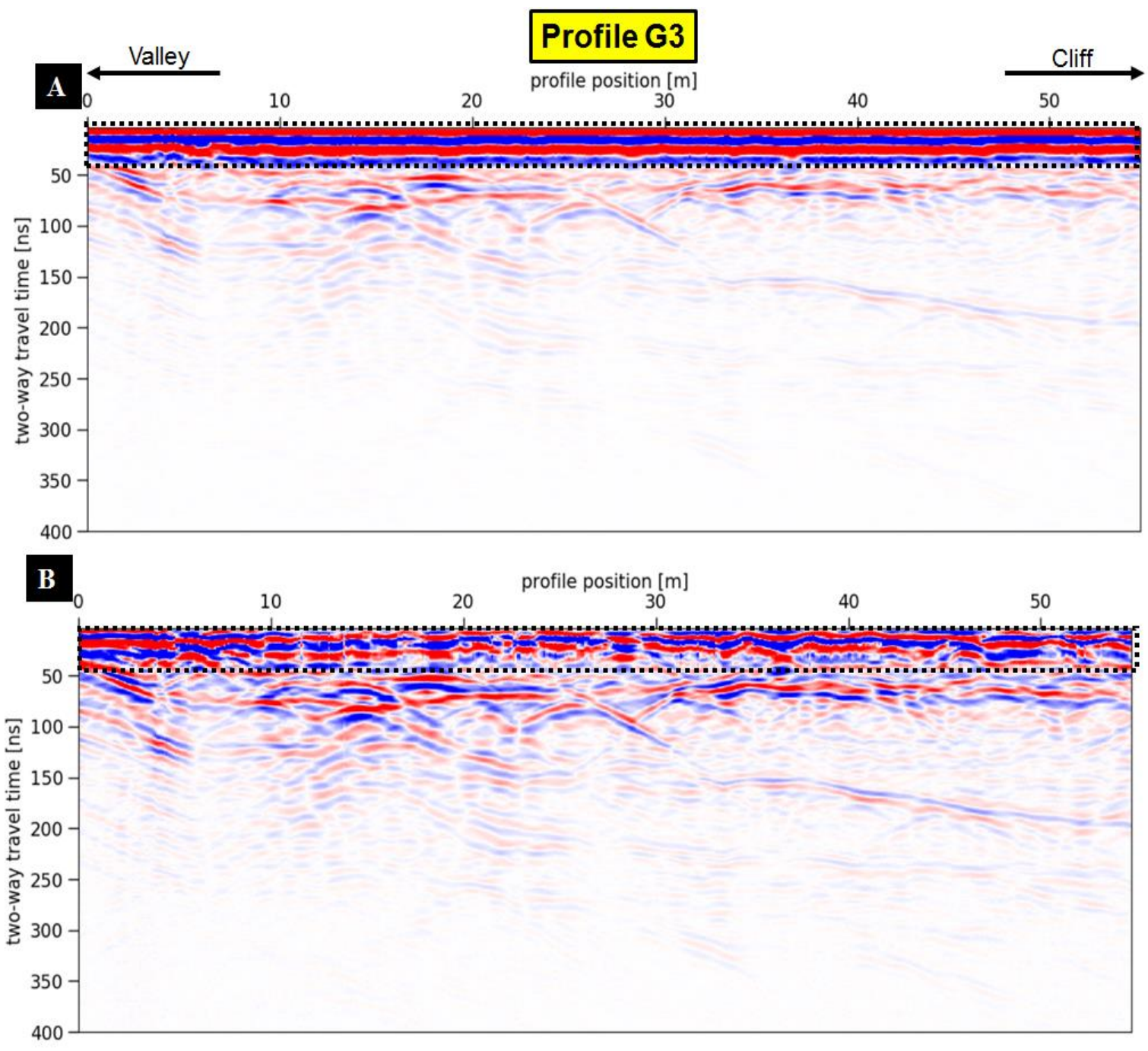

Figure 11: Profile G3 before (A) and after (B) the removal of the mean trace. Black dotted rectangle highlights the airwave and groundwave position in the radargram. 


\subsubsection{Gain - T-Power}

As radar-signal strength generally decreases with increasing depth (travel time), due to geometric spreading and material-based attenuation, it is usually necessary to artificially increase the strength of weaker signals at depth (later times). This is achieved by applying gain to data (Neal, 2004). Gain enhances the amplitude of the signal at late arrival times making it easier to be visualized and interpreted. The gain technique applied to our data set was the t-power gain, which increases the amplitude of the signal by a factor of $t^{p}$, where t represents the two-way travel time and $\mathrm{p}$ is the power chosen by the user.

It is important to note that when gain is applied it will not only enhance the amplitude of desired signal but also the amplitude of unwanted signal (noise). Therefore, it is necessary to pay close attention to the raw data to identify possible reflectors of interest. In figure 12 we highlighted three possible reflectors of interest.

\section{$\underline{3.2 .6 \text { Velocity Analysis }}$}

The Y axis of a GPR survey is recorded in two-way travel time. This is the time it takes the signal to travel from the transmitter to the receiver. Because we typically refer to structures in the subsurface in terms of depth or elevation, stating that such structures are " $x$ " nanoseconds away from the surface, has little or no geological meaning. In order to convert the $\mathrm{Y}$ axis of the radargrams from two-way travel time to depth, we first need to estimate the velocity or velocities of the electromagnetic wave in the local subsurface.

For this reason, we collected a Wide-Angle Reflection and Refraction (WARR) data. WARR soundings are carried out by keeping one antenna fixed and moving the other antenna. (Davis \& Annan, 1989; Annan \& Davis, 1976). And the result of this survey is a plot of antenna separation (m) against two-way travel time (ns) (Figure 13). This plot shows us how long it took waves to travel from the transmitter to the receiver ( $\mathrm{Y}$ axis) as we increase the space between antennas ( $\mathrm{X}$ axis). To facilitate our 
understanding, we can divide the groups of waves recorded in two: Direct Waves and Reflected Waves (Figure 13 B).

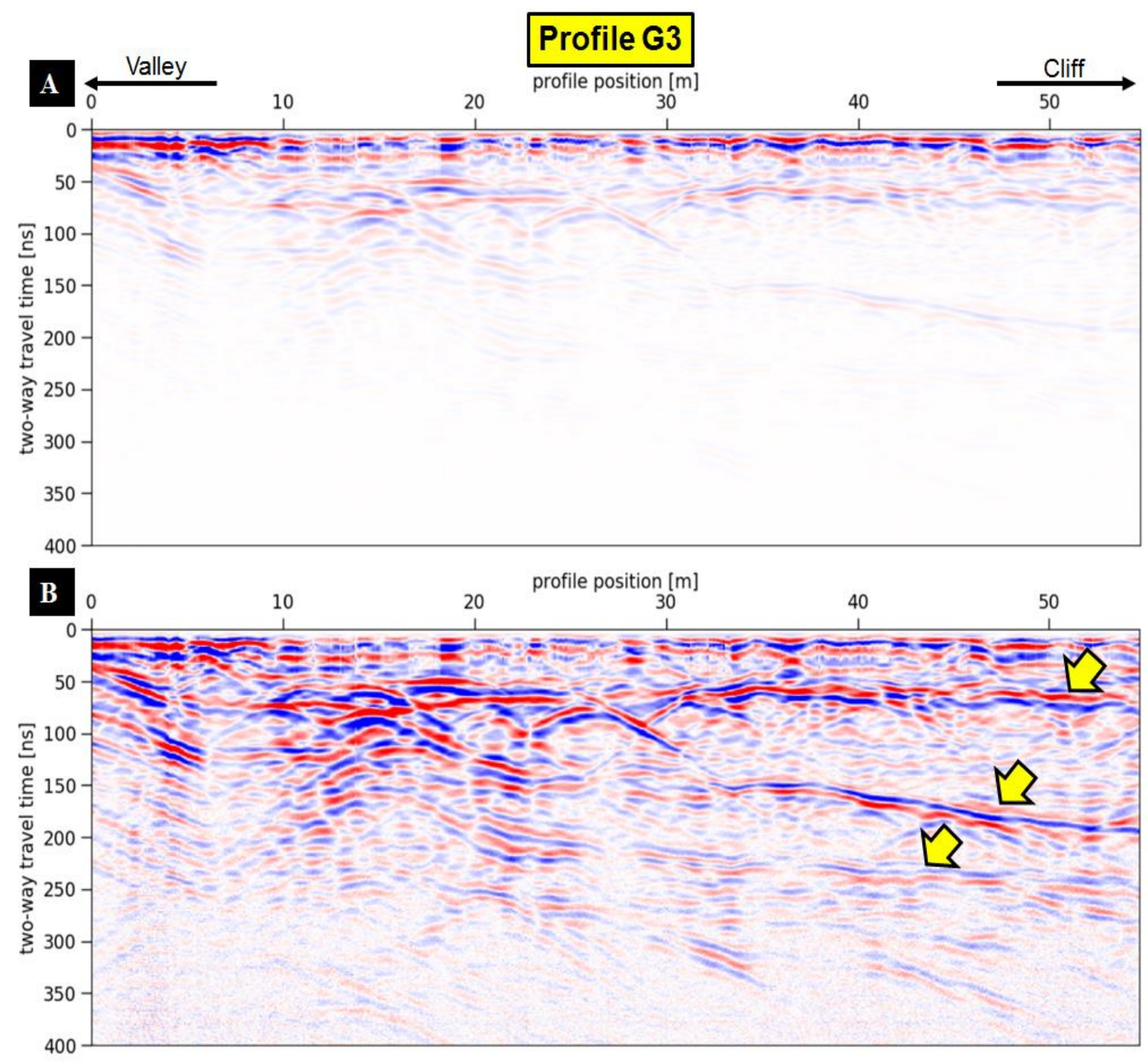

Figure 12: Profile G3 before (A) and after (B) the application of t-power gain. Yellow arrows highlight the position of possible reflectors of interest.

3.2.6.1 Direct waves. Direct waves travel directly from the transmitter to the receiver, this includes the direct air-wave and direct ground wave. The direct air wave propagates from the transmitter to the receiver through the air with nearly the speed of the light in the air $\left(\mathrm{C}_{\text {air }}\right)$, which is close to the speed of the light in a vacuum. Because of 
its high velocity, this wave will typically arrive "sooner" (high in our plot) (Figure 13 B), and its travel time (t) can be mathematically expressed as:

$$
t_{\text {air }}=\frac{\text { Distance }}{C_{\text {air }}}
$$
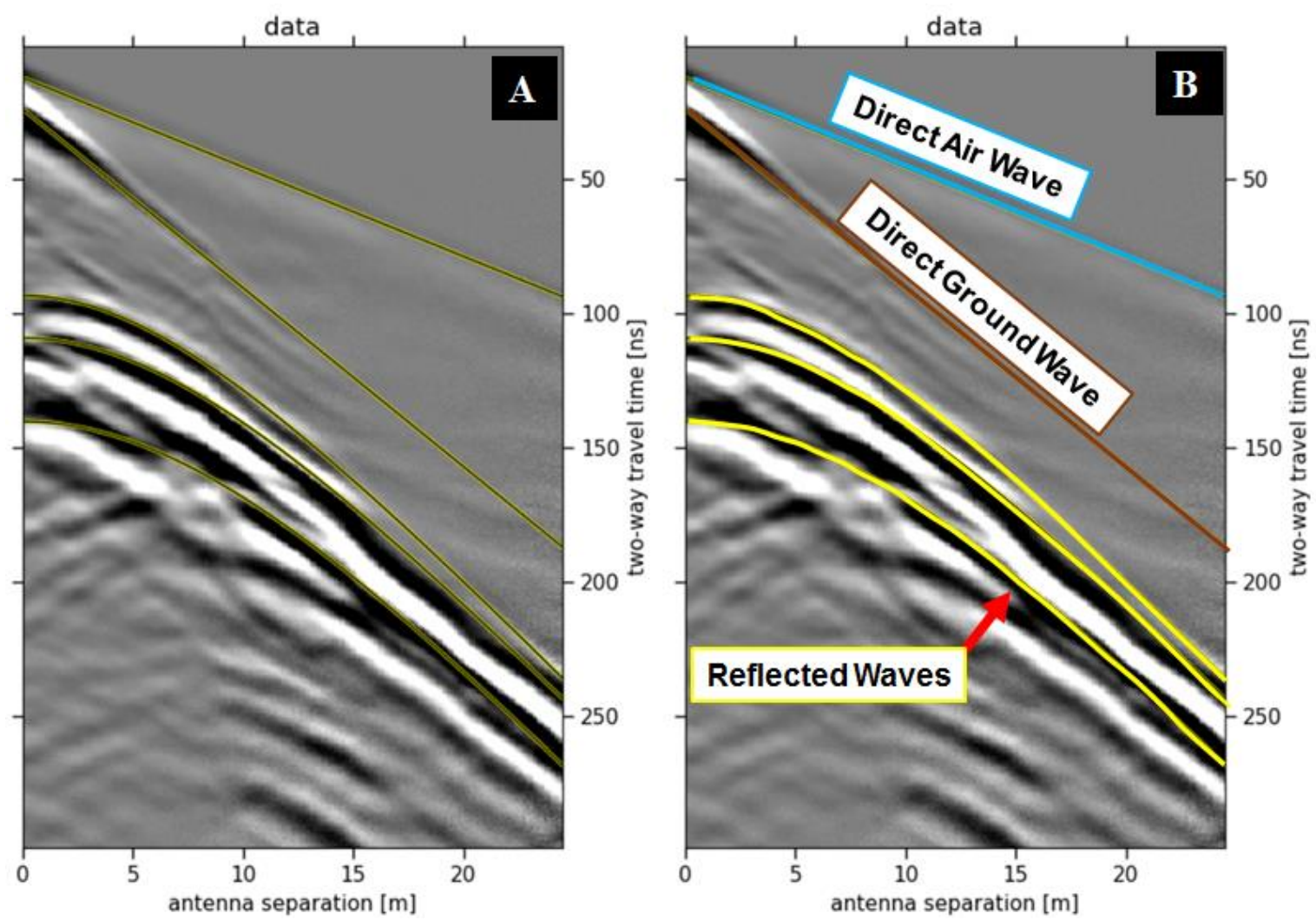

Figure 13: WARR plot. (A) recorded waves and (B) colorful lines and hyperbolas highlighting direct and reflected waves.

After the air wave, we usually see the direct ground wave as second top-most in our plot, this wave travels along the interface between the air and the ground.. Waves propagating in this interface travel with radar wave velocity of the ground ( $\left.\mathrm{V}_{\text {ground }}\right)$. And its travel time can be mathematically expressed as:

$$
t_{\text {ground }}=\frac{\text { Distance }}{V_{\text {ground }}}
$$


Note that waves that travel directly from the transmitter to the receiver will take a time that is linear with respect to the distance between the transmitter and the receiver. In other words, as we increase the distance between antennas, time increases in a linear base for the direct waves. Figure 14 illustrates how the data are recorded for the direct ground wave as we increase the distance between the antennas.

3.2.6.2 Reflected waves. Those are waves that reflect off buried interfaces and then arrive at the receiver. Because those waves travel a longer path, they typically arrive latter in our radargram. Figure 15 illustrates a typical path of a reflected wave (red arrows) given a distance $(\mathrm{X})$ along a profile, a height (h) and three mediums with different velocities $\left(\mathrm{V}_{0}, \mathrm{~V}_{1}\right.$ and $\left.\mathrm{V}_{2}\right)$.

Given that the angle of incidence is equal to the angle of reflection (Figure 15), we can use trigonometry to express the time (tref) that the reflected wave takes to leave the transmitter and arrive at the receiver as:

$$
t_{\text {ref }}=\frac{\sqrt{X^{2}+4 h^{2}}}{V_{1}}
$$

Equation (3) describes a hyperbola, which explains the hyperbolic shape of reflected waves in the WARR data (Figure 13). Because we know the antenna separation $(\mathrm{X})$, and the travel time (tref), we can attempt to estimate the velocity $\left(\mathrm{V}_{1}\right)$ and the height (h). 

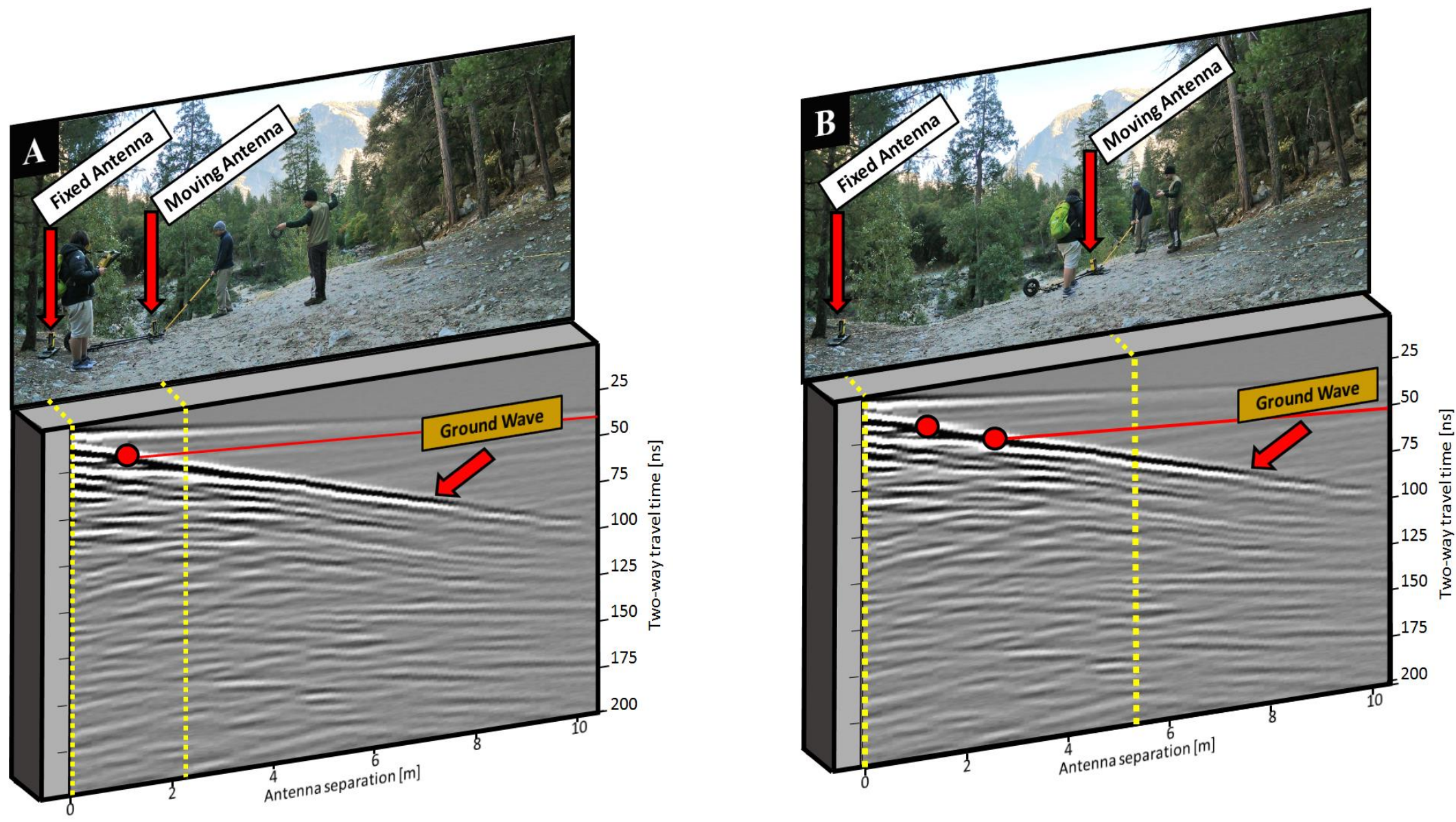

Figure 14: WARR data acquisition at the Mirror Lake Rock Avalanche. (A) and (B) illustrate how the direct ground wave data is recorded (red circles) in regards of the antenna separation distance (dotted yellow lines). Red lines illustrate the time that takes the signal to travel from transmitter to receiver. 


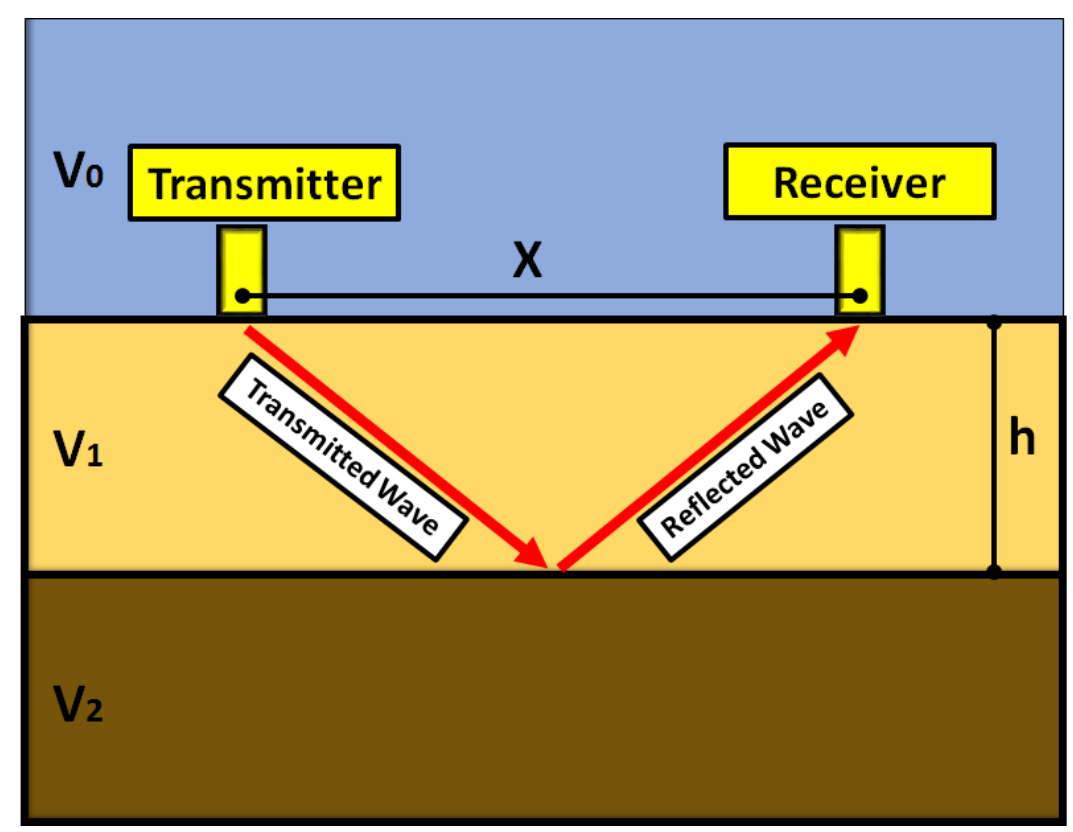

Figure 15: Reflected wave path (red arrows) given a distance (X) along a profile, a height (h) and three mediums with different velocities $\left(\mathrm{V}_{0}, \mathrm{~V}_{1}\right.$ and $\left.\mathrm{V}_{2}\right)$.

\subsubsection{Wave Velocity Estimation}

From equations (2) and (3) we can obtain the wave velocities based on the slope of the direct waves and hyperbola shape of the reflected waves. Note that for equation (3) we are missing two pieces of information: the velocity of the wave $\left(\mathrm{V}_{1}\right)$ and the height of the layer (h). To solve this problem, we test different velocity values and plot the resulting hyperbola over the WARR data. Once we input the correct velocity, the plotted hyperbola should overlap the hyperbola recorded in the data (Figure $16 \mathrm{~A}$ ). The same steps are also applied for the slope of direct waves.

To automate this process, we can have the computer draw lines and hyperbolas for a whole range of velocities on top of the WARR data and sum up the pixel values of the data underneath the lines or hyperbolas. The result of this step is the hyperbolic and linear stacked amplitude semblance (Plattner, 2019). When the computer tests a velocity that creates a line or hyperbola that fits well the lines and hyperbolas on the collected data 
(Figure 16 A), the data pixel values will all have the same sign and will sum up constructively, leading to a large absolute value. As a result, this velocity/travel time combination will have a high "stacked amplitudes" value (bright yellow color in Figure $16 \mathrm{~B}$ and $\mathrm{C})$. And in case of a misfit the positive and negative pixel values of the data underneath the line or hyperbola will cancel each other out, leading to a low stacked amplitude value for that velocity/travel time pair (dark and purple color in Figure $16 \mathrm{~B}$ and C). Based on this step, we can pick the velocity value that best fit our reflected waves, which is $0.113 \mathrm{~m} / \mathrm{ns}$ (Figure $16 \mathrm{D}$ ).

We can also determine the radar velocity of the subsurface from profile data alone without the help of a WARR survey, if we happen to find a hyperbola in one of the profiles, such as for example the one in the section (140-180m) of profile G6, shown in in Figure 17 (A).

This allows us to confirm or improve our velocity analysis. Given a specific velocity (V) for the subsurface, a spatially confined reflector such as a boulder or a pipe cutting across our profile would lead to reflected wave arrival times to create a hyperbolic shape. The plotted hyperbola (blue dashed line) is what a theoretical hyperbola at that location would look like for a velocity of $0.125 \mathrm{~m} / \mathrm{ns}$. It nicely overlaps the hyperbola observed in the radargram (Figure 17 B) and hence confirms our velocity analysis from the WARR data set. 

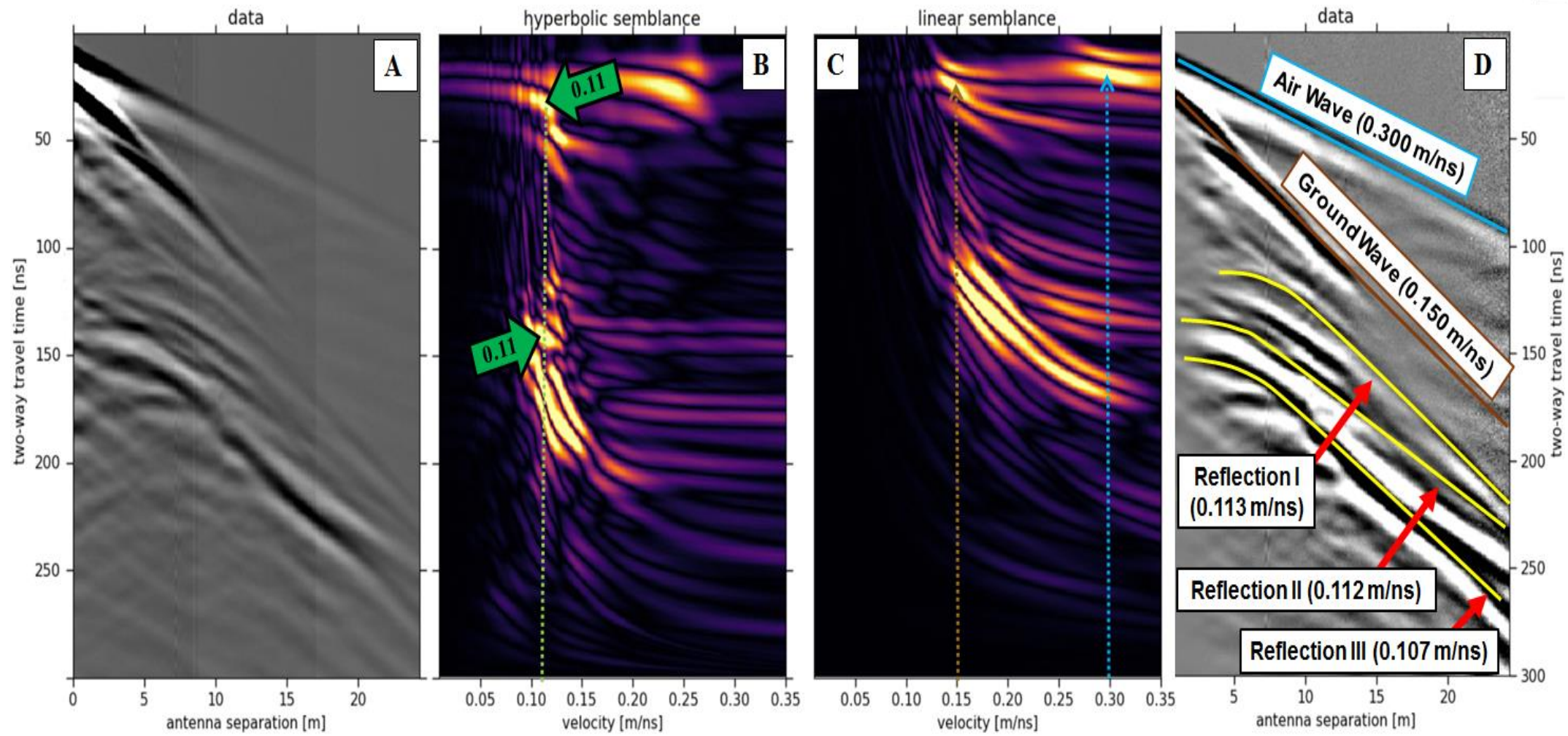

Figure 16: (A) Raw WARR data. (B) hyperbolic stacked amplitudes velocity semblance (green arrows highlight the best hyperbolic fit). (C) linear stacked amplitudes velocity semblance (brown and blue arrows highlight the best linear fit for ground and air wave respectively), and (D) picked velocities for air, ground and reflected waves. 


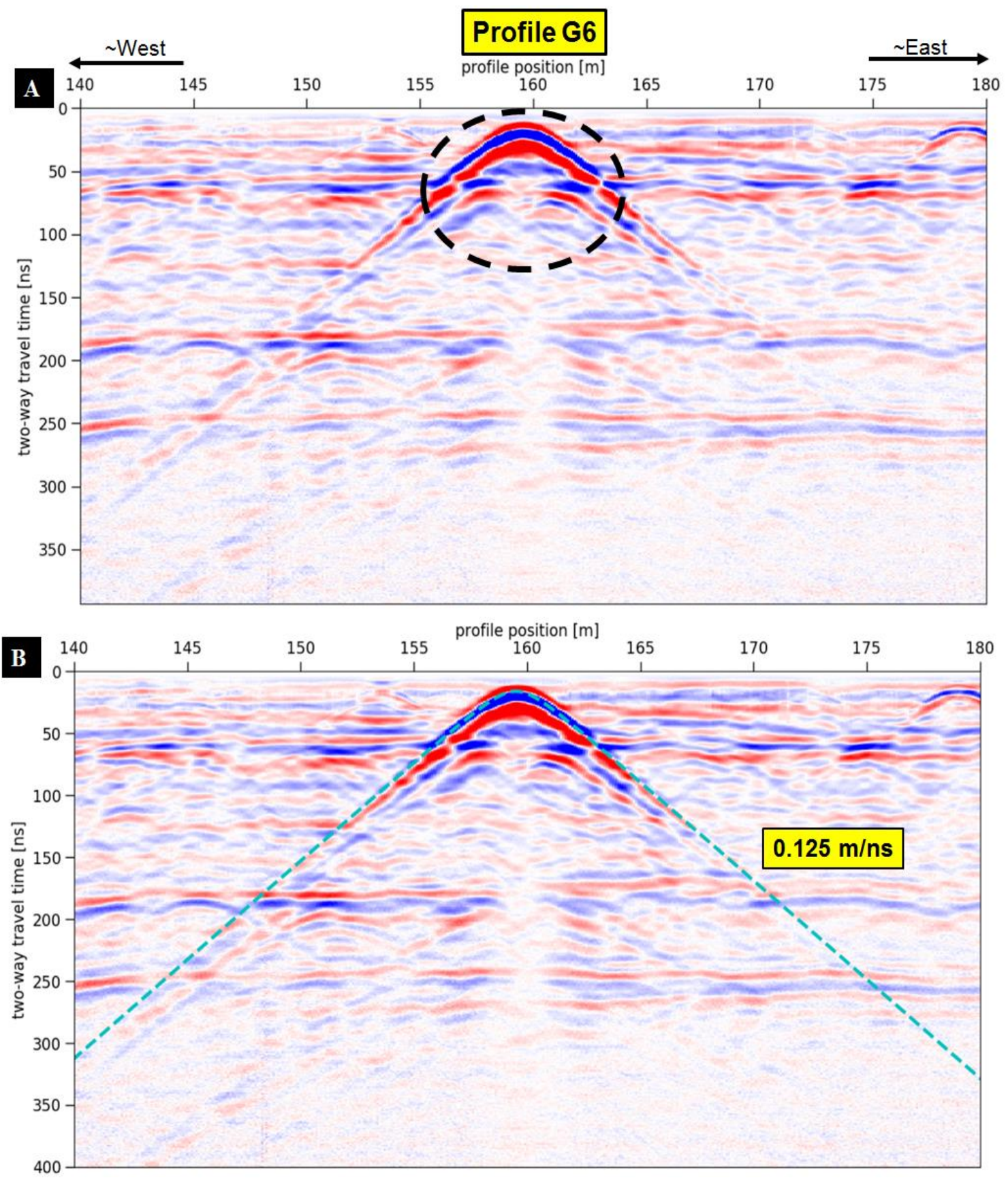

Figure 17: (A) hyperbola found within profile G6 (highlighted in the dashed black circle) and (B) plotted hyperbola with velocity of $0.125 \mathrm{~m} / \mathrm{ns}$ (blue dashed hyperbola). 


\subsubsection{Depth Conversion and Migration}

After setting the average velocity $(0.11 \mathrm{~m} / \mathrm{ns})$ that better represent the medium, we can now convert and display our radargram in depth (Figure 18).

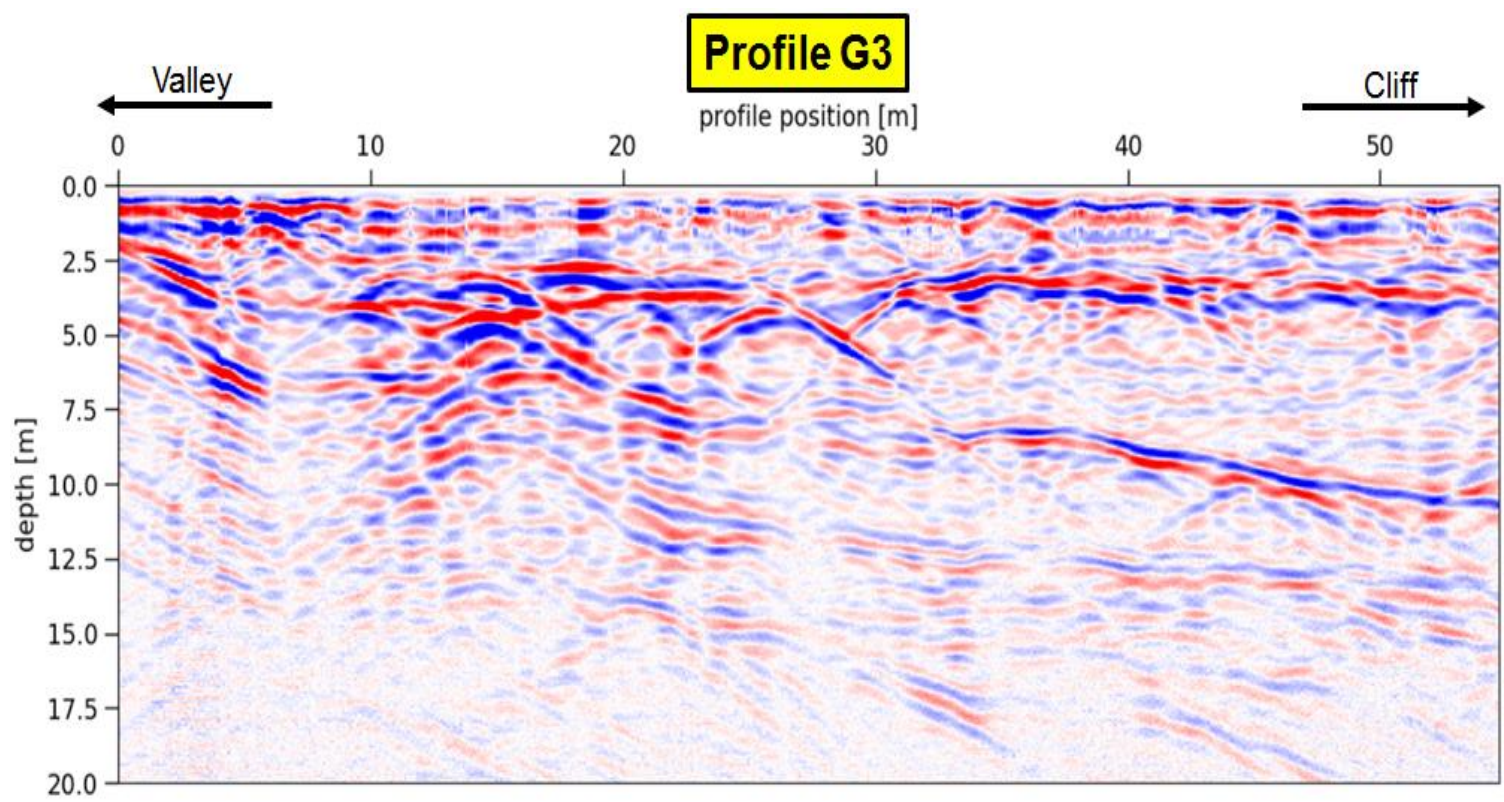

Figure 18: Profile G3 Two-way travel time (ns) axis converted into depth (m).

When plotting traces next to each other to create a radargram, we assume that the recorded reflections originated directly underneath the transmitter-receiver midpoint. They could, however, originate from reflections from the side, for example when a dipping layer is present (Figure 19).

For a zero-offset survey (none or insignificant space between receiver and transmitter) considering a dipping layer (non-parallel to the surface), the GPR system knows that reflection 1,2 and 3 took $X$ nanoseconds to happen. But it is unable to infer the real direction of the reflection (arrow lines in Figure 19. We simply plot the radar wave arrivals directly underneath the antennae. As a result, we underestimate the dip. 


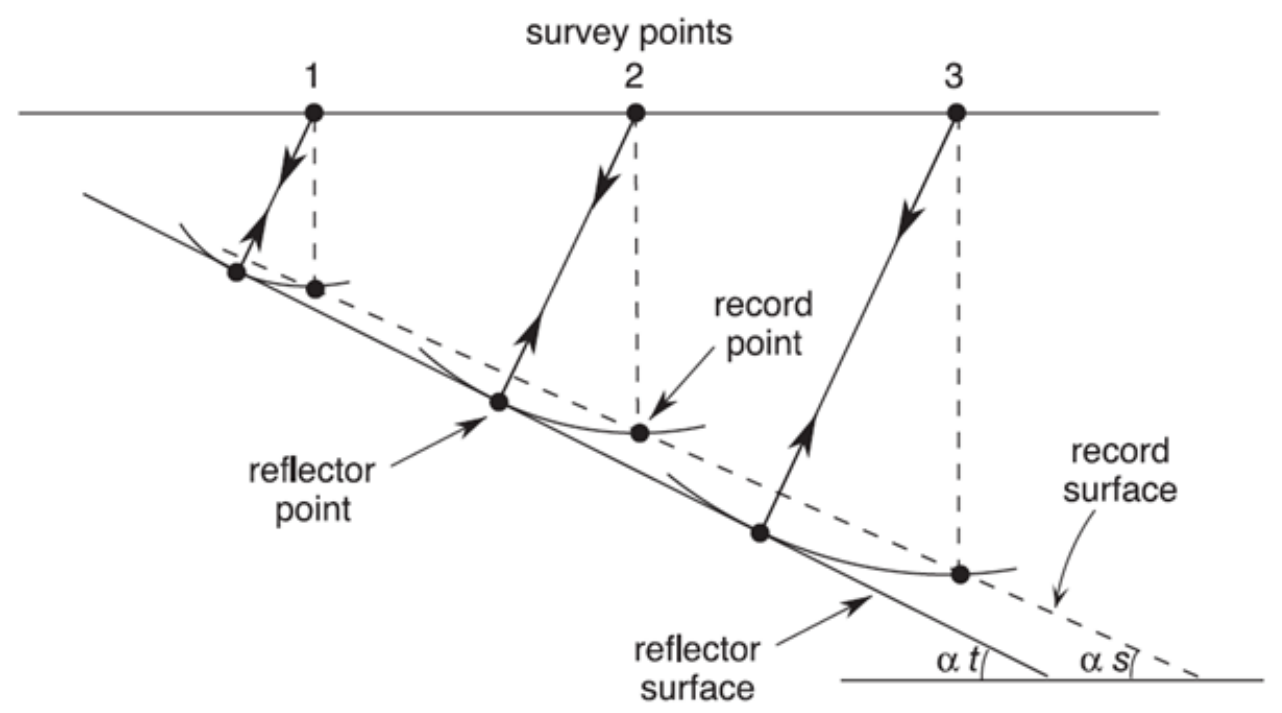

Figure 19: On an unmigrated reflection profile, reflector points from a planar, dipping reflector $($ dip $=\alpha$ t) have undergone down-dip movement and the resulting record surface has a shallower dip (as). Source: Neal, (2004) Modified from Kearey, Brook, \& Hill (2002)

To correct this problem, we can migrate the data. The goal of Migration is to reconstruct the geometrically correct radar reflectivity distribution of the subsurface. This step requires knowledge of the subsurface velocity of the medium (Jol, 2008), which we obtained from velocity analysis using WARR data and confirmed with the hyperbola in profile G6. We used the F-K migration technique proposed by Stolt (1978), which uses a single velocity to correct the spatial position of reflectors (preferably the average velocity that best represent the medium).

After migrating our data, we have corrected the position for some of our reflectors, making the radargram easier to be interpreted. Note that some of the hyperbolas observed in Figure 20 (A) were collapsed and do not appear after migrating the data (Figure $20 \mathrm{~B}$ ). Because the F-K Migration technique accepts only one velocity as input, some spurious patterns may appear. If, for example, the velocity used in the migration is too high, "smile" shapes will appear. In contrast, when the chosen velocity is lower than the necessary velocity to correct the reflector position, it will appear as a 
"frown" shape (i.e. hyperbolas persist). And since we cannot use a range of velocities to correct our data, the best that we can do is to use the average velocity that best correct the features of our interest.
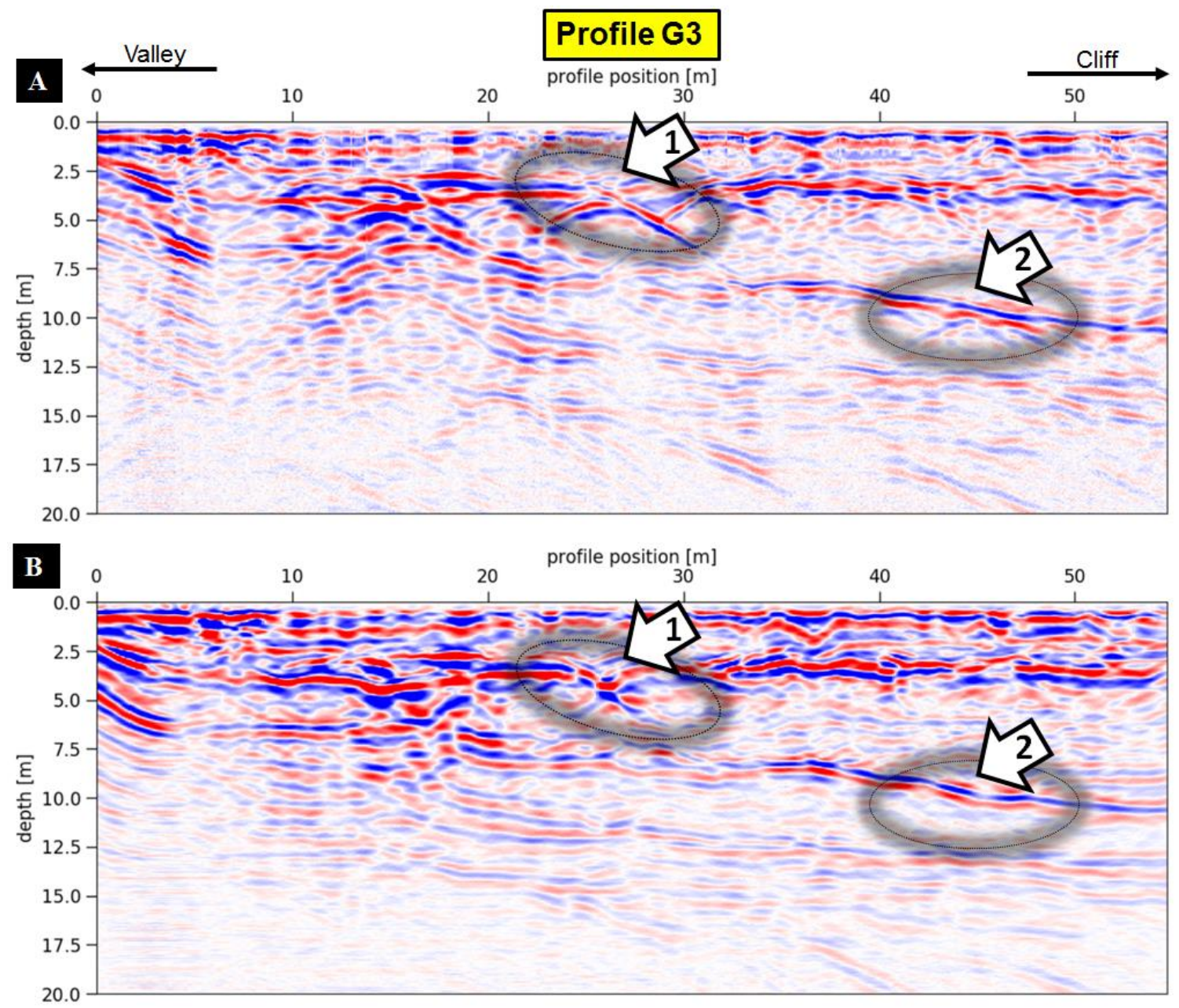

Figure 20: (A) before and (B) after the application of the F-k Migration. Black circles and arrows point to collapsed hyperbolas in the radargram.

\subsubsection{Topographic Correction}

Until now we have been treating the GPR profile as it had flat topography, which is not true for a study area. Topographic correction can be applied by moving traces up 
and down by an appropriate two-way travel time (or depth) relative to a common datum (Neal, 2004). Figure 21 illustrates before (A) and after the topographic correction (B).
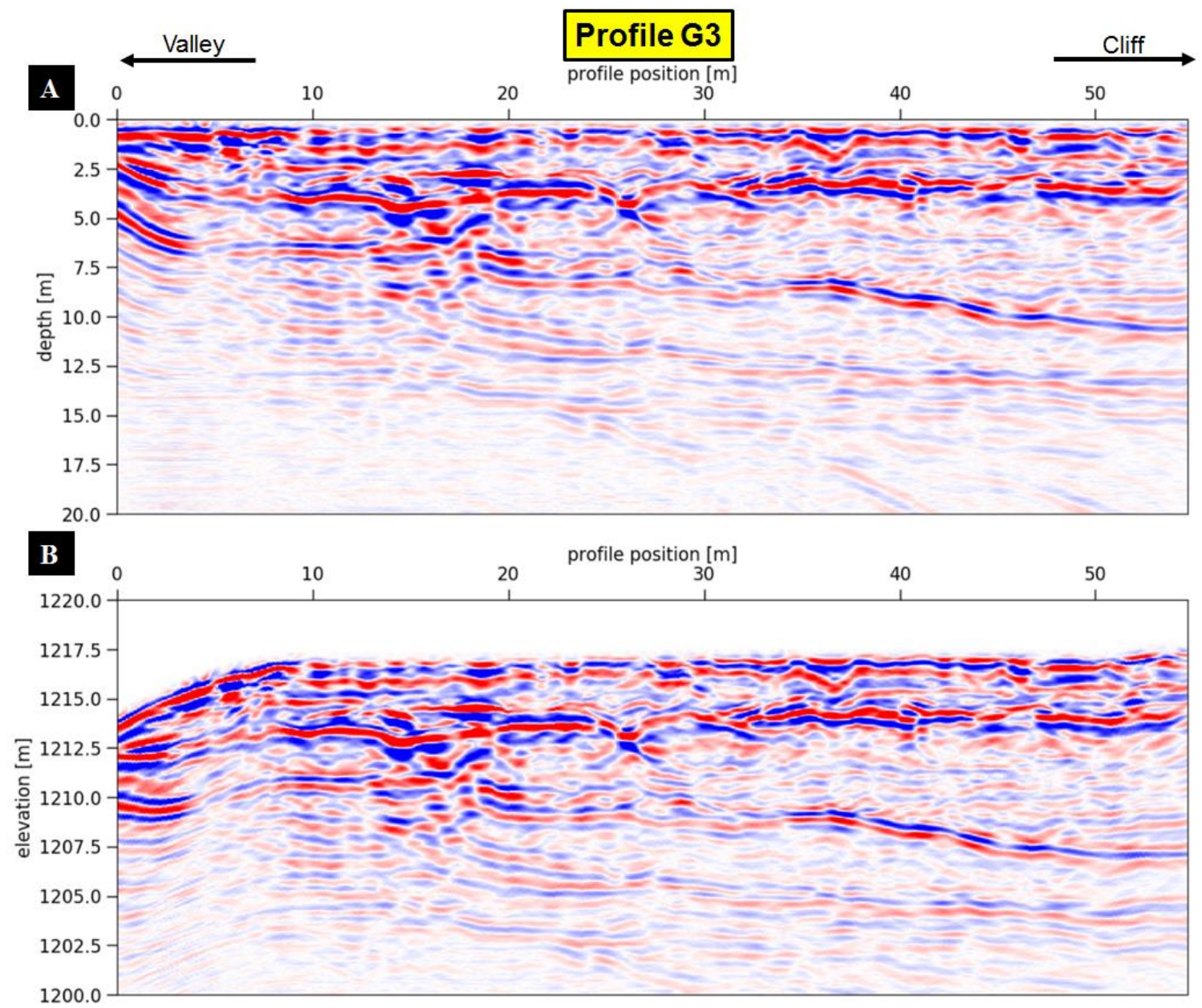

Figure 21: Profile G3: (A) Before and (B) after topographic correction.

\subsubsection{Depth Uncertainty of GPR $\underline{\text { Reflectors }}$}

Here we quantify the level of uncertainty of a reflector's position with respect to depth. The main source of depth uncertainty in GPR data comes from the velocity analyses. A velocity value that is slightly off can result in meters of depth difference. Depth uncertainties can also be created by other effects such as picking the exact point of 
reflected wave arrival, and the offset between receiver and transmitter. But because those effects created uncertainties inferior to five centimeters, we decided to focus on the main source of uncertainty - the subsurface velocity.

Section 3.2.7 indicates a best average radar velocity of $0.110 \mathrm{~m} / \mathrm{ns}$, this velocity was chosen based on where the hyperbolic stacked amplitude semblance plot showed the highest degree of similarity. Note that we could also pick the velocity slightly to the left $(0.108 \mathrm{~m} / \mathrm{ns})$ or to the right $(0.125 \mathrm{~m} / \mathrm{ns})$, where this plot also shows a strong similarity.

Choosing a different velocity value such as $0.125 \mathrm{~m} / \mathrm{hs}$ instead of $0.110 \mathrm{~m} / \mathrm{ns}$ would still be reasonable but would place reflectors in a different depth. To quantify this shift we calculated the difference in vertical position between the two different velocities, and how this difference increases in depth (Figure 22):

$$
D_{\text {error }}=\frac{t_{t w t} * V_{\text {shift }}}{2}
$$

Where $D_{\text {error }}$ is the resulting depth error, $t_{t w t}$ is the two-way travel time, and $V_{\text {shift }}$ is the difference between the two chosen velocities $(0.012 \mathrm{~m} / \mathrm{ns})$.

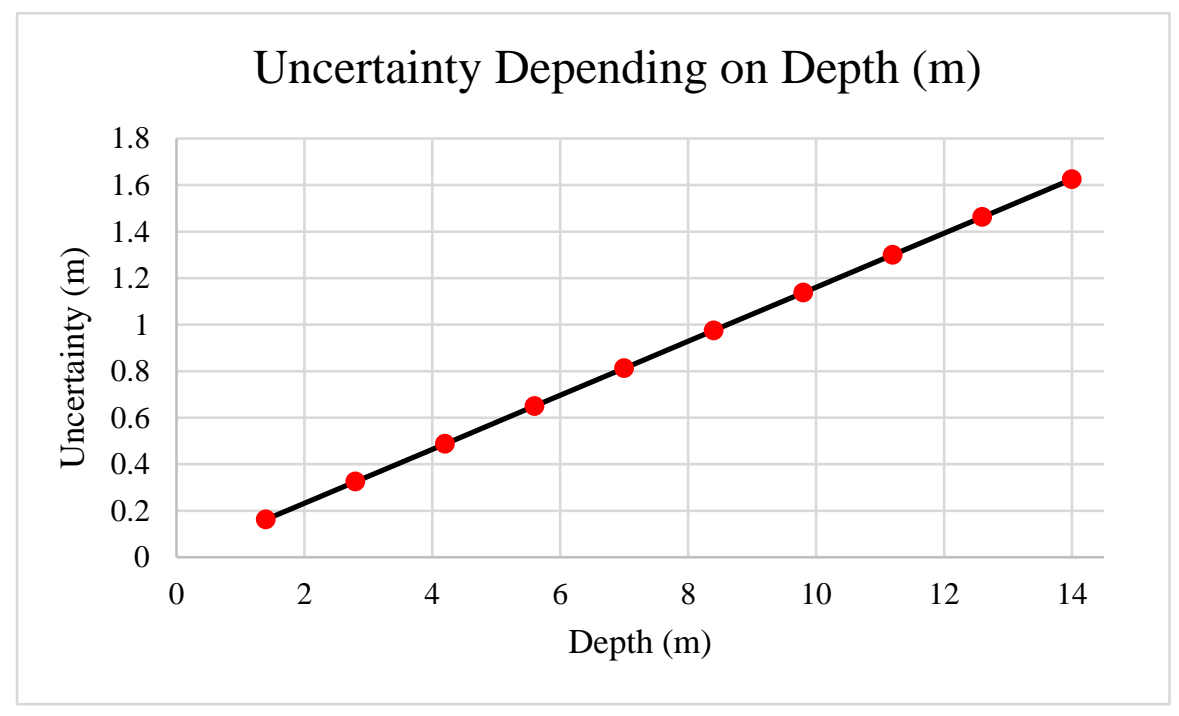

Figure 22: Graph shows the depth error for a velocity shift of $0.012 \mathrm{~m} / \mathrm{ns}$. 
Based on this chart we can infer that our uncertainties increase as depth increases. For example, a reflector with an estimated depth of $8.5 \mathrm{~m}$, could be shifted by $1 \mathrm{~m}$.

\subsubsection{Radar Facies}

As described by Mitchum et al., (1977), reflection seismic data can be used to interpret sedimentological and stratigraphy relationships based on: (1) shape of reflection; (2) dip of reflections; (3) relationship between reflectors; and (4) reflection continuity. Later on, because of the similarity between GPR data and seismic reflection data, those concepts were adapted to GPR data interpretation for stratigraphy and sedimentology.

Neal (2004), described radar surfaces, radar packages and radar facies as the building blocks of the radar stratigraphy for a GPR reflection profile (Figure 23). For this project we use those concepts to track and interpret reflectors.

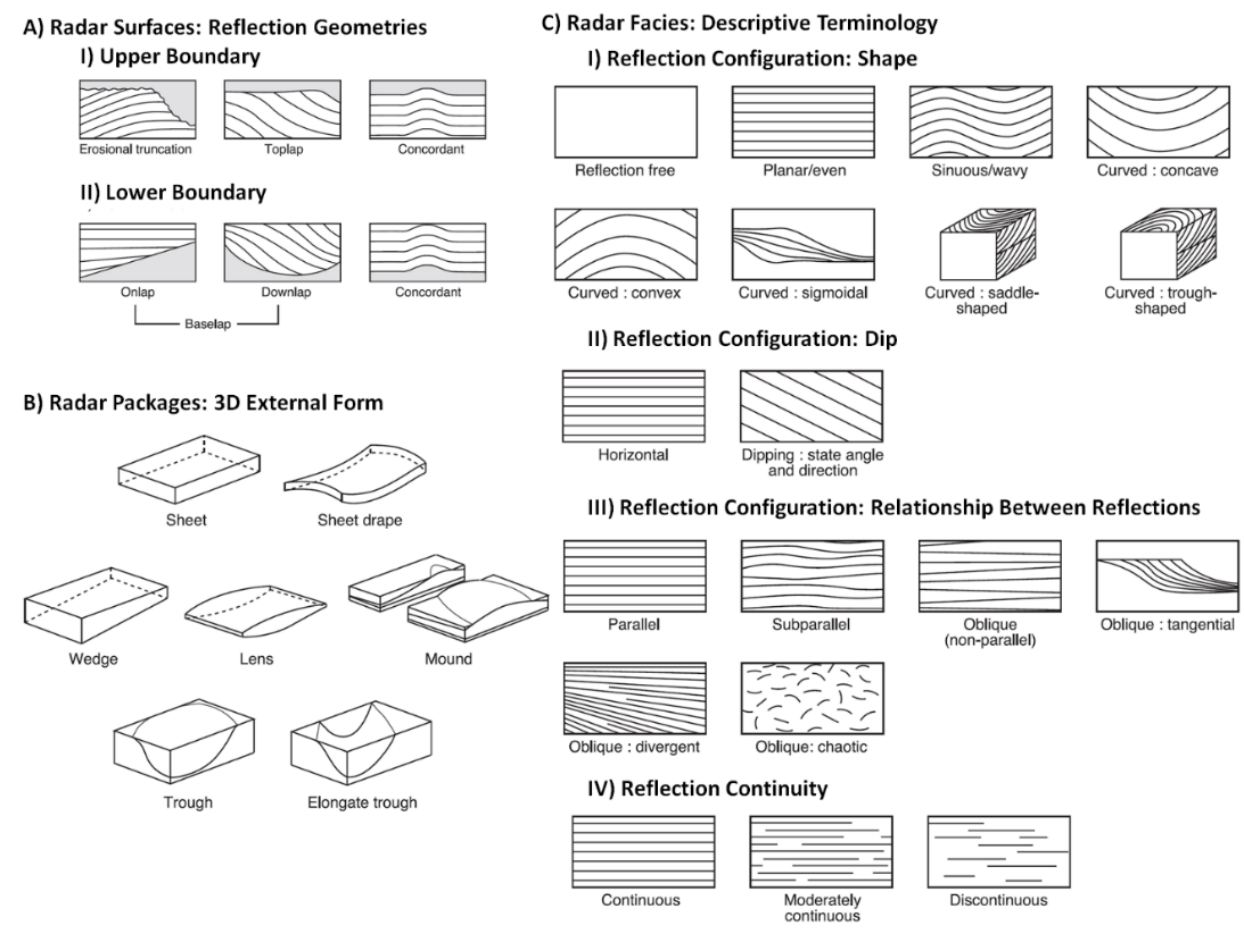

Figure 23: Terminology to define and describe radar surfaces, radar packages and radar facies. Source: Neal (2004) (Modified in part from Mitchum et al. (1977), Campbell (1967) and Allen (1982)). 


\subsection{Electrical Resistivity Tomography (ERT)}

Electrical resistivity tomography images the subsurface spatial distribution of electrical resistivity using weak currents injected from the surface. Typically, the current is injected through two current electrodes, while two potential electrodes measure voltage differences (Figure 24).
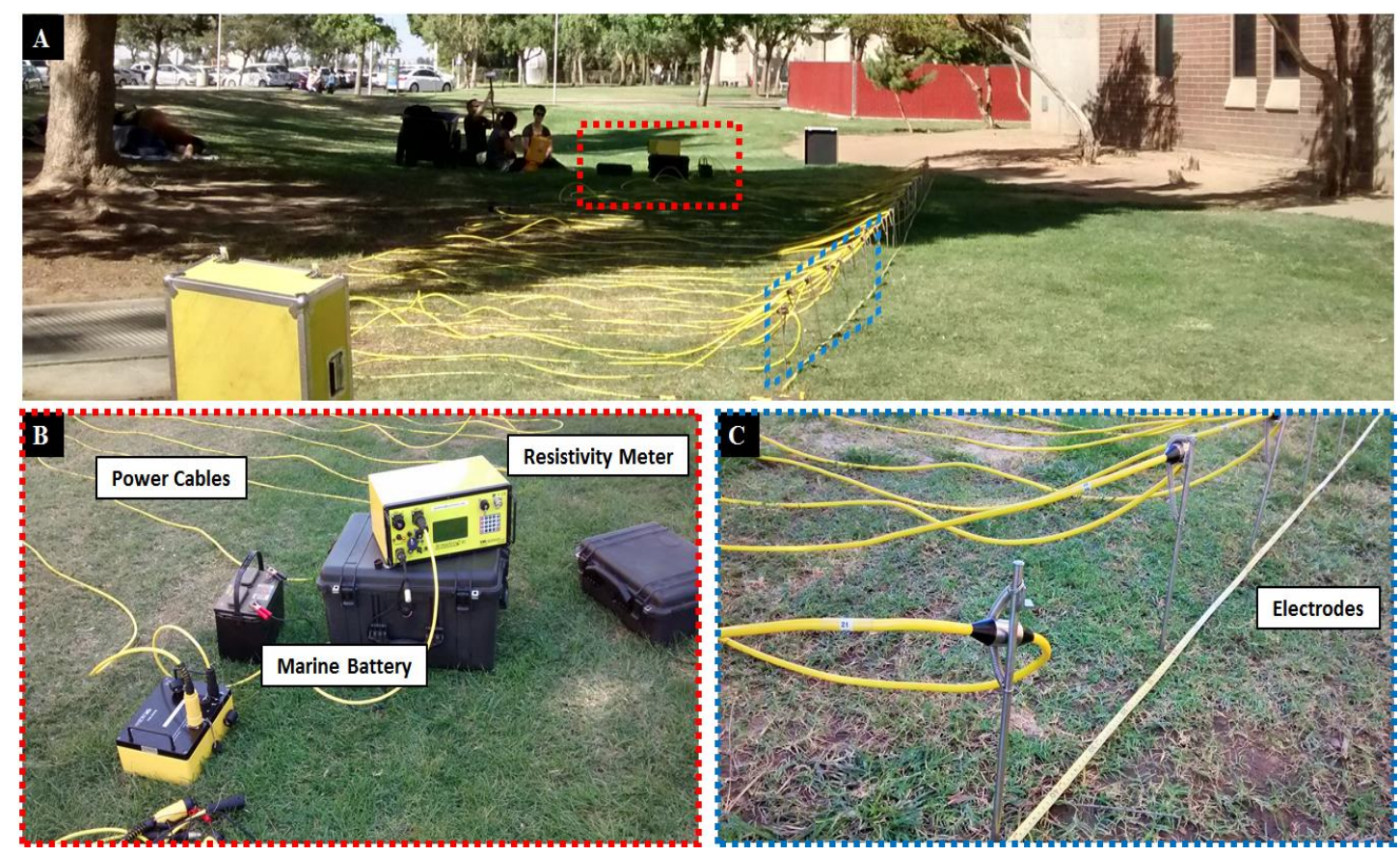

Figure 24: ERT field equipment testing at CSU, Fresno campus. (A) field setup. (B) Resistivity meter, power cables, and marine battery. And (C) electrodes.

\section{$\underline{\text { 3.3.1 Raw Data and Pseudosection }}$}

In its most basic form, the resistivity meter has a current source and voltage measuring circuitry connected by cables to a minimum of four electrodes. Current (I) is injected into the ground and the resulting voltage difference $(\Delta \mathrm{V})$ between the potential electrodes is measured. (Loke, Chambers, Rucker, Kuras, \& Wilkinson, 2013):

$$
\Delta v=\frac{I \cdot \rho_{a p p}}{2 \pi}\left(\frac{1}{A M}-\frac{1}{B M}-\frac{1}{A N}+\frac{1}{B N}\right)
$$


If the Earth was flat and had a homogeneous electrical resistivity, then we could calculate apparent resistivity ( $\left.\rho_{a p p}\right)$ using equation (5), where A and B are the current injection electrodes, $\mathrm{M}$ and $\mathrm{N}$ are the electrical potential measurement electrodes, and AM, BM, AN, BN are the distances between the electrodes (Koefoed, 1979, as cited in Loke et al., 2013). But because the Earth is not flat nor homogeneous, the quantity $\rho_{\text {app}}$, called "apparent resistivity", does not represent the true subsurface resistivity.

As a rule of thumb, the distances between electrodes in the surface influences the depth where the measurement is the most sensitive to the subsurface resistivity. For instance, a short spacing between electrodes in the surface will sense mostly the shallow subsurface. In contrast, a longer distance between electrodes in the surface will sense resistivity at greater depths (Figure 25).

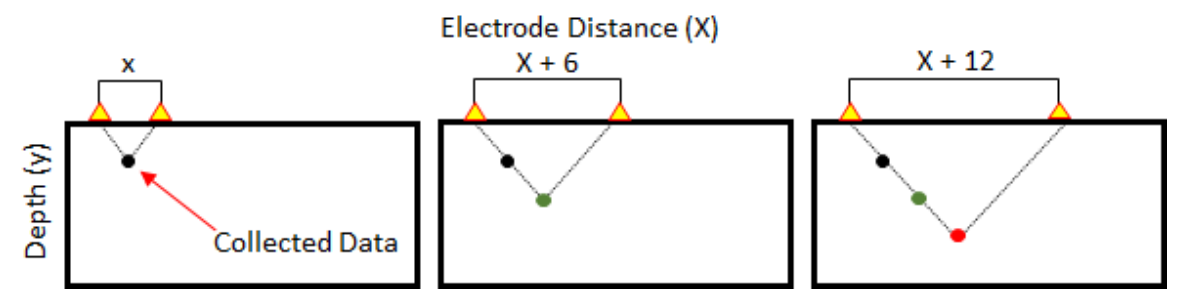

Figure 25: Explained scheme of the relationship between electrode distance (red triangles), and the depth of collected data (colored circles).

A pseudosection is a way of representing the raw data by plotting the apparent resistivities next to/or underneath each other, based on the center location of their four electrodes and the separation of these electrodes. Because our investigation site is neither flat nor homogeneous, the pseudosection should not be interpreted as a profile, but can be used to identify data outliers. Figure 26 shows two pseudosections created after the data collected at profile E3. Different colors show different resistivity in Ohm $\mathrm{m}$. We have two pseudosections because we collected two different data sets using different electrode configurations: (1) using a "Schlumberger array," where the injection electrodes are outside of the potential electrodes, and (2) using a "dipole-dipole array", where the 
injection electrodes and the potential electrodes form non-overlapping pairs. Note that the vertical axis of a pseudosection represents the distance between electrodes of a single measurement.

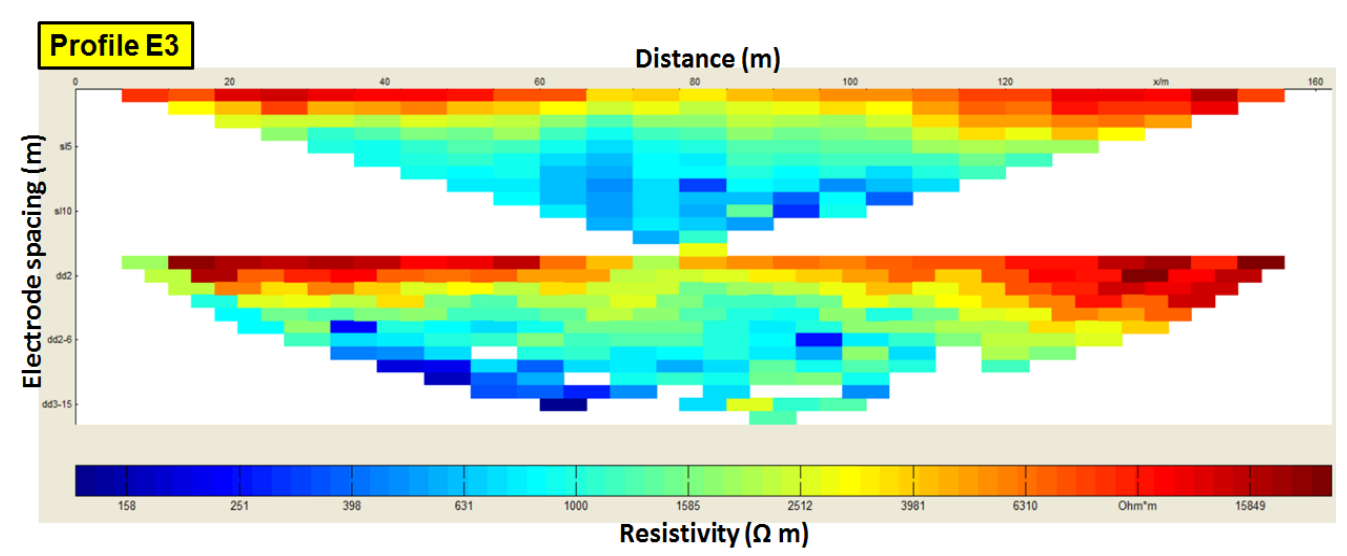

Figure 26: Pseudosections for profile E3. Top pseudosection is for a Schlumberger electrode array, bottom one is for a dipole-dipole electrode array.

\subsubsection{ERT Data Acquisition}

Five ERT transects were collected at the study area (Figure 27) using the Advanced Geosciences Inc SuperSting R1 (28 electrodes). An electrode spacing of six meters was adopted. Profiles E2, E3 and E4 were collected with the simple profile scheme (fixed position for all 28 electrodes) and for profiles E1 and E5 we used the rollalong profile scheme (Table 1). When using roll-along, we first collect data with all the electrodes in a fixed position, then we move the first 14 electrodes of the profile to the end of the profile and resume data collection, this step can be repeated multiple times.

To assure the quality of the data collected, we delete outliers that appear on the pseudosection in order to eliminate anomalous resistivity values, possibly caused by weak coupling with the subsurface. This step was carried on with DC2DInvRes software (www.resistivity.net/dc2dinvres/). Following that, the ERT data were inverted using BERT / GIMLi (Guenther \& Ruecker, 2017; Rücker, Günther, \& Wagner, 2017). The following section explains the basic principle behind ERT inversion. 


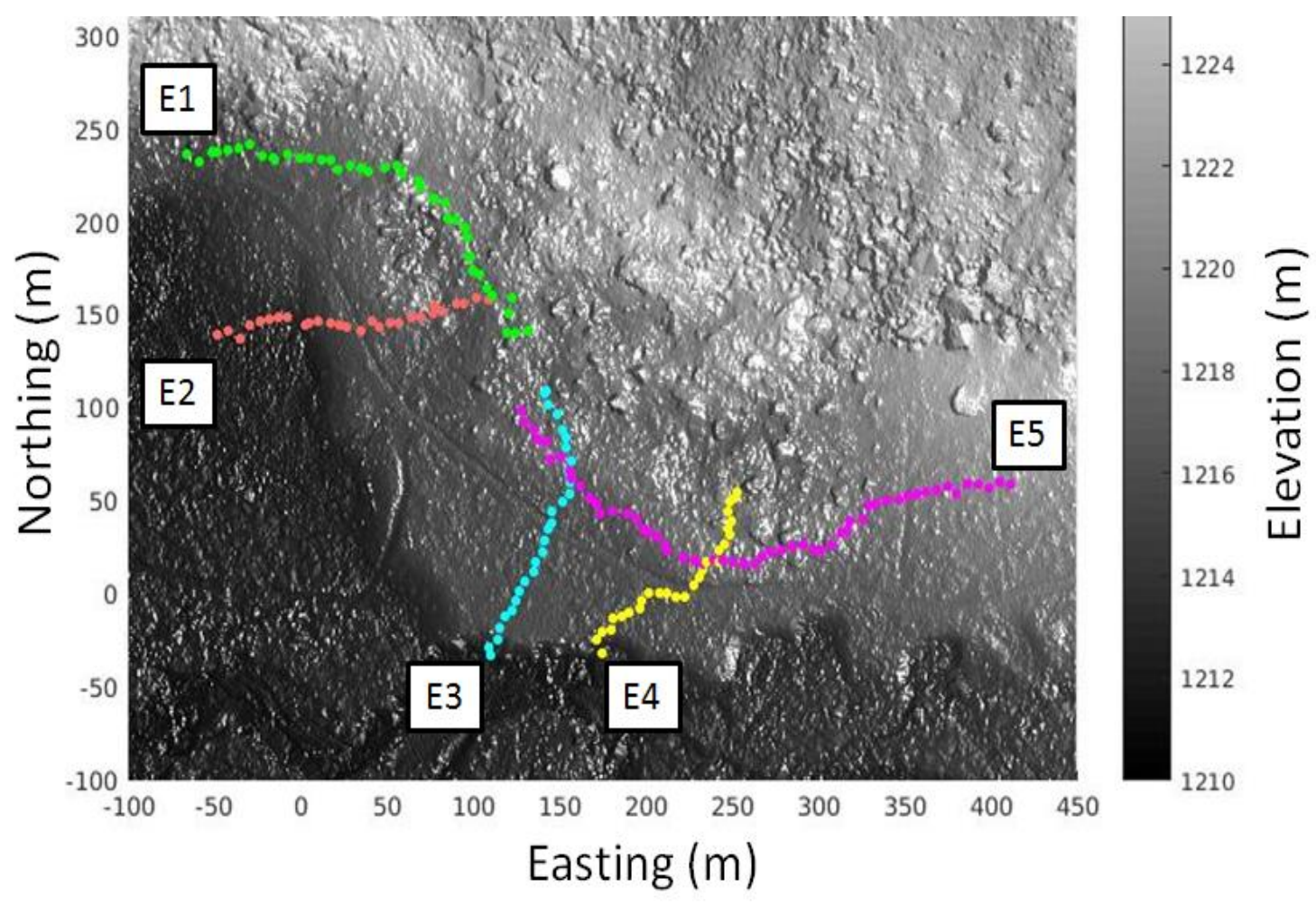

Figure 27: Colored dots illustrate ERT transects at the study area (each individual dot represents an electrode position). Coordinate 0:0 is centered at zone 11S: Easting 274170 $\mathrm{m}$ and Northing $4180400 \mathrm{~m}$.

Table 1: ERT Acquisition Parameters for profiles shown in Figure 27

\begin{tabular}{cccccc} 
Transect & $\begin{array}{c}\text { Electrodes } \\
\text { Spacing }(\mathrm{m})\end{array}$ & $\begin{array}{c}\text { Number of } \\
\text { Electrodes }\end{array}$ & $\begin{array}{c}\text { Length of the } \\
\text { Profile }(\mathrm{m})\end{array}$ & $\begin{array}{c}\text { Number of } \\
\text { Measured } \\
\text { Data }\end{array}$ & $\begin{array}{c}\text { Acquisition } \\
\text { Scheme }\end{array}$ \\
\hline E1 & 6 & 42 & 246 & 614 & $\begin{array}{c}\text { Roll-Along } \\
\text { Profile }\end{array}$ \\
\hline E2 & 6 & 28 & 162 & 380 & Simple Profile \\
\hline E3 & 6 & 28 & 162 & 369 & Simple Profile \\
\hline E4 & 6 & 28 & 162 & 380 & Simple Profile \\
\hline E5 & 6 & 56 & 330 & 943 & $\begin{array}{c}\text { Roll-Along } \\
\text { Profile }\end{array}$ \\
\hline
\end{tabular}




\subsubsection{ERT Inversion}

As mentioned earlier, pseudosections should not be interpreted directly. Instead, we use a mathematical procedure called "inversion". We apply inversion, because we have a limited amount of information, which in this case is the collected data and perhaps some $a$ priory information (e.g., interfaces). The goal is to find a subsurface resistivity image that fits our data and a priory information. We do that by having the computer trying out different subsurface resistivity images and seeing which one fits the data best. Because there are infinite possible subsurface resistivity images, the computer does this in an organized fashion. It starts with a first guess of what the subsurface could look like and then step by step changes that resistivity image to fit the data better and better.

Figure 28 illustrates this idea by displaying two different inversion results for profile E4 obtained with the use of two different regularization approaches. Figure $28 \mathrm{~B}$ shows profile E4 inverted using the "Blocky Model" and "Robust Data" in Bert. And Figure $28 \mathrm{~A}$, shows profile E4 inverted without those regularization options. Detailed description of those regularization options can be found in Guenther \& Ruecker, (2017).

Note that the degree of opaqueness of the cells (small triangles) in Figure 28 as well as in other ERT profiles displayed here, reflect the level of confidence of the model. For example, cells in the border of the profile are fit with less confidence, therefore they are presented with some degree of transparency (less opaque).

\subsubsection{Fitting the Simulated ERT Data}

Qualitatively, we observe only minor differences between the inverted results displayed in Figure 28 (A) and Figure 28 (B). Except the high resistive portion at position $75 \mathrm{~m}$ along the profile on Figure 28 (A).

Quantitatively, we can estimate how well our simulated data $\left(D_{\text {sim }}\right)$ fit the observed data $\left(\mathrm{D}_{\mathrm{obs}}\right)$, by calculating their $\chi^{2}$ value: 


$$
\chi^{2}=\frac{1}{N} \sum_{i=1}^{N} \frac{\left(D_{i}^{\text {sim }}-D_{i}^{o b s}\right)^{2}}{e_{i}^{2}}
$$
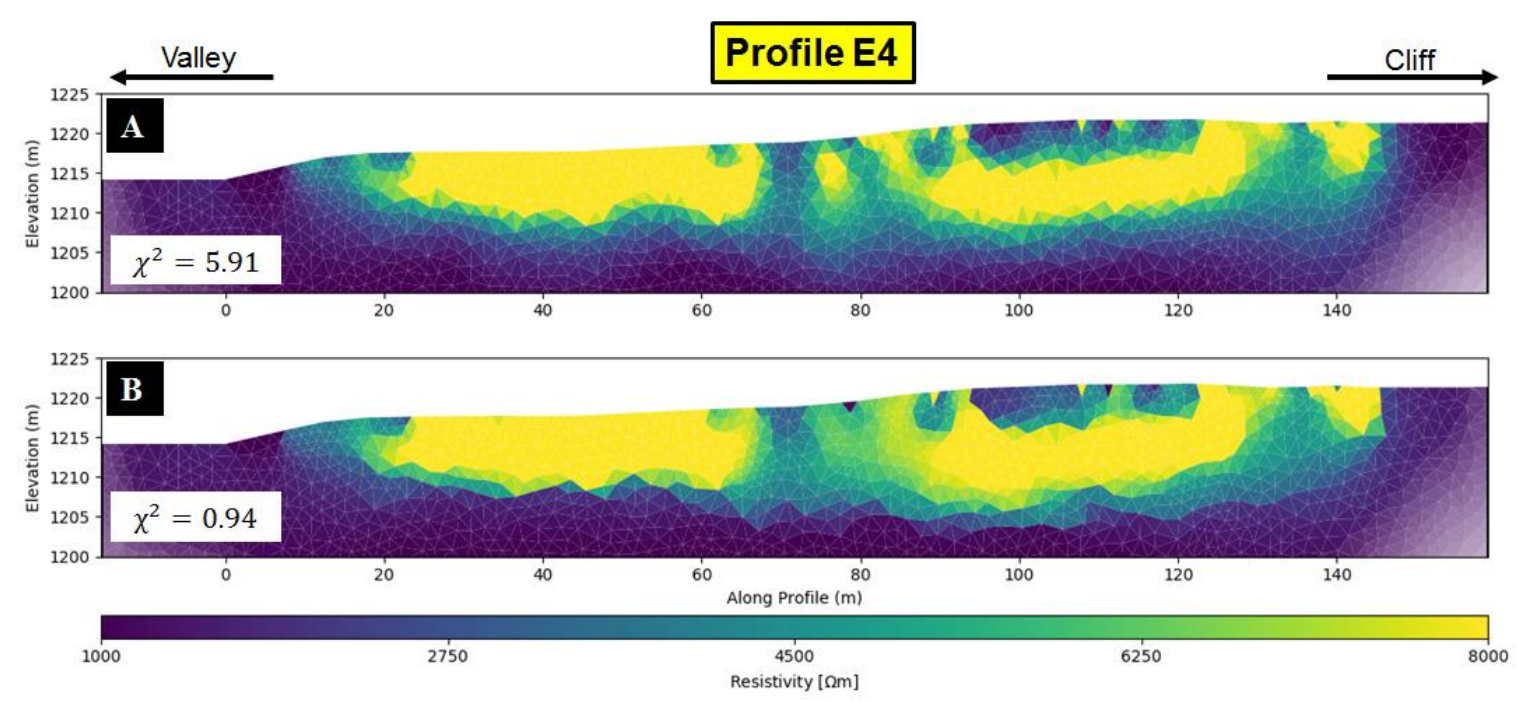

Figure 28: Different inversions for profile E4. (A) without Blocky Model and Robust Data and. $x^{2}=5.91$ (B) with Blocky Model and Robust Data. $x^{2}=0.94$.

Here, $\mathrm{e}_{\mathrm{i}}$ is the estimated error for the $\mathrm{i}$-th data value $\left(e_{i}^{2}\right.$ is the variance of the $\mathrm{i}$-th data value), $D_{i}^{\text {sim }}$ is the $\mathrm{i}$-th simulated data value and $D_{i}^{o b s}$ is the i-th measured data value.

We set our estimation of the error to $3 \%$ of the apparent resistivity value of each datum. Although we used a consistent spacing of 6 meters, eventually we had to move some electrodes a couple of centimeters in other to properly hammer them into the ground and/or to avoid boulders and trees. Another source of error is the electrodes profile position. Some of our electrode's profiles do not fully follow a straight-line shape on the ground surface, instead, they bend and curve. Ideally, we would use a 3-D inversion, but the lack of data in between lines and large spacing between electrodes compels us to use a $2.5 \mathrm{D}$ approach. $\chi^{2}$ depends strongly on our estimation for the error of each of the recoded data values. Errors include noise in the data but also other factors such as positioning error of the electrodes and estimating these errors can be difficult. If the resulting $\chi^{2}$ value is less 
than 1 , then this means that we are consistently fitting the observed data better than the estimated error in our data, hence we are running the risk of fitting noise. If on the other hand, the resulting $\chi^{2}$ value is greater than 1 , then we are "underfitting" our data, meaning that the data contain information above the error level that have not yet been incorporated into our inversion result (A. Plattner, personal communication).

\subsection{Constraining the ERT data with Selected GPR $\underline{\text { Reflectors }}$}

Both ERT and GPR are geophysical methods that depend on the same physical property (electrical resistivity) to image the subsurface, however the ways that these methods sense the subsurface is quite different. ERT can image bulk electrical resistivity distribution of the medium, but it is limited when it comes to determining sharp boundaries. In contrast, the traditional GPR approach cannot image radar velocity variations in the subsurface (radar velocity depends on electrical resistivity) but can locate radar velocity interfaces. Based on this principle, GPR profiles G1, G2, G3, G4, and G5 were collected (or partially collected) along the same paths of ERT profiles E1, E2, E3 E4 and E5. Then, we used the reflectors found in the GPR data to constrain the ERT inversion, meaning to provide additional information for the inversion. This is a standard approach when it comes to use ERT data combined with GPR data (e.g., Musil, Maurer, \& Green, (2003); Doetsch et al., (2012); and Orlando, (2013)).

Here we use profiles G3 and E3 to illustrate our constrained inversion approach (Figure 29). We used the GPR profile (Figure 29 A) to track strong reflectors that show lateral continuity along the profile (Figure 29 B) and across other profiles collected in the area of study. This step helps us to map large structures/morphologies with possible stratigraphic meaning (e.g., the contact between the rock avalanche deposit and the overlaying valley sediments). 


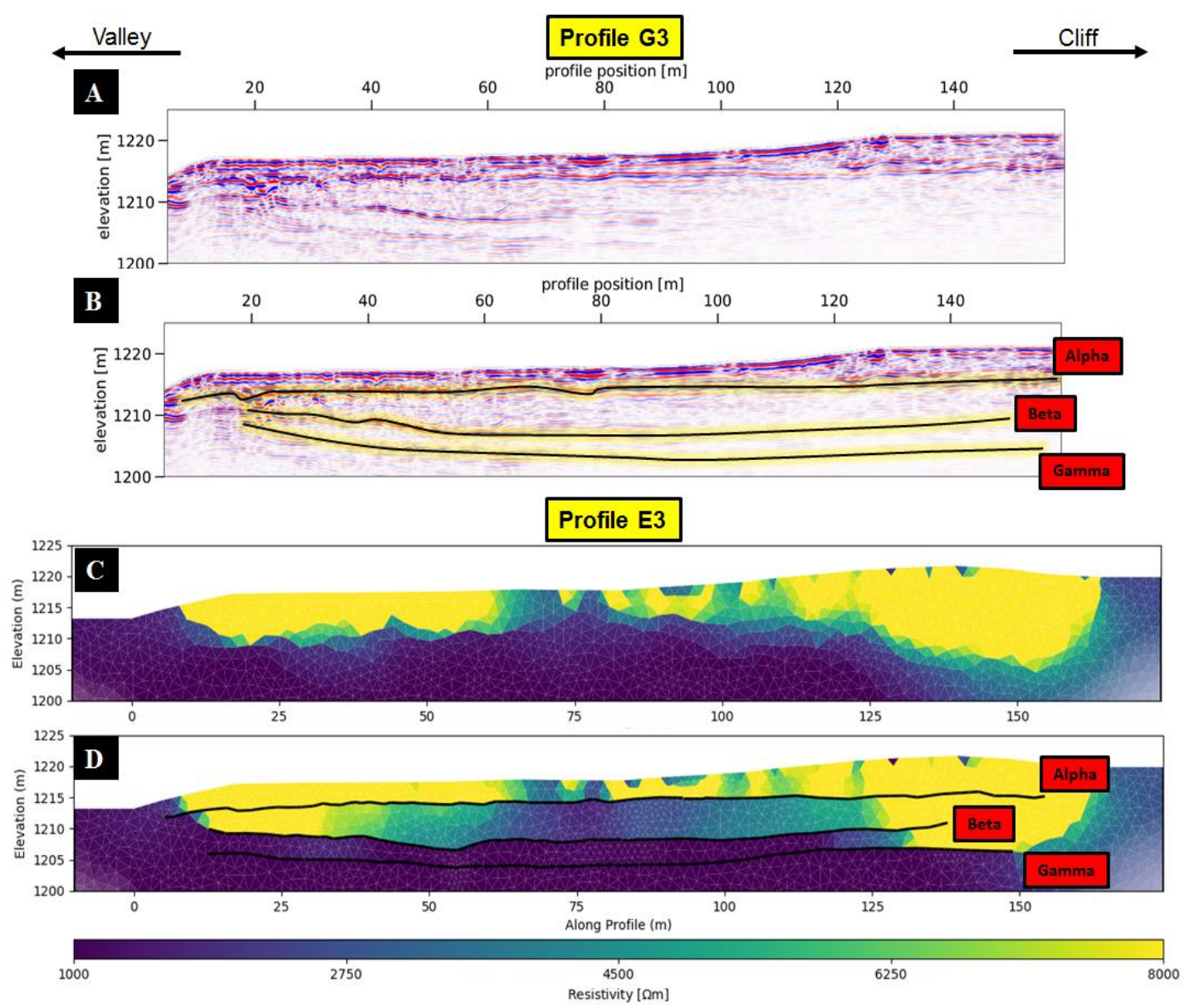

Figure 29: GPR and ERT data integration. (A) GPR profile G3. (B) GPR profile G3 with the reflectors Alpha, Beta and Gamma marked. And $(C)$ inversion of the ERT profile E3 with the reflectors Alpha, Beta and Gamma.

The next step is to use the tracked reflectors from the GPR profiles to constrain our inversion. As mentioned previously, several subsurface models can fit the same ERT data equally well, and to constrain the range of possible results, we can input additional information into our inversion. Here we do this by informing the ERT inversion about the position of interfaces (picked reflectors) that might represent a sharp transition between resistive and non-resistive material. And in case one of those interfaces are indeed a sharp transition, it should improve our inversion, and therefore the fidelity of our subsurface image to the real geological setting (Figure 29 D). 
Note that not all GPR reflectors represent a sharp transition in resistivity, they simply represent horizons from which the radar waves reflect to the surface. For example, two different rock avalanches deposits could have a strong reflector between them, however both would be very resistive. There are many other reasons for strong GPR reflection, such as sediments layering, sedimentary structures, orientation of sediments, water table/water content, etc.

To test which of those selected three reflectors (Alpha, Beta and Gamma) is the interface between the rock avalanche and the underlying valley surface, we ran several inversions with different combinations of reflectors. Figure 30 (A) illustrates an inversion without any reflector, while (B), (C) and (D) show the results of the inverted ERT data considering reflectors Alpha, Beta and Gamma respectively. We also combine different reflectors to test multiple scenarios (Figure 31).

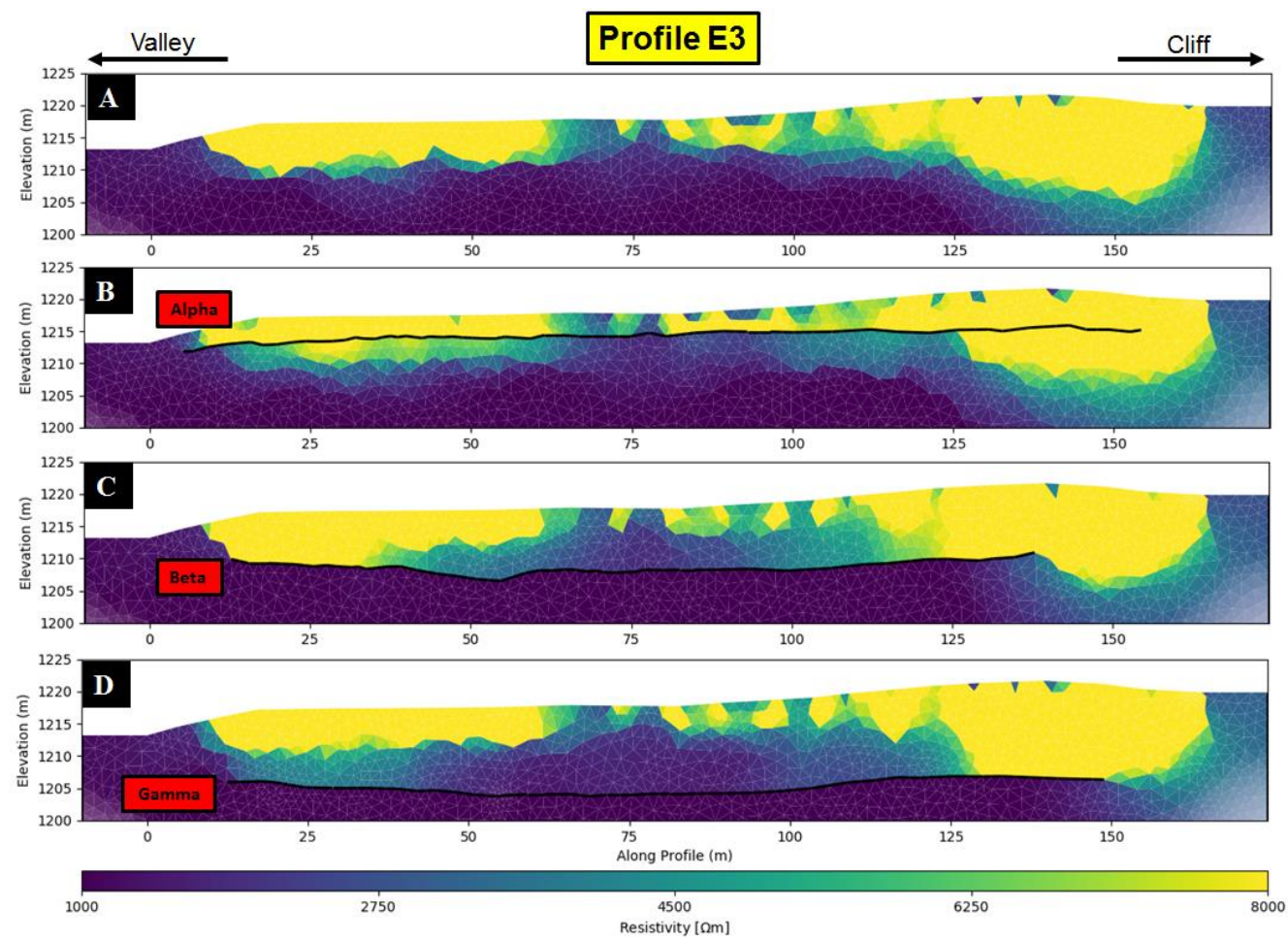

Figure 30: ERT profile E3 data inversion constrain using GPR reflectors. (A) inversion without any reflector, (B) Inversion with Alpha, (C) Inversion with Beta and (D) Inversion with Gamma. 

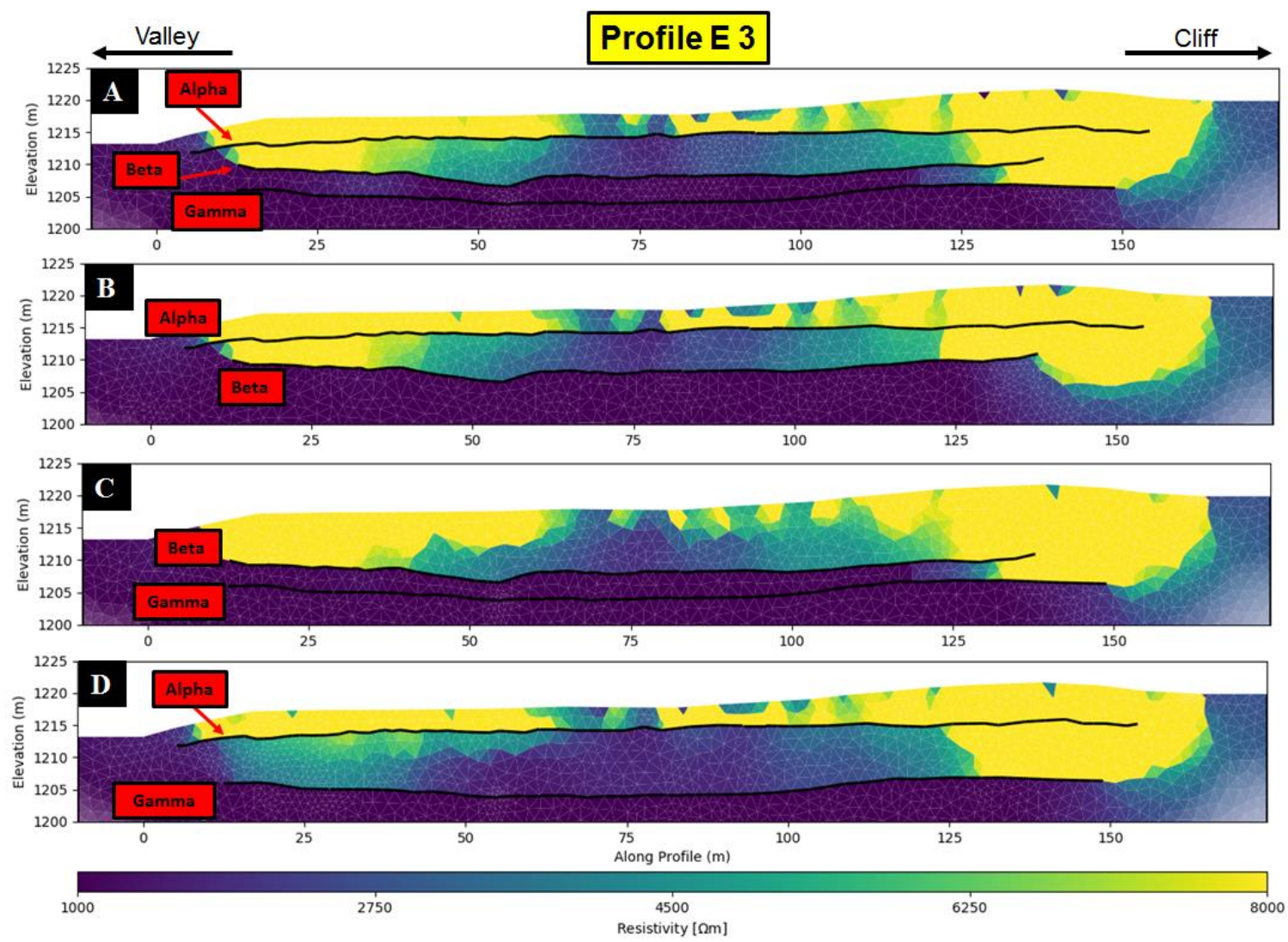

Figure 31: ERT profile E3 data inversion constrain using GPR reflectors. (A) using Alpha, Beta and Gamma; (B) using Alpha and Beta; (C) using Beta and Gamma; and (D) using Alpha and Gamma.

Most of the images displayed in Figures 30 and 31 are quite similar, reaffirming the idea that a reflector does not necessarily represent a sharp transition between resistive and non-resistive material. The exception can be observed in the inverted result using only reflector Beta (Figure $30 \mathrm{C}$ ). When reflector Beta is used as additional information for the data inversion, a clear separation between resistive material (shades of yellow) and conductive material (shades of blue) can be observed.

\section{$\underline{3.5 \text { Sensitivity Tests }}$}

As demonstrated in section 3.2.10, the chosen velocity to convert the profile from TWT time to depth impacts the position of reflectors, and possibly the ERT inversion results using those reflectors. To investigate the relationship between the uncertainty of 
the reflector's depth and the resulting inversion, we tracked reflector Beta given three distinct velocities: $0.108 \mathrm{~m} / \mathrm{ns}, 0.110 \mathrm{~m} / \mathrm{ns}$, and 0.125 (Figure 32). Then, we used those selected reflectors to invert the ERT data (Figure 33).

We note that the average elevation for Beta changes in the scale of centimeters. And the inversion results given the three selected reflectors are very similar.
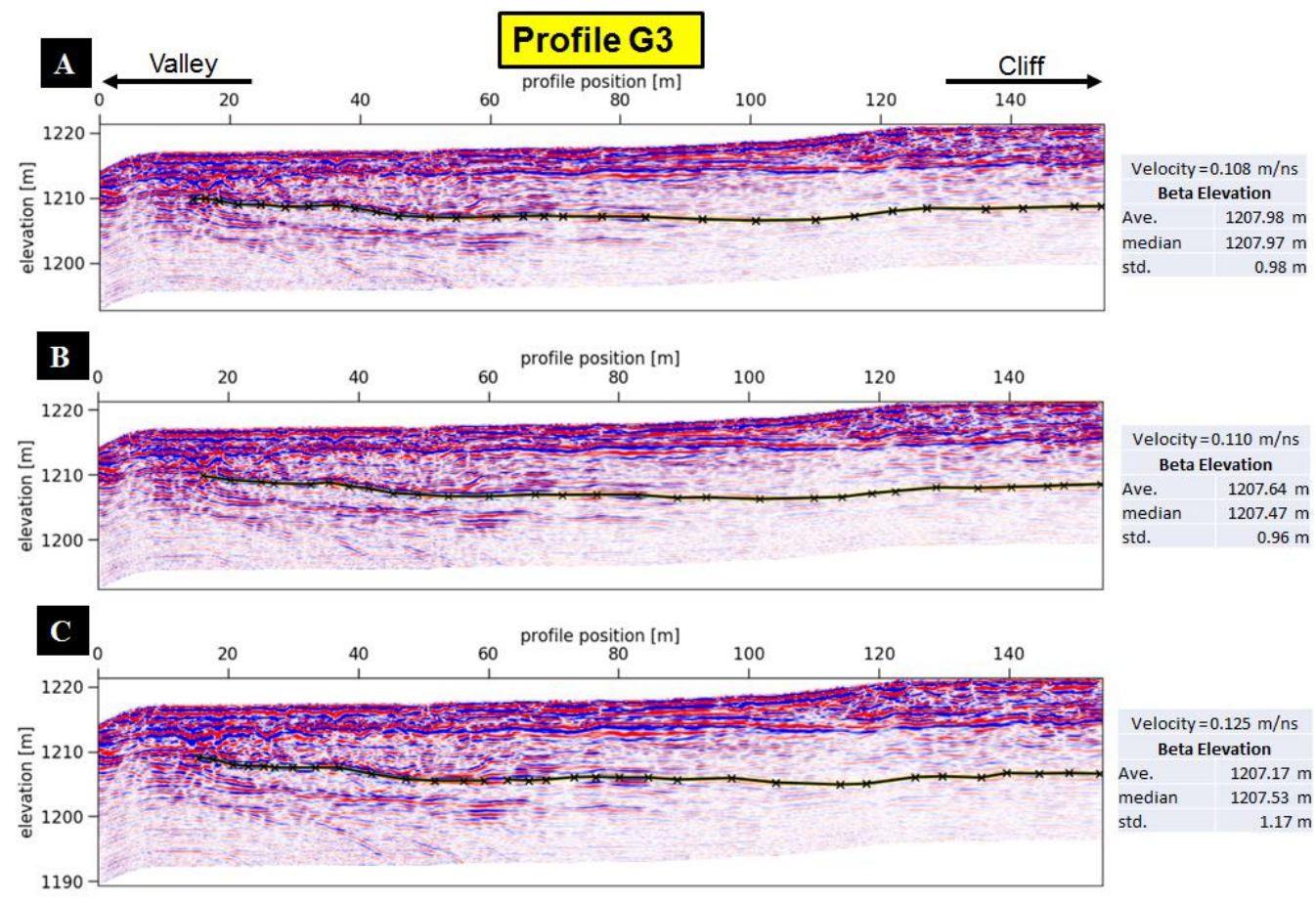

Figure 32: GPR profile G3 converted to depth/elevation using three different velocities: (A) $0.108 \mathrm{~m} / \mathrm{ns}$, (B) $0.110 \mathrm{~m} / \mathrm{ns}$, and (C) $0.125 \mathrm{~m} / \mathrm{ns}$. 

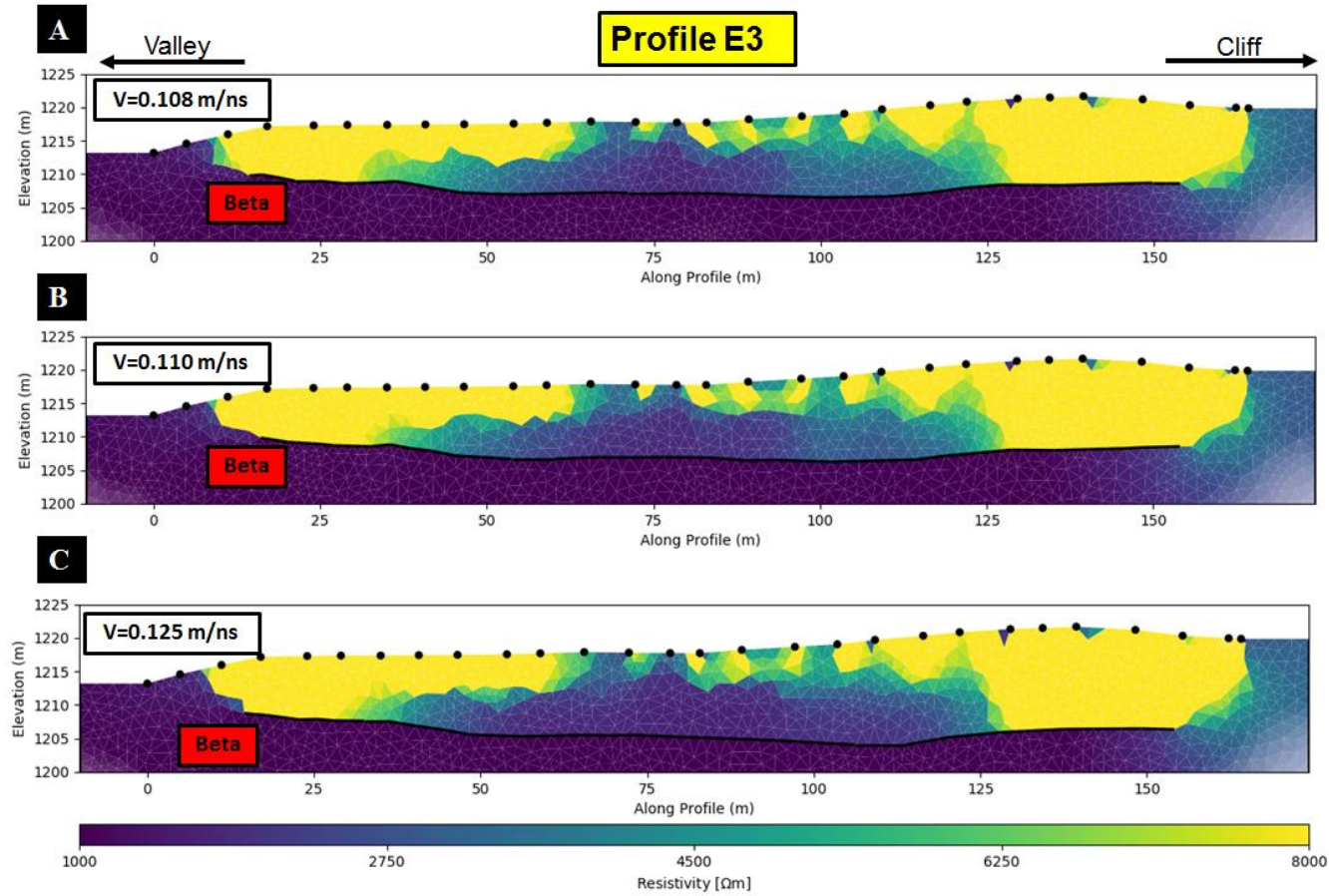

Figure 33: ERT profile E3 inverted using reflector Beta, tracked from radargrams converted with three different velocities: (A) $0.108 \mathrm{~m} / \mathrm{ns}$, (B) $0.110 \mathrm{~m} / \mathrm{ns}$, and (C) 0.125 $\mathrm{m} / \mathrm{ns}$. 


\section{RESULTS}

We acquired, processed, and analyzed a total of five ERT and eight GPR profiles (Figure 34) (Appendix A and B - including electrodes position). This allowed us to estimate the extent and the local depth of the Royal Arches Meadow Rock Avalanche. As described in the methods section, we used GPR reflectors to constrain the ERT data to find the interface between the bottom of the rock avalanche and surrounding sediments.

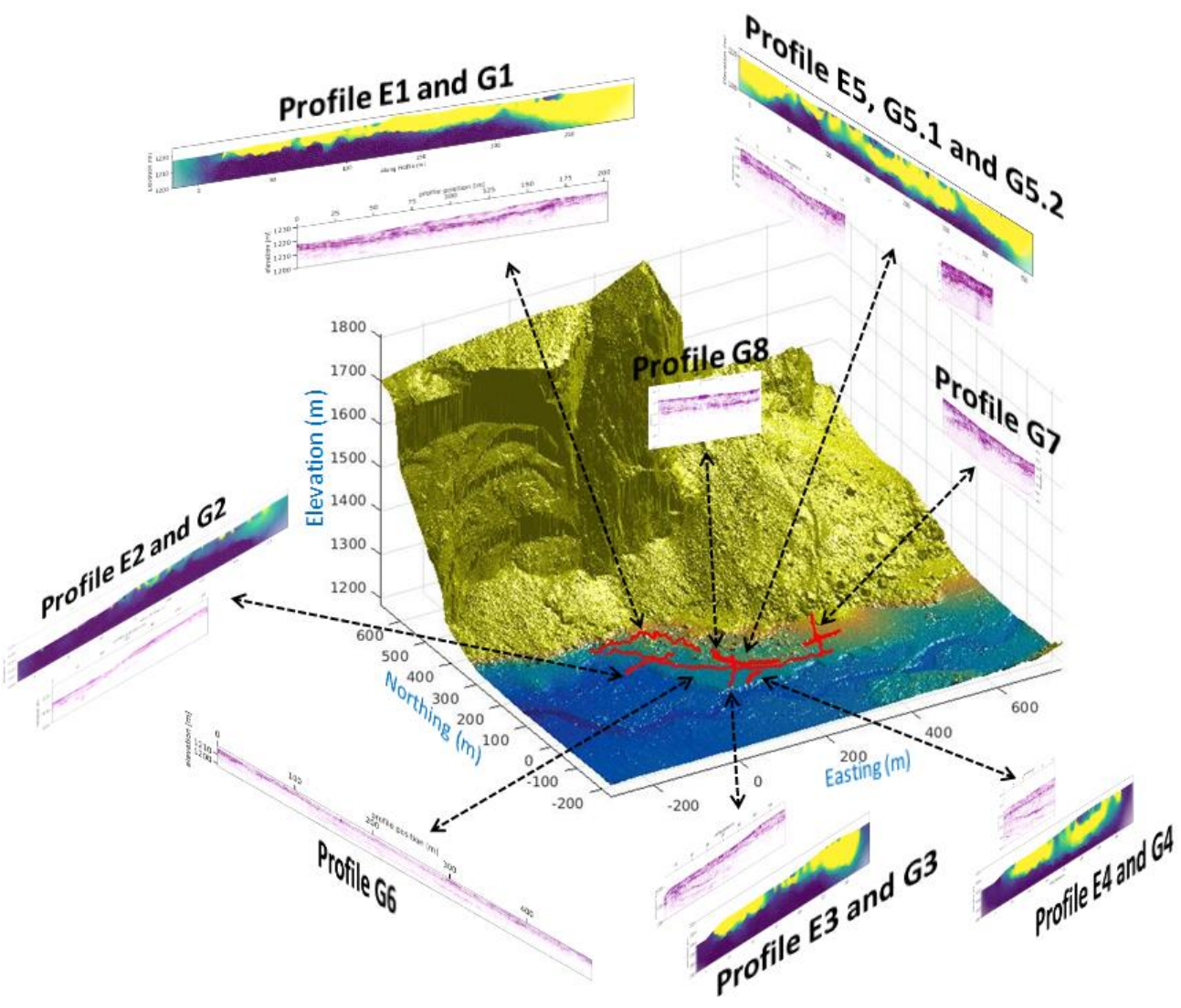

Figure 34: Oblique view of the study area with acquired geophysical profiles' position (red lines). Larger images of the processed geophysical data can be found in Appendices A and B (including electrodes position).

Since the rock avalanche studied here has a large surficial expression (hundreds of meters scale), we expect that its expression in the subsurface would be similar or even larger. Following this line of reasoning, we browsed the GPR profiles for continuous 
reflectors along and across profiles that could possibly represent the bottom of the rock avalanche.

We started the identification process at profiles G3 and G4, where the expression of four reflectors can be easily tracked along the profile (Figure 35). We named those reflectors Kappa, Alpha, Beta and Gamma. Then we tracked where profiles G3 and G4 intersect or approximate with profile G6 and tracked the same reflectors along this profile (Figure 36). Then, we repeated this process for all other GPR profiles.
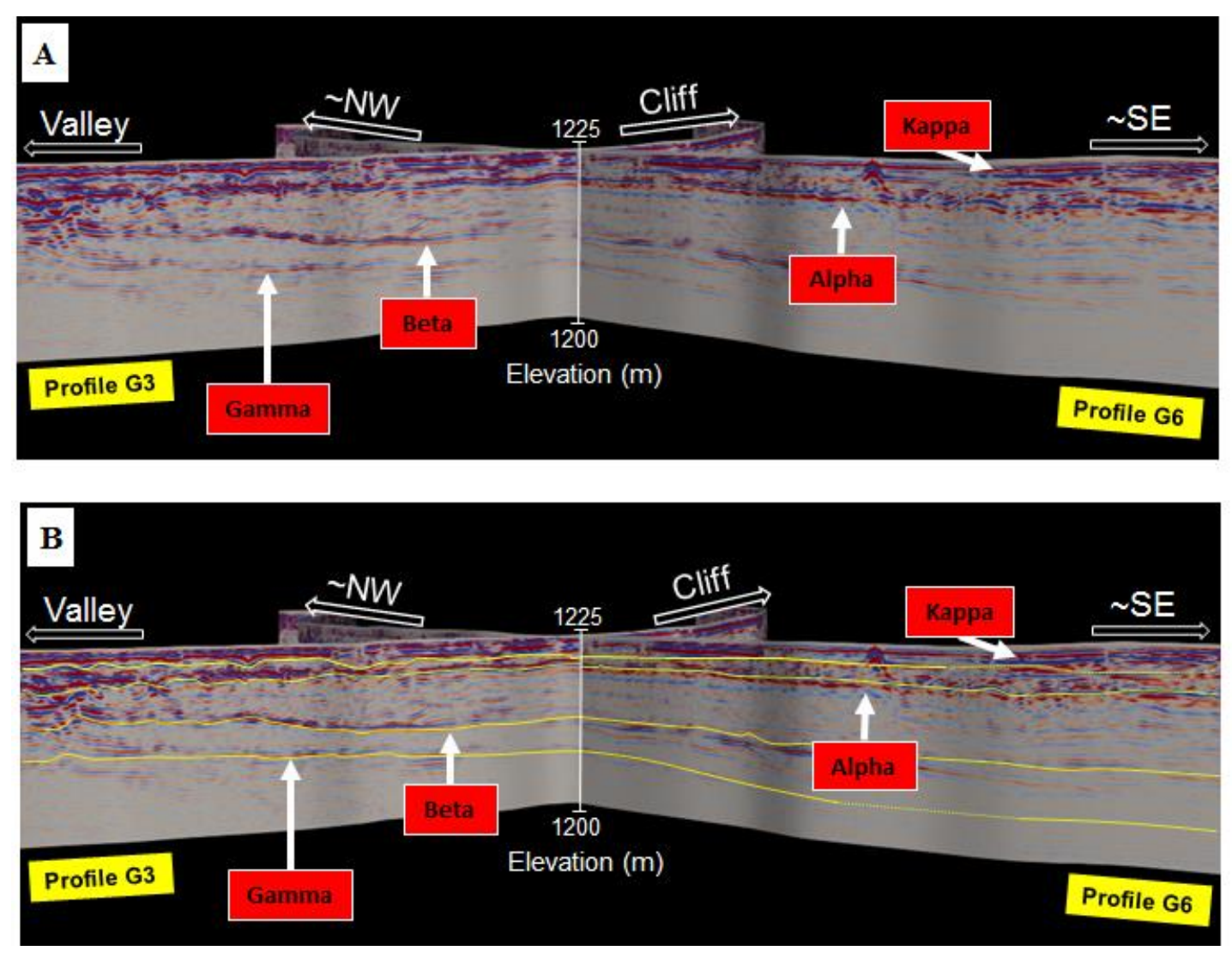

Figure 35: Three-dimensional view of profile G3 crossing profile G6. (A) continuous reflectors identified across GPR profiles. (B) Lateral continuity of reflectors Kappa, Alpha, Beta, and Gamma highlighted with yellow lines. Inferred continuity of the reflectors marked as dotted yellow line. 

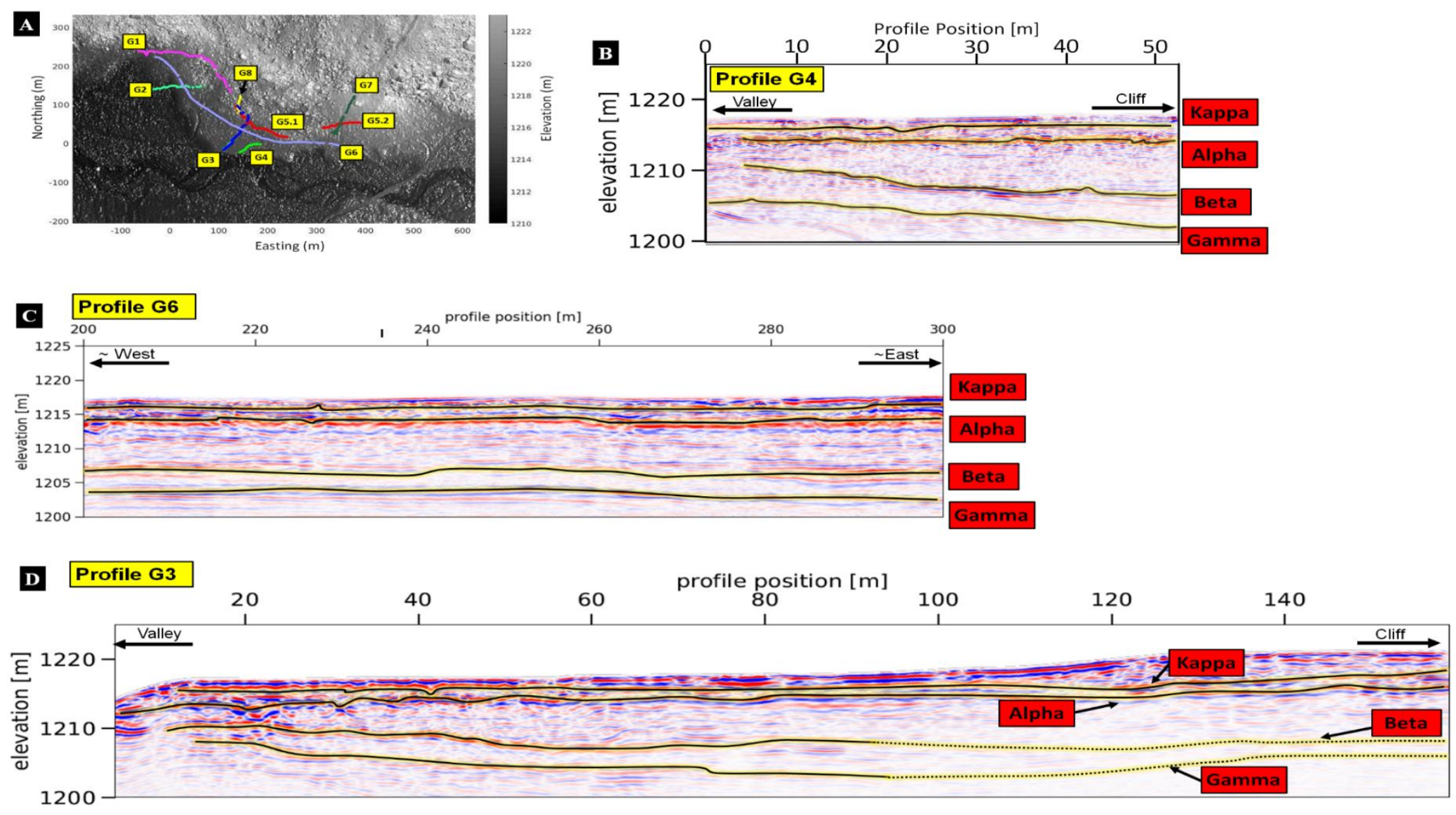

Figure 36: (A) map view showing the position of the GPR profiles, (B) profile G4, (C) section of profile G6 and (D) profile G3. Yellow lines highlight the position along the profile of reflectors Alpha, Beta and Gamma. 
Not all profiles showed all four reflectors. In addition, the elevation of those reflectors varied in scale from centimeters to meters depending of their location. Table (2) shows a compilation of the average elevation (along the profile) of the tracked reflectors (we use an " $\mathrm{x}$ " to mark the absence of data).

Table 2: Reflector's Average Elevation Along Specific Profiles.

\begin{tabular}{|c|c|c|c|c|c|c|c|c|c|}
\hline \multirow{2}{*}{ Reflectors } & \multicolumn{10}{c|}{ GPR Profile } \\
& G1 & G2 & G3 & G4 & G5.1 & G5.2 & G6 & G7 & G8 \\
\hline Kappa & 1216.9 & 1216.2 & 1216.2 & 1215.8 & 1217.7 & 1218.8 & 1216.0 & 1217.1 & 1216.7 \\
\cline { 2 - 10 } Alpha & 1216.3 & 1214.6 & 1214.0 & 1214.3 & 1214.7 & 1217.7 & 1214.2 & 1214.9 & 1214.6 \\
\cline { 2 - 10 } Beta & 1216.0 & 1207.1 & 1208.7 & 1207.9 & 1205.9 & 1211.4 & 1207.3 & 1211.9 & 1206.7 \\
\hline Gamma & $\mathrm{xx}$ & 1202.6 & 1205.3 & 1204.5 & 1200.7 & $\mathrm{xx}$ & 1202.6 & 1205.3 & $\mathrm{xx}$ \\
\hline
\end{tabular}

We also estimated the overall elevation across profiles for each of the tracked reflectors, by calculating their average, standard deviation (Std), mode and median (Table 3).

Table 3: Reflector's Elevation (m) Across Profiles.

\begin{tabular}{|c|c|c|c|c|}
\hline Reflector & Average & Std & \multicolumn{1}{c|}{ Mode } & Median \\
\hline Kappa & 1216.4 & 1.4 & 1216.1 & 1216.1 \\
\cline { 2 - 5 } Alpha & 1215.0 & 1.4 & 1214.2 & 1214.4 \\
\cline { 2 - 5 } Beta & 1209.2 & 3.2 & 1206.3 & 1208.0 \\
\cline { 2 - 5 } Gamma & 1203.3 & 1.7 & 1202.2 & 1203.3 \\
\hline
\end{tabular}

As we learned from the processed GPR profiles, the tracked reflectors are mostly flat and continuous, but they do present some small variance in elevation (Figure 35 and 36). Therefore, it is likely that the standard deviation presented in table (3) indicates how much reflectors Kappa, Alpha, Beta and Gamma varied in elevation along and across profiles. To better illustrate this lateral variation, we interpolated those reflectors to create four interfaces (Figure 37). Note that the interpolated interfaces present a practical way to visualize the continuity of the reflectors, but we should limit interpretation to the locations where we measured data (not interpreting extrapolated data). 

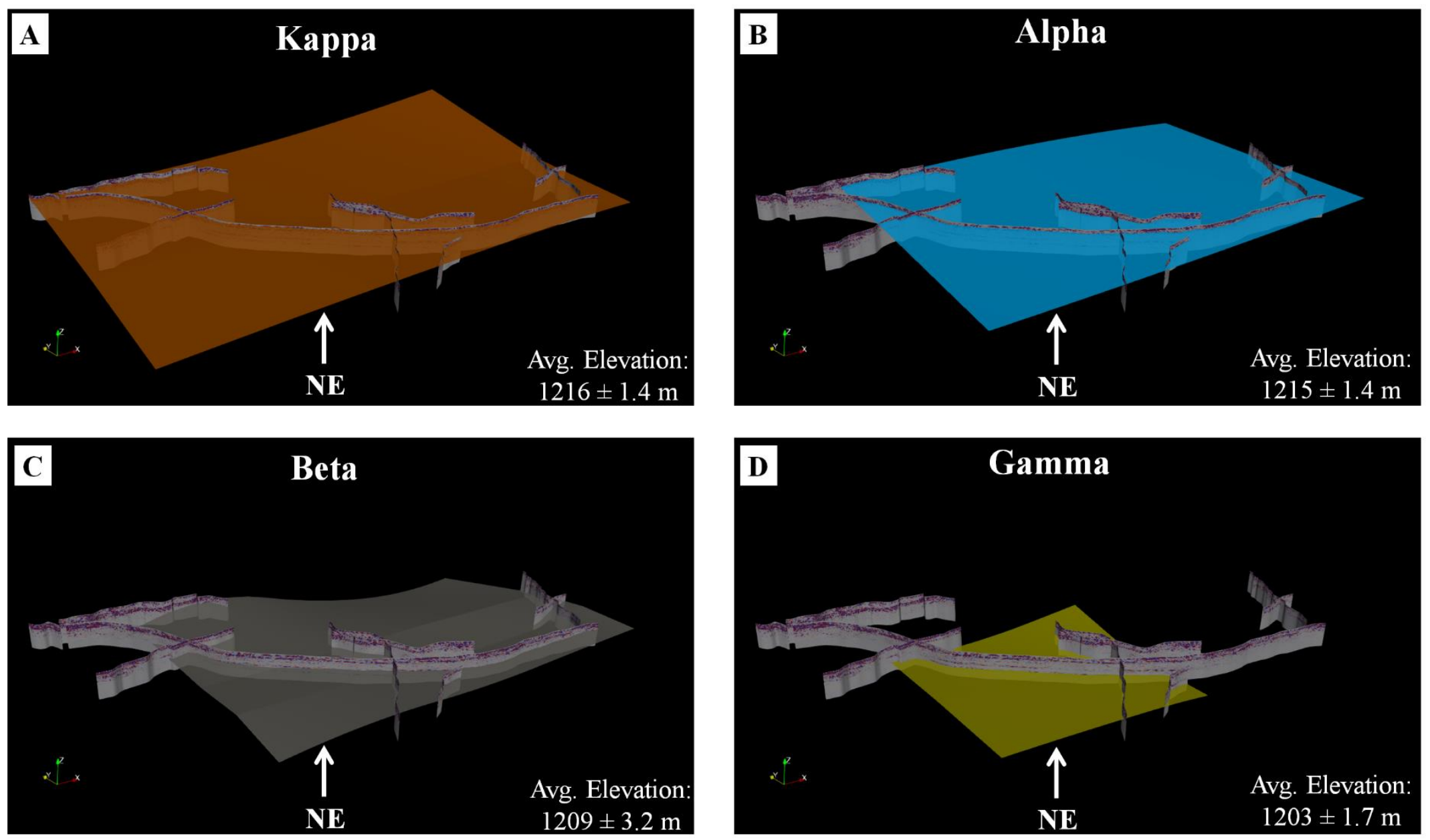

Figure 37: Oblique view (NE) of the GPR profiles with the interpolated reflectors: (A) Kappa, (B) Alpha, (C) Beta, and Gamma. 


\section{INTERPRETATION}

Our interpretations are based on: I) results obtained with the combination of ERT and GPR data; II) the correlation between our results and the local surficial/stratigraphic description proposed by Haddon et al., (2016); and III) previous geophysical work dedicated to image mass wasting deposits in Yosemite Valley and elsewhere (e.g., Sass, (2006); Otto \& Sass, (2006); Socco et al., (2010); Brody et al., (2015), Liu \& Plattner (2018)).

In this section we present estimations for:

A) The interface between the Royal Arches Meadow rock avalanche deposit and the underlying valley sediments.

B) The lateral extent of the Royal Arches Meadow rock avalanche.

C) A timeline of events in the study area.

\subsection{Estimating the Bottom of the Rock Avalanche}

As mentioned previously, we expect the lateral extent of the rock avalanche deposit in subsurface to be in the scale of hundreds of meters. Based on: (1) the present surficial expression of the deposit and (2) the large volume and runout characteristic of rock avalanche deposits (Wieczorek, Morrissey, Iovine, \& Godt, 1999; Stock and Uhrhammer, 2010). Therefore, to infer the bottom of the rock avalanche using geophysical methods, we must look for:

I) In the GPR profiles: a continuous reflector in multiple directions in the hundreds of meters scale.

II) In the ERT profiles: a sharp contrast between high resistivity values (> $3000 \mathrm{ohm}$ $\mathrm{m})$ contrasting with low resistive values $(<3000 \mathrm{ohm} \mathrm{m})$. 
As described in our results, we have identified four continuous reflectors (Kappa, Alpha, Beta and Gamma) that satisfy the first premise. The question is: which of them represents a sharp transition between resistive material (rock avalanche deposit) and conductive material (valley floor deposits)? To answer this question, we used the methodology described in chapter 3.4. This methodology suggests that reflector Beta is the interface that best constrains the inversion among different pair of ERT and GPR profiles. Therefore, interface Beta is interpreted here as the bottom of the Royal Arches Meadow rock avalanche.

Figure 38 (A), (B) and (C), shows the result of the inversions for profiles E3, E4 and E5 constrained respectively with reflector Beta tracked along profile G3, G4, G5.1 and G5.2. Figure 38 (E) displays the interpolated result of reflector Beta along those GPR profiles.

We observed that while interface Kappa, Alpha, and Gamma are almost parallel to the surface, interface Beta gently slopes upward while approaching the edge of the avalanche (Figure 39).

\subsection{Estimating the Top of the Rock Avalanche}

Assuming that the interface "top of the rock avalanche" and "modern valley deposits" (sediments deposited after the rock avalanche event) would also create a strong reflector, we can analyze the strong reflectors that we mapped in the study area to investigate the elevation of the top portion of the rock avalanche.

We can eliminate Gamma as a possibility, because this reflector is in a lower elevation when compared to Beta (bottom of the rock avalanche). The next candidate is reflector Alpha, which we also excluded as a possibility because we believe that interface Alpha is the water table. Two points support this interpretation: 
A

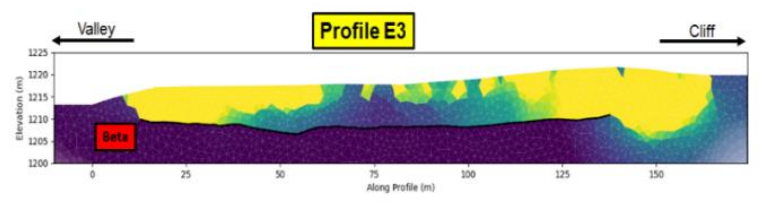

B
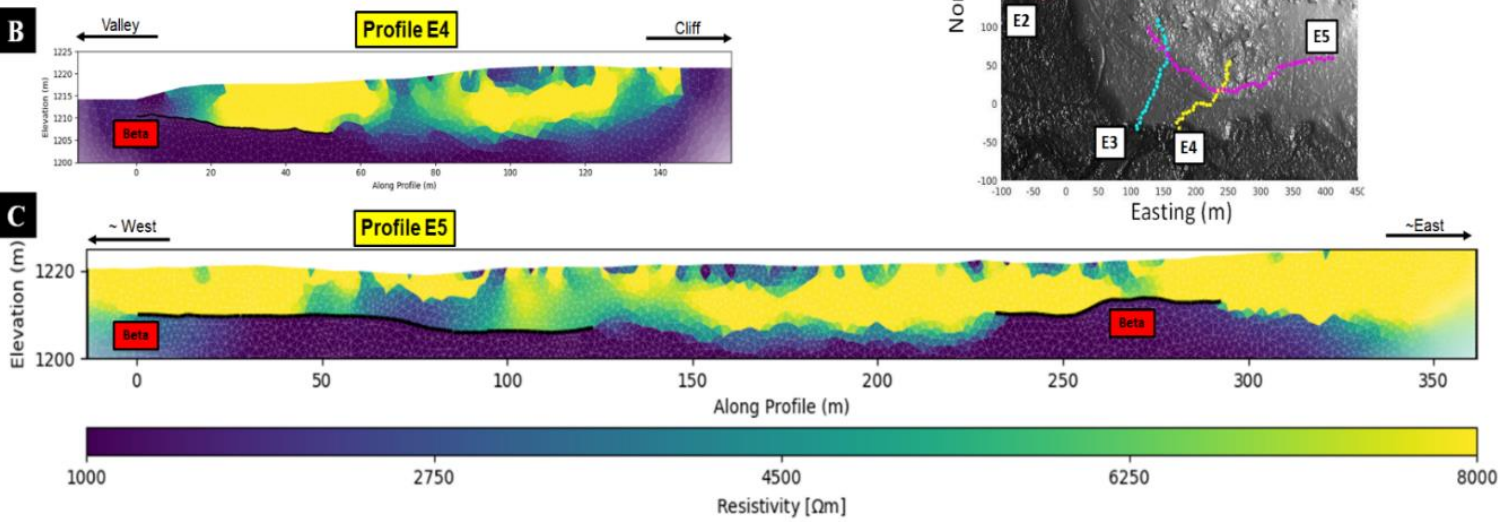

E
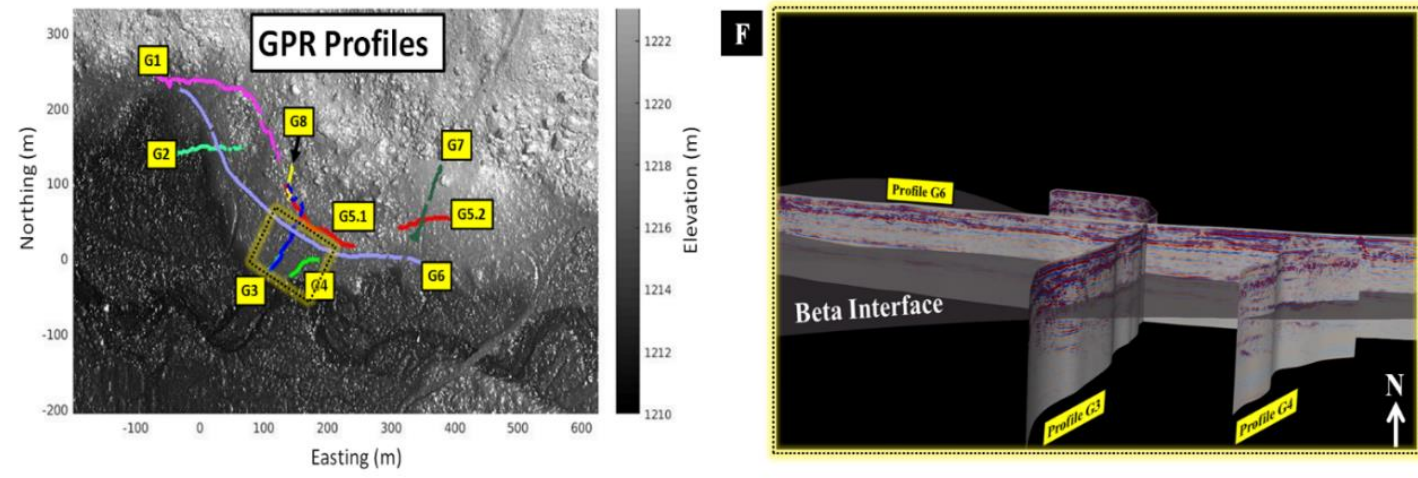

Figure 38: Inverted result using reflector Beta for profiles: (A) E3, (B) E4 and (C) E5. (D) ERT profiles position in map view, (E) GPR profiles position in map view and (F) oblique view of GPR profiles with Beta Interface. Note that we were not able to collect GPR data all the way along profile E4 and E5. Therefore, Beta is not present all the way on profile E4 because of the absence of GPR data at this area. The same is true for the missing part of reflector Beta on the display of profile E5. 
A

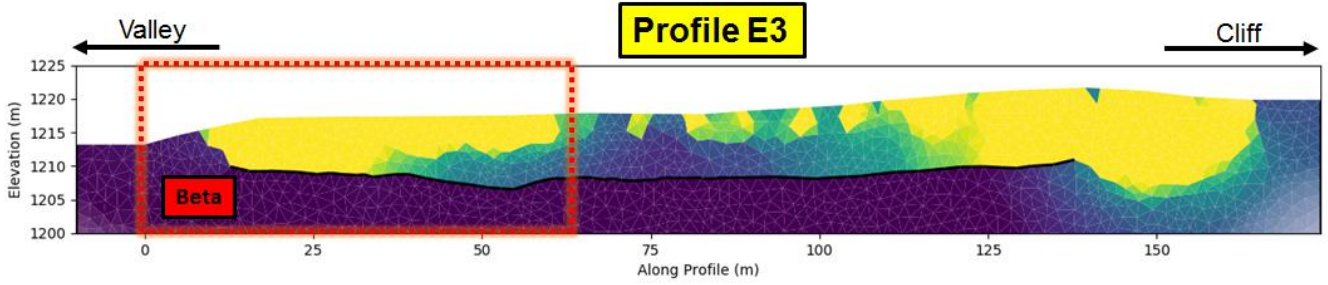

B
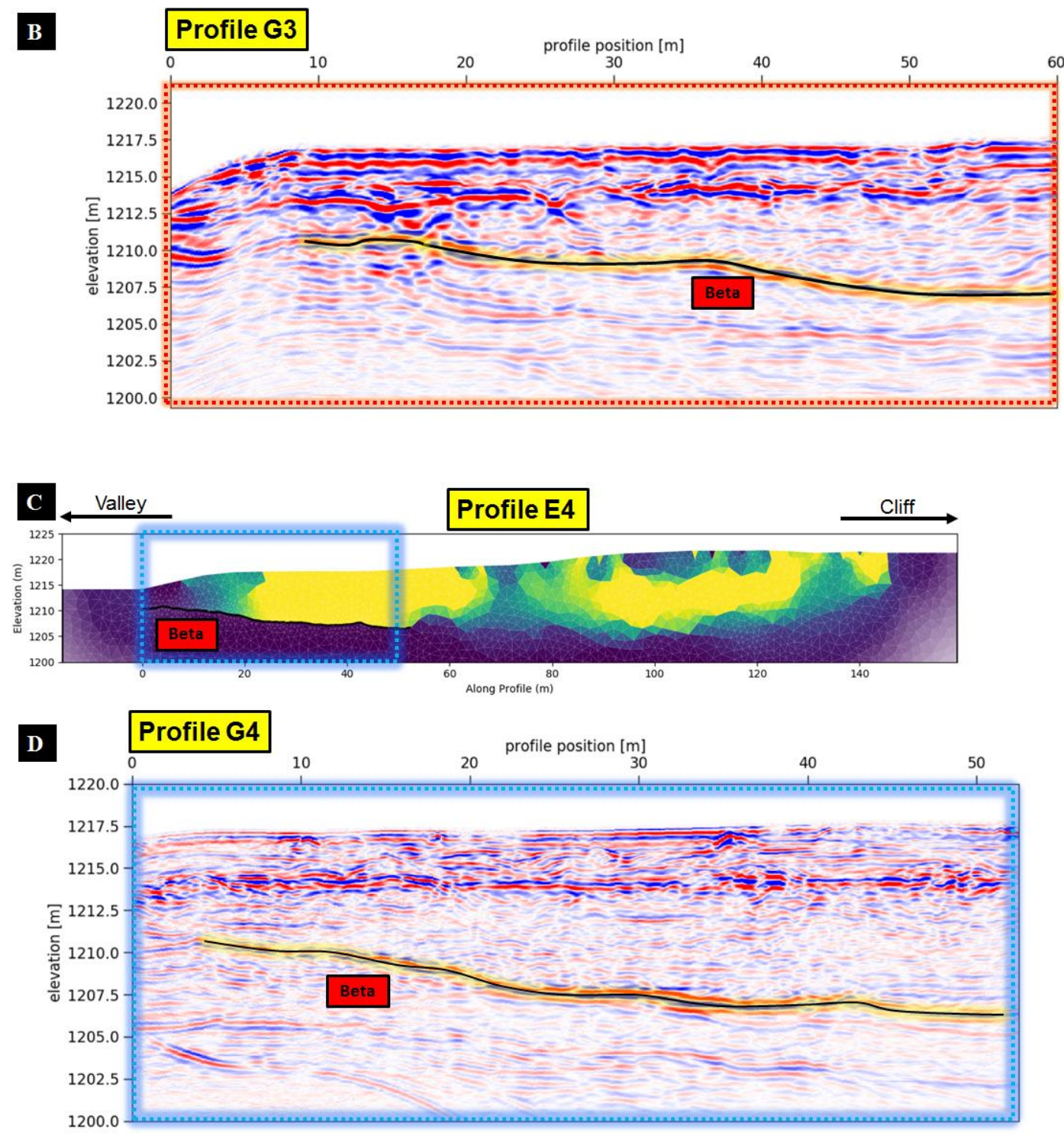

Figure 39: Beta interface sloping upward in the valley direction (A) ERT profile E3. (B) GPR profile G3. (C) ERT profile E4. And (D) GPR profile G4 (Note that the zero position for this GPR profile is equivalent to the $5 \mathrm{~m}$ position of the ERT profile. 
(I) The water table elevation in this region is set by the elevation of the Tenaya Creek, the local base level (G. Stock personal communication), and reflector Alpha presents an elevation consistent with the elevation of the Tenaya Creek at the time of this study (Figure $40 \mathrm{~A}$ ).

(II) The typical expression of water tables in GPR data is a flat and continuous interface that follows parallel or subparallel to the surface topography (e.g., Neal, 2004; and Jol, 2007), and this is exactly what we observe in reflector Alpha (Figure $40 \mathrm{~B}$ ).

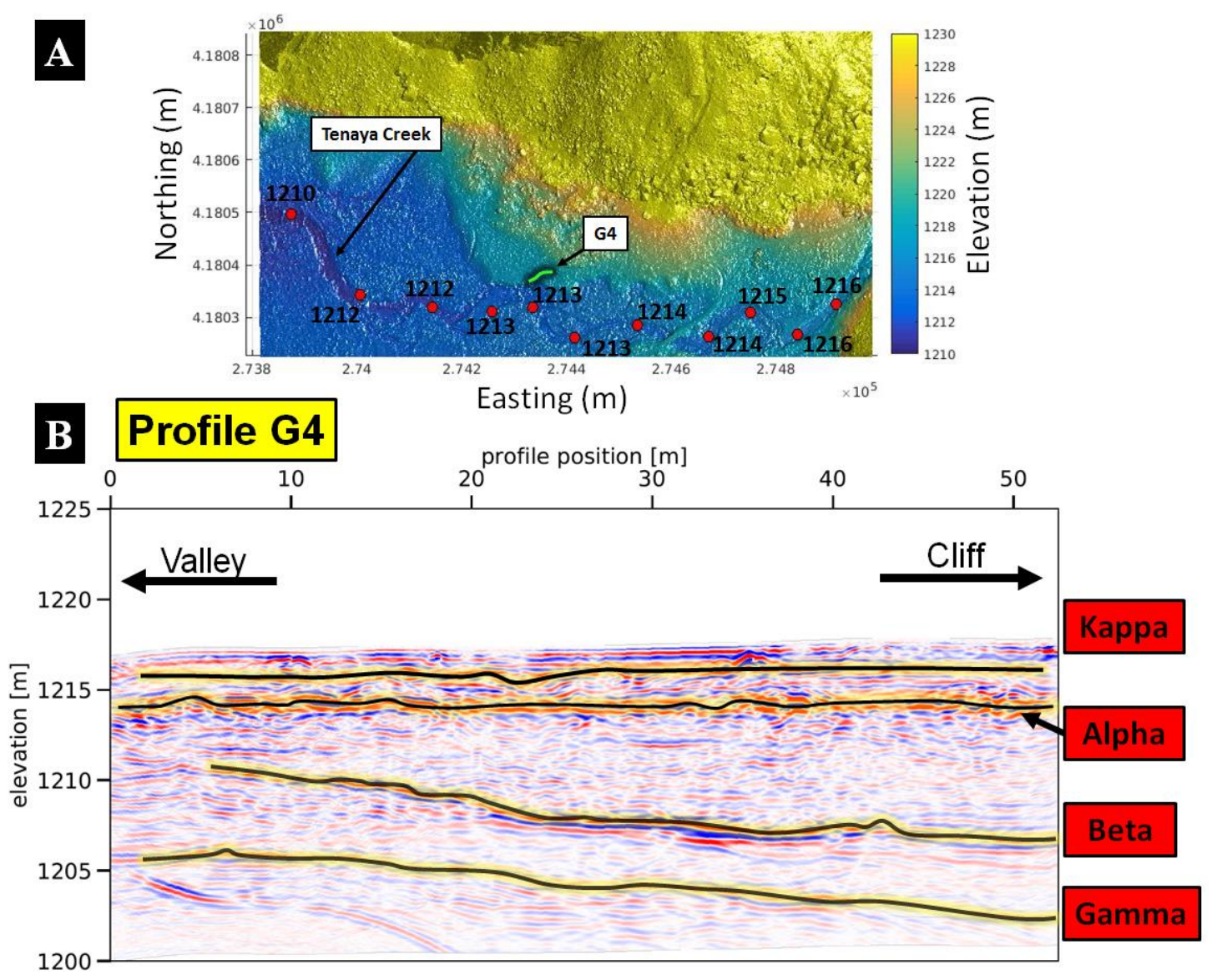

Figure 40: (A) Map view of the study area, green line highlights the position of GPR profile G4 and red dotes highlight the elevation of the Tenaya creek at that position in meters. (B) GPR profile G4, with tracked reflectors highlighted with black lines. 
Consequently, we were left with two final options for the top of the rock avalanche. The first would be reflector Kappa, which is also a reflector that presents a parallel to subparallel shape (in relation to the topography) and is present along all GPR profiles observed here. Second, it is possible that our vertical resolution did not allow us to image the interface that marks transition between the modern valley deposits and the top of the avalanche.

\subsection{Distal Extent of the Rock Avalanche in Subsurface}

We mark the distal (southernmost) limit of the rock avalanche deposit at GPR profiles G3 and G4 (Figure 41 B and D), where we can observe the lateral continuity of interface Beta, and where the resistive material ends along ERT profiles E3 and E4 (Figure $41 \mathrm{~A}$ and $\mathrm{C}$ ).

\subsection{Lateral Extent of the Rock Avalanche in Subsurface}

We were not able to precisely track the lateral continuity of Beta for the GPR profiles in the Western and Eastern most portion of our study area. Consequently, we were not able to precisely estimate the position of the lateral edges of the RAMRA. Instead, we here make an educated guess about the lateral edges of the avalanche deposit, based on the estimated depth of interface Beta.

We speculate that the following two reasons explain why we were not able to precisely image the edges of the deposit in the western and eastern part of the study area.

\section{I) Resolution}

After collecting the first set of ERT data, we realized that the bottom of the rock avalanche was deeper than expected (approximately $10 \mathrm{~m}$ from the surface). This then, forced us to change our strategy for data acquisition. To increase the depth of investigation for the ERT survey, we needed to space our electrodes further from each 

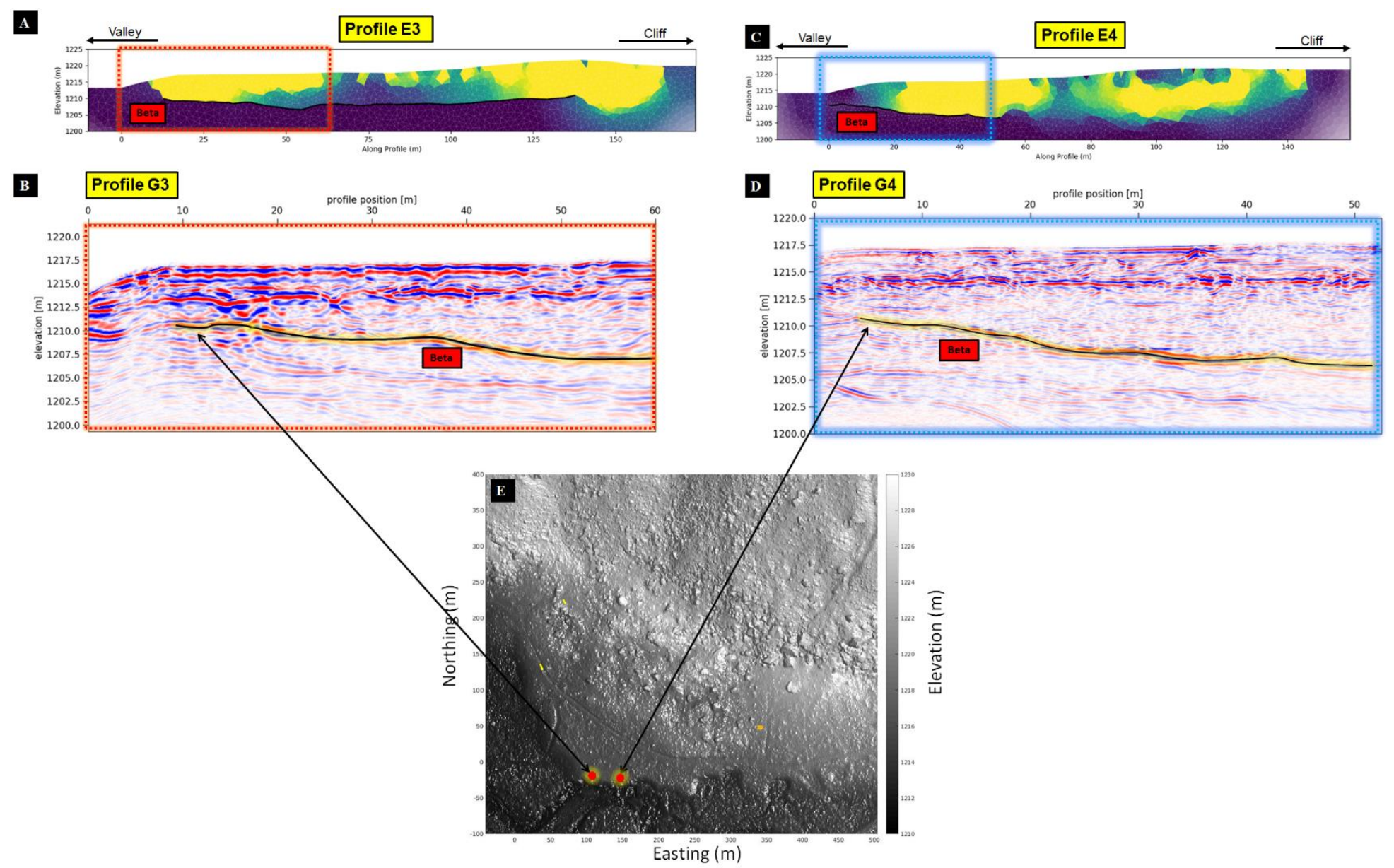

Figure: 41: (A) and (C) are inverted results considering reflector Beta (black line) for profile E3 and E4 respectively. (B) and (D) show the possible distal edge of the RAMRA identified on GPR profiles G3 and G4 respectively. And (E) Plan view of the identified features in the study area. 
other. This gave us the ability to reach deeper structures into the subsurface. However, we lost resolution in the shallow portion of the survey. For the GPR, we needed to use an antenna with low frequency (we used 50 and $100 \mathrm{MHz}$ ). This gave us the chance to image deeper layers, but we also lost vertical resolution (our capacity to recognize and distinguish layers and structures).

As a result, it is possible that the resolution of both ERT and GPR were not enough to distinguish the structures that would help us to identify the lateral extent of the rock avalanche deposit.

\section{II) Data Collected close to Talus Deposits}

Contrast in physical properties of the medium is probably one of the most important factors when comes to geophysical imaging. The data collected in the distal portion of the study area fulfill this requirement, because the physical properties (e.g., electrical resistivity and dielectric permittivity) of the rock avalanche deposit are different from the valley fill deposits. (e.g., profiles G3, G4, E3 and E4).

The reciprocal is not true for the profiles collected closer to the talus deposit below the cliff. In this portion of the study area, talus deposits overlay the rock avalanche deposits. By observing Figure 42, we note that the beginning of GPR profiles G1 and G6; and the end of G5.2 and G7 are close to the talus deposits. The same is true for the ERT profiles that overlap those profiles (E1 and E5).

The presence of talus deposits on the top of the rock avalanche deposits brings a margin of uncertainty to our interpretation, because we were unable to distinguish if the resistive material overlying the valley floor sediments at those areas are part of the rock avalanche, talus deposits, or fine material washed down slope from the talus during rain storms (all those materials would give us a resistive answer). 


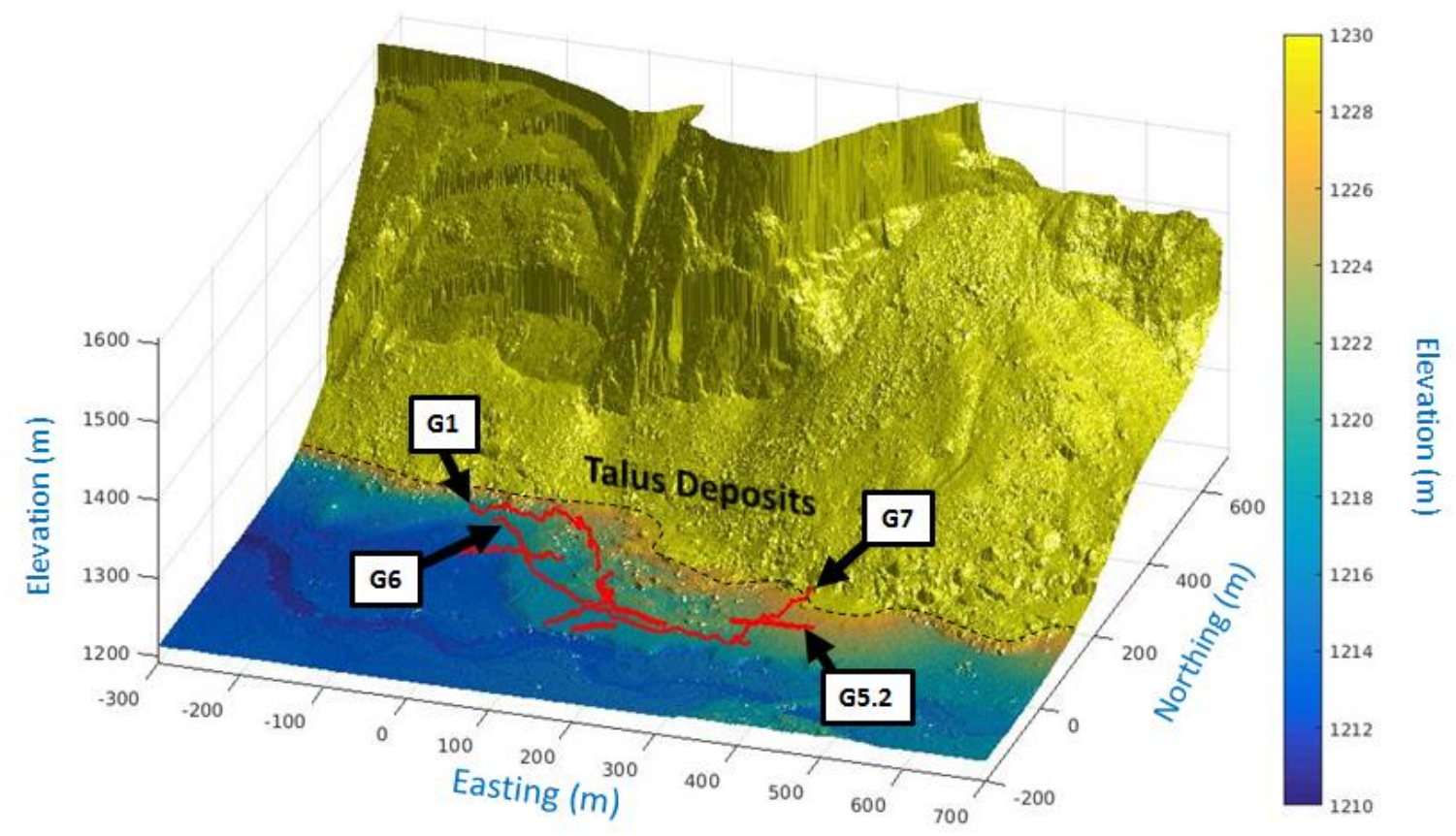

Figures 42: Oblique view of the study area with GPR profiles (red lines), highlighting the profiles close to talus deposits (yellow portion of the map. Elevation > 1223).

Since the ERT profiles do not provide a high degree of certainty, we can analyze corresponding GPR profiles. For example, on GPR profile G1 (Figure 43 A), we note the presence of three continuous reflectors between the elevation of $1212 \mathrm{~m}$ and $1218 \mathrm{~m}$. The reflector that starts at $\sim 1215 \mathrm{~m}$ of elevation (named here reflector " $\mathrm{X}$ ") constrains well the ERT data for profile E1 (Figure 43 B). Unfortunately, we were not able to collect GPR data beyond the $200 \mathrm{~m}$ of this profile. From this point forward we need to rely only on the ERT data.

Observing where the ERT profile E1 bends SE (beyond 200m), we note the presence of resistive material from the surface directly downwards to elevation to $1200 \mathrm{~m}$. At this point, we feel confident to affirm that we are looking at the rock avalanche deposit, due to the depth of the resistive material 
Consequently, it is possible that the resistive material present in the W-E portion of the ERT profile E1 (0-200m) is laterally continuous. However, two main factors add uncertainty to this interpretation:

(A) We were not able to distinguish if the resistive material observed on the W-E portion of profile E1 (0-200 m) is indeed the rock avalanche deposit or modern talus deposits.

(B) Reflector "X" does not connect well with the reflector interpreted as the bottom of the rock avalanche (Beta).

Therefore, we decided to mark the western edge of the avalanche close to where the deposit is deeper $(200 \mathrm{~m}-300 \mathrm{~m}$ along ERT profile E1) and where we are confident about the presence of the avalanche deposit (Figure 44).

A similar problem occurs when analyzing ERT profile E5 (Figure 45). We used reflector Beta tracked in GPR profiles G5.1 and G5.2 (Figure 45 B) to constrain this inversion. As a result, we note that the bottom of the rock avalanche is between the elevation of $1210 \mathrm{~m}$ and $1215 \mathrm{~m}$. However, the lack of GPR data beyond the $270 \mathrm{~m}$ for the ERT profile E5 prevent us from further interpreting the resistive material at this point. In other words, it is possible that the rock avalanche deposit is continuous east of $270 \mathrm{~m}$ of the ERT profile, but we decided to mark on the map the eastern-most portion of the rock avalanche imaged by both GPR and ERT (Figure 45 B). Lastly, ERT profile E5 and GPR profile G5.2 helped us to confirm the idea that there is an elevation gradient between the proximal and distal portion of the rock avalanche deposit. At the distance of $250 \mathrm{~m}$ we slightly shift the direction of the profile from $\sim \mathrm{E}$ to $\sim$ ENE, then we shift again to $\sim$ E direction. As a result of those shifts in direction, reflector Beta gained elevation. 

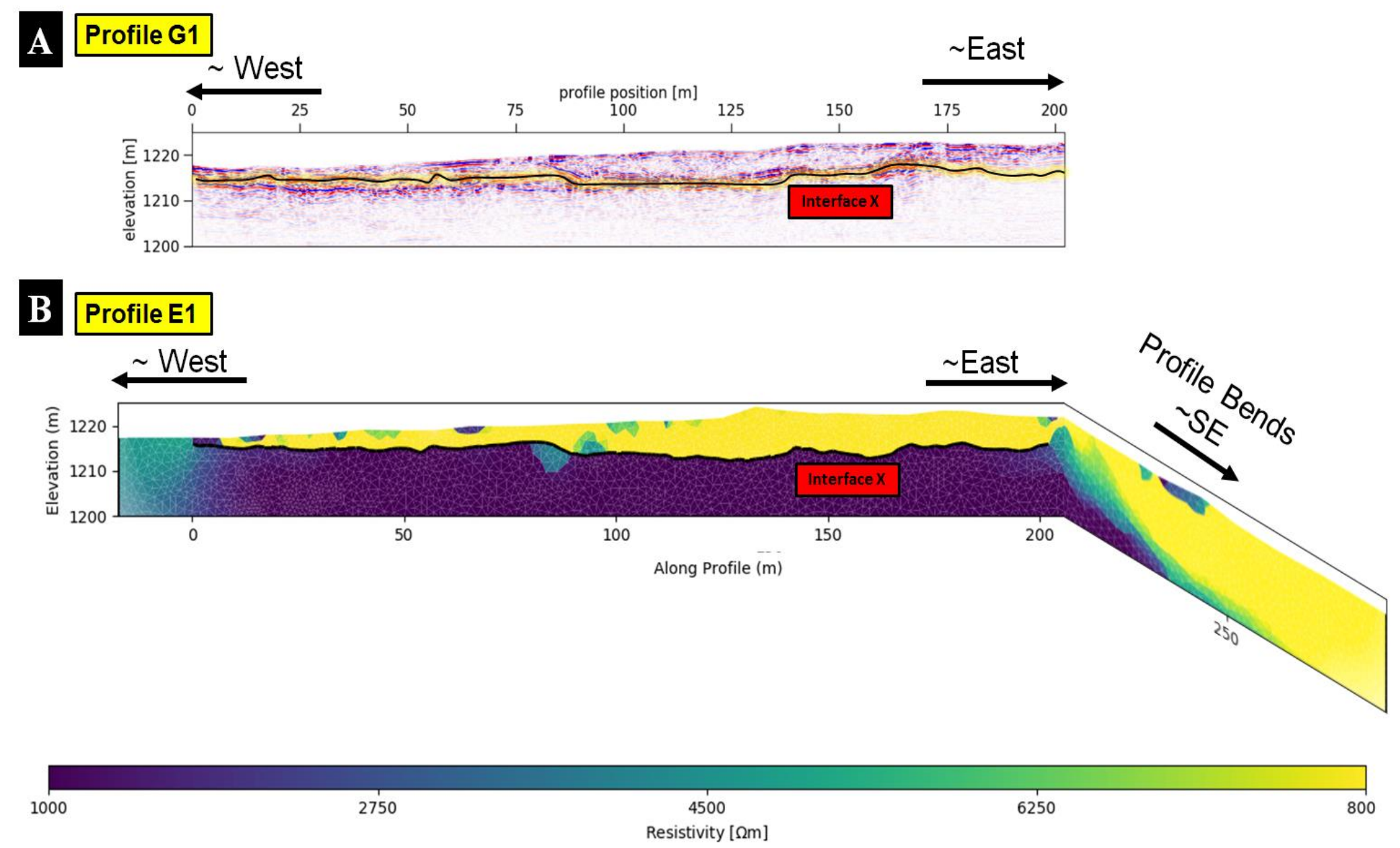

Figures 43: (A) GPR profile G1 with reflector "X" (black line). (B) ERT profile E1 inverted with reflector "X" (black line). White arrow highlights the approximate direction of the flow of the avalanche. 


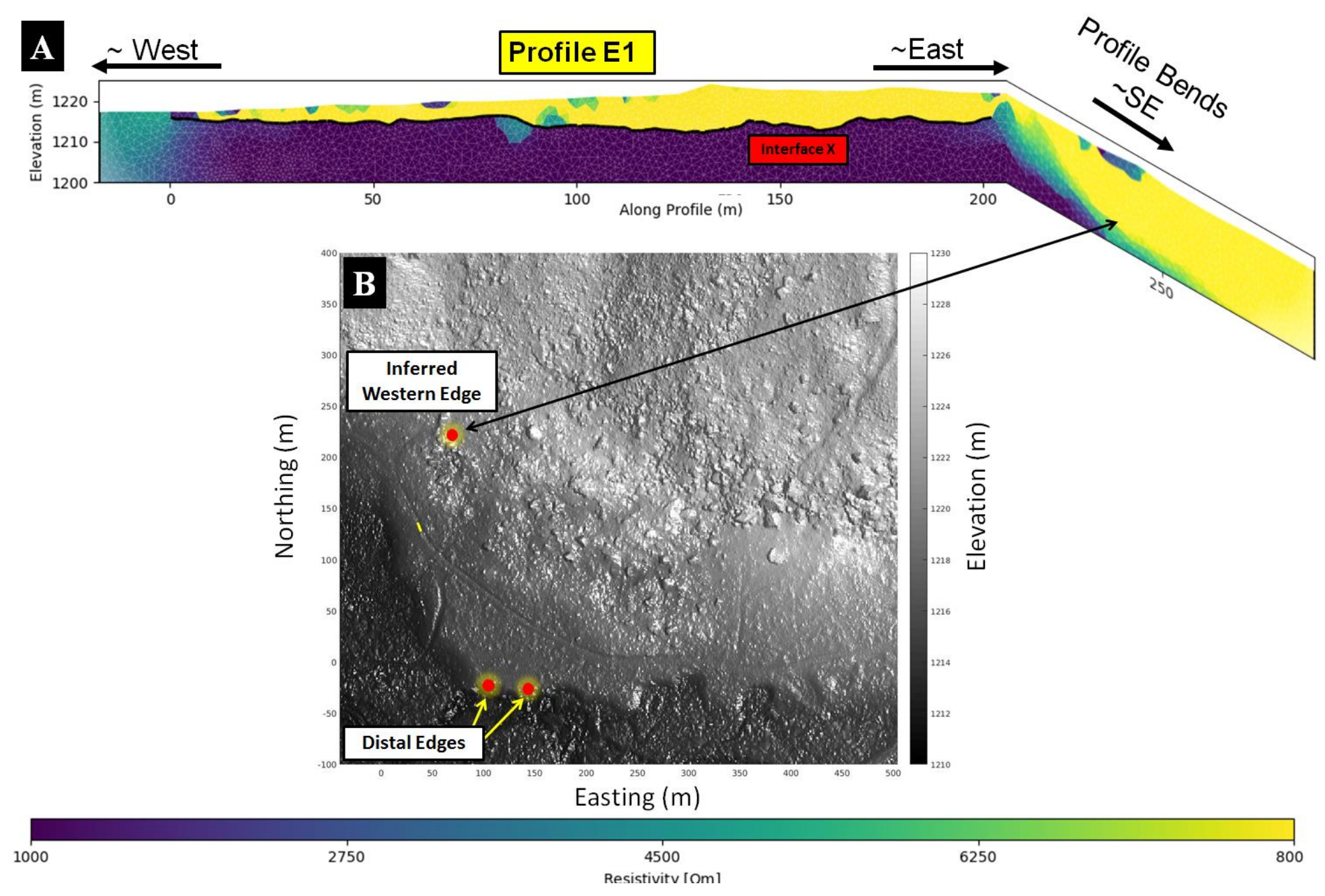

Figure 44: (A) ERT profile E1 and (B) inferred western position of the rock avalanche based on ERT profile 1. 


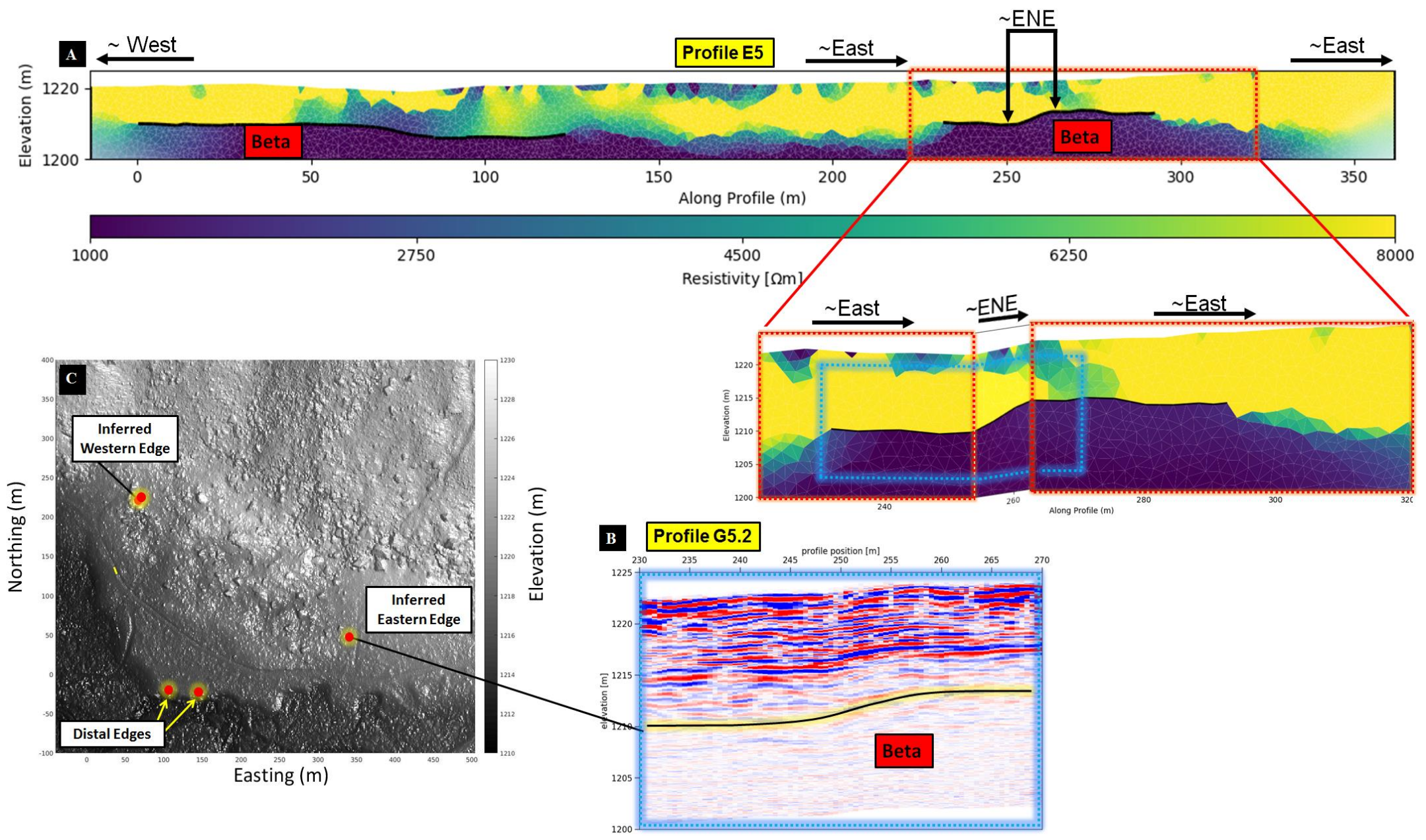

Figure 45: ERT profile E5 constrained with GPR reflector Beta. (B) section of GPR profile 5.2, yellow line highlights reflector Beta. And (C) map view of morphologies interpreted as edges of the avalanche. 


\subsection{Possible Rock Avalanche Outline}

Connecting the mapped extent (red dotes) and following the Beta interface, we were able to infer the possible extent of the Royal Arches Meadow rock avalanche in the valley (Figure 46).
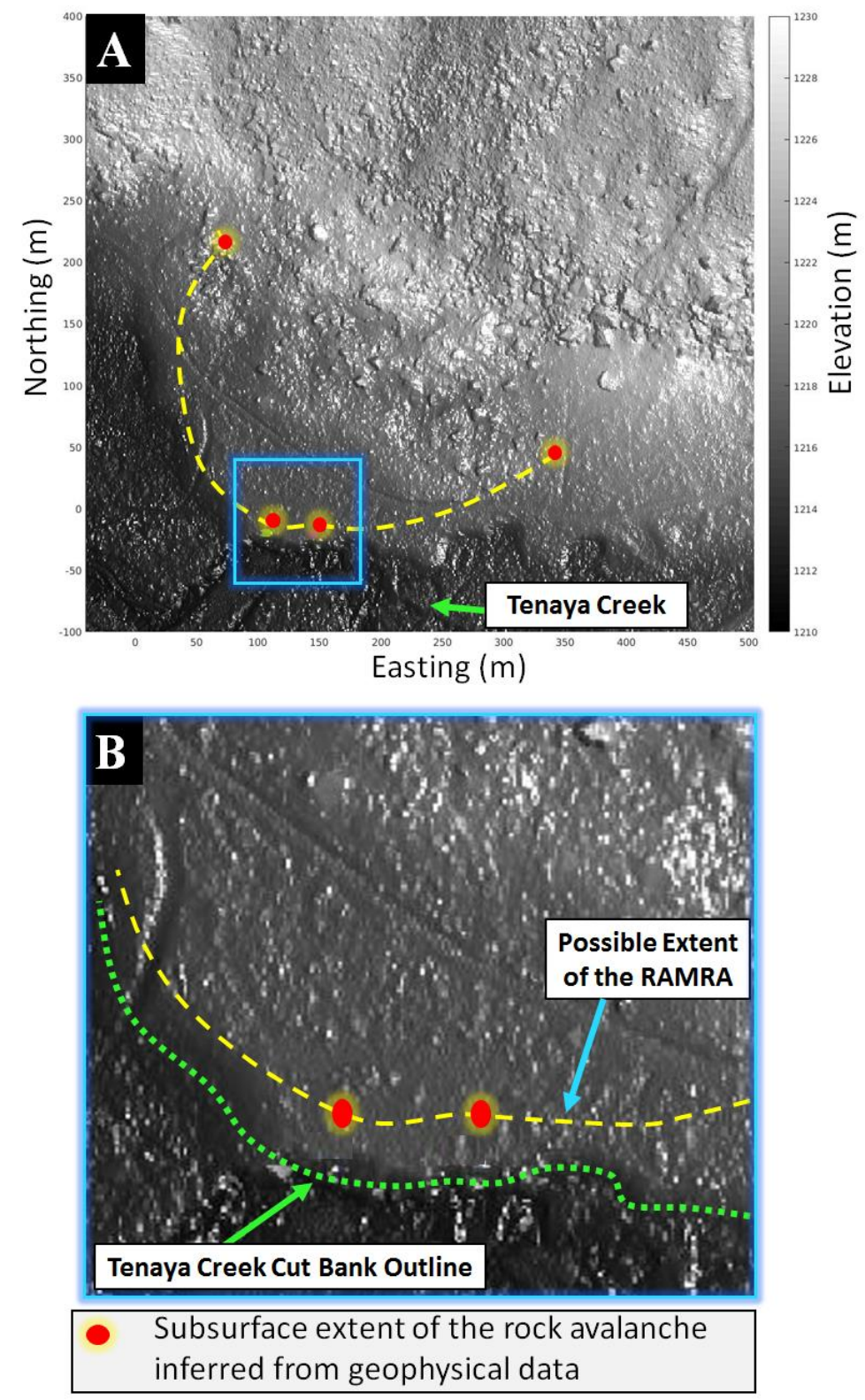

Figure 46: (A) Map view of the study area with the possible extent of the avalanche (dashed yellow line). And (B) zoom in in of the distal most portion of the study area (green dotted line highlights the terrace). 


\subsection{Events Timeline in the Study Area}

Yosemite Valley is thought to have deglaciated by about 15,000 to 17,000 years ago (Huber, 1987; Stock \& Uhrhammer, 2010), leaving behind a relatively flat valley floor free of slope movement deposits (Stock et al., 2012). After the retreat of Tioga ice from the valley, glacial Lake Yosemite formed behind a recessional moraine at the western edge of El Capitan Meadow and extended far up the valley (Matthes, 1930). The presence of a lake in the valley represents an increase in the base level, creating accommodation space for sequences of sediments to be deposited (Figure $48 \mathrm{~A}$ ).

Subsequently, as the large supply of sediment coming from the melting glacial ice wane, rivers started incising in the valley (Figure $48 \mathrm{C}$ ). In between the Lake Yosemite stage and the fluvial incision stage, the Royal Arches Meadow Rock Avalanche (RAMRA) took place ( 14,000 years BP) (Haddon et al., 2016) (Figure 48 B).

The timeline presented in Figure 48 illustrates the idea that the RAMRA can be used as a timestamp of the stage of the valley after the LGM. It also helps us to understand the lack of a strong marked geomorphic expression on the surface of the Royal Arches Meadow rock avalanche. In this case, it is likely that aggradation of modern deposits such as talus deposits in the proximal part of the avalanche and fluvial deposits in the distal portion has partially covered the geomorphic expression of the RAMRA (Haddon et al., 2016). 

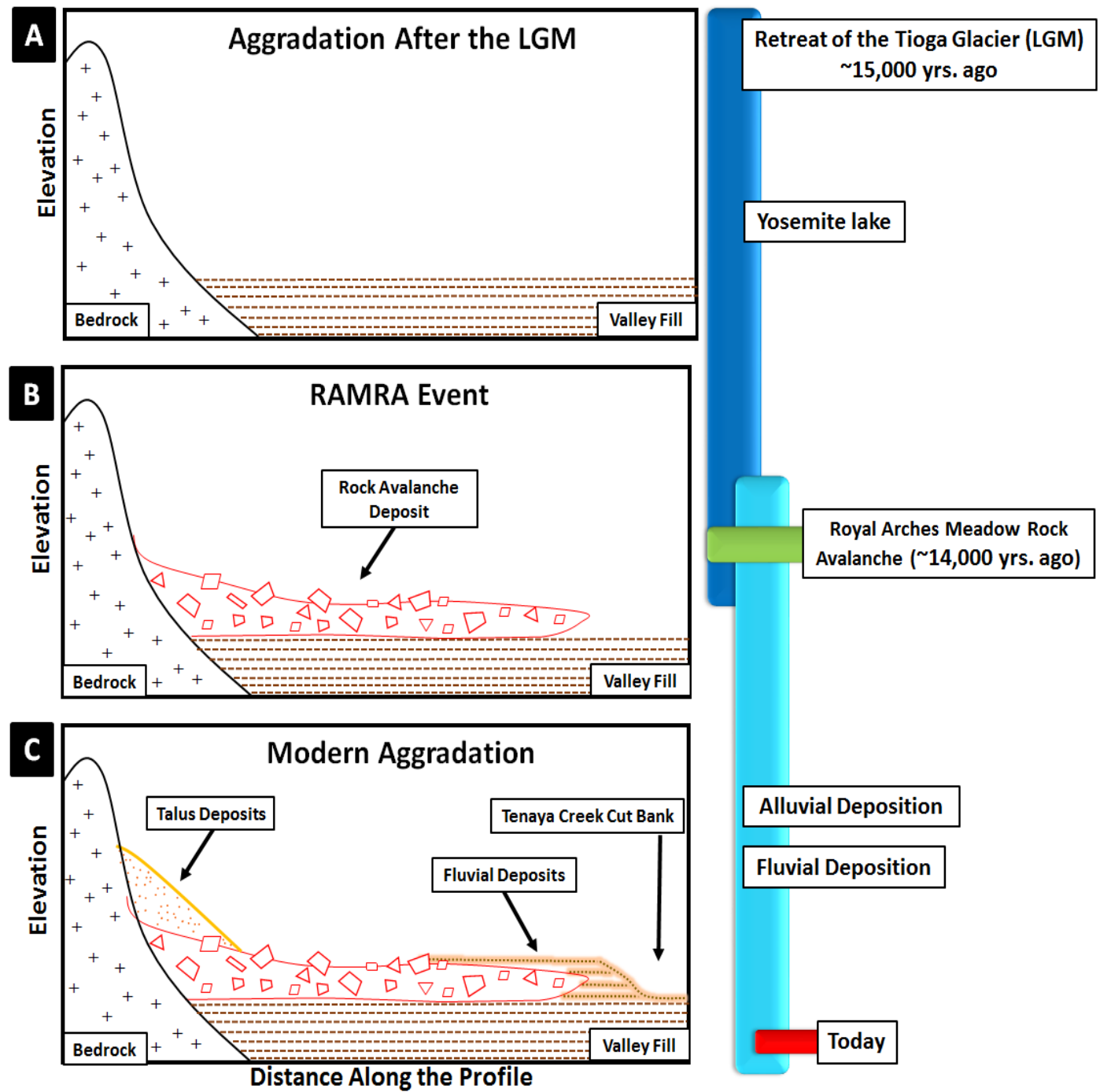

Figure 48: Cartoon illustrating the sequence of events in the study area. (A) Study area during the LGM and Yosemite lake stage. (B) RAMRA event. (C) Modern aggradation in the study area. 


\section{CONCLUSIONS}

The combination of GPR and ERT has been proven to be a powerful tool to image the subsurface of the Royal Arches Meadow rock avalanche. Our results allowed us to investigate the subsurface of the deposit. This then, allowed us to precisely image the southernmost (distal extent) part of the deposit.

Our results also allowed us to pinpoint the local elevation of Yosemite Valley shortly after LGM deglaciation. We found that the surface of the valley underneath the Royal Arches Meadow Rock Avalanche averages 1209m elevation with a variation of +/$3.2 \mathrm{~m}$. In average, the bottom of the rock avalanche is located $10 \mathrm{~m}+/-3.0 \mathrm{~m}$ below the present valley. Unfortunately, we were not able to image the pinpoint the lateral extent of the rock avalanche deposit.

\subsection{Data Fidelity}

Because of the uncertainties associated with geophysical data, it is important to verify how well the imaged features emulate the real geological setting. Here we list evidences that helped us to confirm the consistence of the two methods individually and combined:

\subsubsection{GPR}

1) The raw data already showed all the interpreted features, meaning that the interpreted features were not artifacts created by the data processing.

2) We were able to track reflectors along and across profiles for hundreds of meters. That indicates that those reflectors were a true expression of the subsurface, and not artifacts from reflections from objects located above ground or mountain faces.

3) Different processing strategies resulted in similar results. 
4) Data acquired with different antennas (50 MHz and $100 \mathrm{MHz}$ ) along the same profile presented similar structures.

5) the GPR data is consistent with the ERT data.

6) The processed data made geological sense.

\section{$\underline{6.1 .2 \mathrm{ERT}}$}

1) The consistent pattern of resistive material overlaying conductive material, along the profile and in different profiles confirms the consistency of the inverted results.

2) Different inversion configurations produced similar results.

3) the ERT data is consistent with the GPR data.

4) The processed data made geological sense.

\subsection{Supportive Physical Evidences}

The hypothesis that the rock avalanche deposit extends beyond the range of the large boulders in the study area and that its southmost distal portion was partially covered by modern aggradation was confirmed by the integration of geophysical data. This hypothesis was also confirmed by stratigraphy description of Haddon et al., (2016).

\section{$\underline{6.3 \text { Future Work }}$}

Using purely geophysical data to estimate the volume of the Royal Arches Meadow rock avalanche deposit is a challenging task, given that: (1) It is unclear from the geophysical data where the top of the rock avalanche is; (2) the proximal area of the rock avalanche deposit is buried beneath talus deposits; and (3) the rough terrain does not allow an optimal detailed survey in all directions. Consequently, the ideal would be a combination of subsurface information (geophysical data), surface information (GIS), and cores. 
Traditionally, rock avalanche deposits along with other mass wasting deposits volumes have been estimated using Digital Elevation Models (DEMs). For example, Wieczorek \& Jäger (1996) estimated the volume of mass wasting deposits in Yosemite Valley using three DEMs: One of the present topography, a second depicting the underlying bedrock topography, and a third representing the hypothetical datum of the flat valley level soon after filling of glacial lake Yosemite.

The interface Beta (bottom of RAMRA/valley floor) mapped in this work marks the state of the valley soon after the retreat of the Tioga Glacier in the valley $(\sim 15,000$ yrs. BP) and the filling of glacial lake Yosemite. Therefore, we hope that this mapped interface can be used as future reference for the local elevation of Yosemite Valley shortly after the LGM. 


\section{REFERENCES}

Annan, A. P., \& Davis, J. L. (1976). Impulse radar sounding in permafrost. Radio Science, 11(4), 383-394. https://doi.org/10.1029/RS011i004p00383

Bateman, P. (1992). Plutonism in the Central Part of the Sierra Nevada Batholith, California. In Latest Pleistocene and Holocene surficial deposits and landforms of Yosemite Valley, California (Vol. 1483, pp. 1-194).

Bedrock Geology Of The Yosemite Valley Area Yosemite National Park, California Prepared by. (2016). In Latest Pleistocene and Holocene surficial deposits and landforms of Yosemite Valley, California.

Brody, A. G., Pluhar, C. J., Stock, G. M., \& Greenwood, W. J. (2015). Near-Surface Geophysical Imaging of a Talus Deposit in Yosemite Valley, California. Environmental \& Engineering Geoscience, 21(2), 111-127. https://doi.org/10.2113/gseegeosci.21.2.111

Davis, J. L., \& Annan, a. P. (1989). Ground-Penetrating Radar for High-Resolution Mapping of Soil and Rock Stratigraphy. Geophysical Prospecting, (May 1988), 531-551. https://doi.org/10.1111/j.1365-2478.1989.tb02221.x

Doetsch, J., Linde, N., Pessognelli, M., Green, A. G., \& Günther, T. (2012). Constraining 3-D electrical resistance tomography with GPR reflection data for improved aquifer characterization. Journal of Applied Geophysics, 78, 68-76. https://doi.org/10.1016/j.jappgeo.2011.04.008

Glazner, A. F., \& Stock, G. M. (2010). Geology Underfoot in Yoemite National park.pdf. Missoula, Montana: Mountain Press Publishing Company.

Guenther, T., \& Ruecker, C. (2017). Boundless Electrical Resistivity Tomography BERT 2 - The user tutorial. Retrieved from http://www.resistivity.net/download/berttutorial

Gutenberg, B., Buwalda, J. P., \& Sharp, R. P. (1956). Seismic explorations on the floor of Yosemite Valley, California. Bulletin of the Geological Society of America, 67(8), 1051-1078. https://doi.org/10.1130/0016-7606(1956)67[1051:SEOTFO]2.0.CO;2

Guzzetti, F., Reichenbach, P., \& Wieczorek, G. F. (2003). Rockfall hazard and risk assessment in the Yosemite Valley, California, USA. Natural Hazards and Earth System Science, 3(6), 491-503. https://doi.org/10.5194/nhess-3-491-2003

Haddon, E., Stock, G., \& Booth, D. (2016). Latest Pleistocene and Holocene surficial deposits and landforms of Yosemite Valley, California. Latest Pleistocene and Holocene Surficial Deposits and Landforms of Yosemite Valley, California, (746), 2013. Presented at the AGU Fall Meeting 2016 
Huber, K. N. (1987). The geologic story of Yosemite National Park. In Latest Pleistocene and Holocene surficial deposits and landforms of Yosemite Valley, California (p. 84). Washington, D.C.

Jol, H. (2008). Ground Penetrating Radar Theory and Applications. Elsevier Science (Vol. 27). https://doi.org/10.1016/B978-1-4160-5009-4.50004-2

Kearey, P., Brook, M., \& Hill, I. (2002). An Introduction to Geophysical Exploration. Blackwell Science Ltd (3rd editio). London. https://doi.org/10.1016/j.jafrearsci.2017.04.031

Loke, M. H., Chambers, J. E., Rucker, D. F., Kuras, O., \& Wilkinson, P. B. (2013). Recent developments in the direct-current geoelectrical imaging method. Journal of Applied Geophysics, 95, 135-156. https://doi.org/10.1016/j.jappgeo.2013.02.017

Liu, C., and A. Plattner, 2018, Near surface geophysical imaging of the internal structure of El Capitan Meadow Rock Avalanche in Yosemite National Park, California: Presented at the AGU Fall Meeting 2018

Matthes, F. E. (1930). Geologic history of the Yosemite Valley. U.S. Geol. Surv. Prof. Pap., 160.

Musil, M., Maurer, H. R., \& Green, A. G. (2003). Discrete tomography and joint inversion for loosely connected or unconnected physical properties : application to crosshole seismic and georadar data sets, 389-402.

Neal, A. (2004). Ground-penetrating radar and its use in sedimentology: Principles, problems and progress. Earth-Science Reviews, 66(3-4), 261-330. https://doi.org/10.1016/j.earscirev.2004.01.004

Orlando, L. (2013). GPR to constrain ERT data inversion in cavity searching : Theoretical and practical applications in archeology. Journal of Applied Geophysics, 89, 35-47. https://doi.org/10.1016/j.jappgeo.2012.11.006

Otto, J. C., \& Sass, O. (2006). Comparing geophysical methods for talus slope investigations in the Turtmann valley ( Swiss Alps ), 76, 257-272. https://doi.org/10.1016/j.geomorph.2005.11.008

Plattner, A. (2019). NSGeophysics/GPRPy v1.0.1 (Version v1.0.1). Zenodo. http://doi.org/10.5281/zenodo.255698

R. M. Mitchum Jr., P. R. Vail, S. T. I. (1977). Seismic Stratigraphy and Global Changes of Sea Level: Part 2. The Depositional Sequence as a Basic Unit for Stratigraphic Analysis: Section 2. Application of Seismic Reflection Configuration to Stratigraphic Interpretation. Seismic Stratigraphy - Applications to Hydrocarbon Exploration., 165, 53-62. https://doi.org/10.1306/M26490 
Rücker, C., Günther, T., \& Wagner, F. M. (2017). pyGIMLi : An open-source library for modelling and inversion in geophysics. Computers and Geosciences, 109(January), 106-123. https://doi.org/10.1016/j.cageo.2017.07.011

Sass, O. (2006). Determination of the internal structure of alpine talus deposits using different geophysical methods (Lechtaler Alps, Austria). Geomorphology, 80(1-2), 45-58. https://doi.org/10.1016/j.geomorph.2005.09.006

Socco, L. V., Jongmans, D., Boiero, D., Stocco, S., Maraschini, M., Tokeshi, K., \& Hantz, D. (2010). Geophysical investigation of the Sandalp rock avalanche deposits. Journal of Applied Geophysics, 70(4), 277-291. https://doi.org/10.1016/j.jappgeo.2009.12.005

Stock, G. M., Bawden, G. W., Green, J. K., Hanson, E., Downing, G., Collins, B. D., ... Leslar, M. (2011). High-resolution three-dimensional imaging and analysis of rock falls in yosemite valley, California. Geosphere, 9(2), 381. https://doi.org/10.1130/GES00617.1

Stock, G. M., Collins, B. D., Santaniello, D. J., Zimmer, V. L., Wieczorek, G. F., \& Snyder, J. B. (2013). Historical rock falls in Yosemite National Park, California (1857-2011). U. S. Geological Survey Data Series, 746(746), 17 p. and data files.

Stock, G. M., Luco, N., Collins, B. D., Harp, E. L., Reichenbach, P., Frankel, K. L., ... Park, M. (2012a). Quantitative rock-fall hazard and risk assessment for Yosemite Valley, Yosemite National Park, California. USGS - Yosemite National Park PhD, 30332, 96.

Stock, G. M., \& Uhrhammer, R. A. (2010). Catastrophic rock avalanche 3600 years BP from el Capitan, Yosemite Valley, California. Earth Surface Processes and Landforms, 35(8), 941-951. https://doi.org/10.1002/esp.1982

Stolt, H. (1978). Migration by Fourier Transform. Geophysics, 43(I), $23-48$. https://doi.org/10.1190/1.1440826

Wieczorek, G. F., \& Jäger, S. (1996). Triggering mechanisms and depositional rates of postglacial slope-movement processes in the Yosemite Valley, California. Geomorphology, 15(1), 17-31. https://doi.org/10.1016/0169-555X(95)00112-I

Wieczorek, G. F., Morrissey, M. M., Iovine, G., \& Godt, J. W. (1998). Rock-fall hazards in the Yosemite Valley, California. U. S. Geological Survey Open-File Report, 98 467.

Wieczorek, G. F., Morrissey, M. M., Iovine, G., \& Godt, J. W. (1999). Rock-fall hazards in the Yosemite Valley, California. U. S. Geological Survey Open-File Report, 98 467. 
APPENDICES 
APPENDIX A: GROUND PENETRATIND RADAR MAP AND PROFILES 

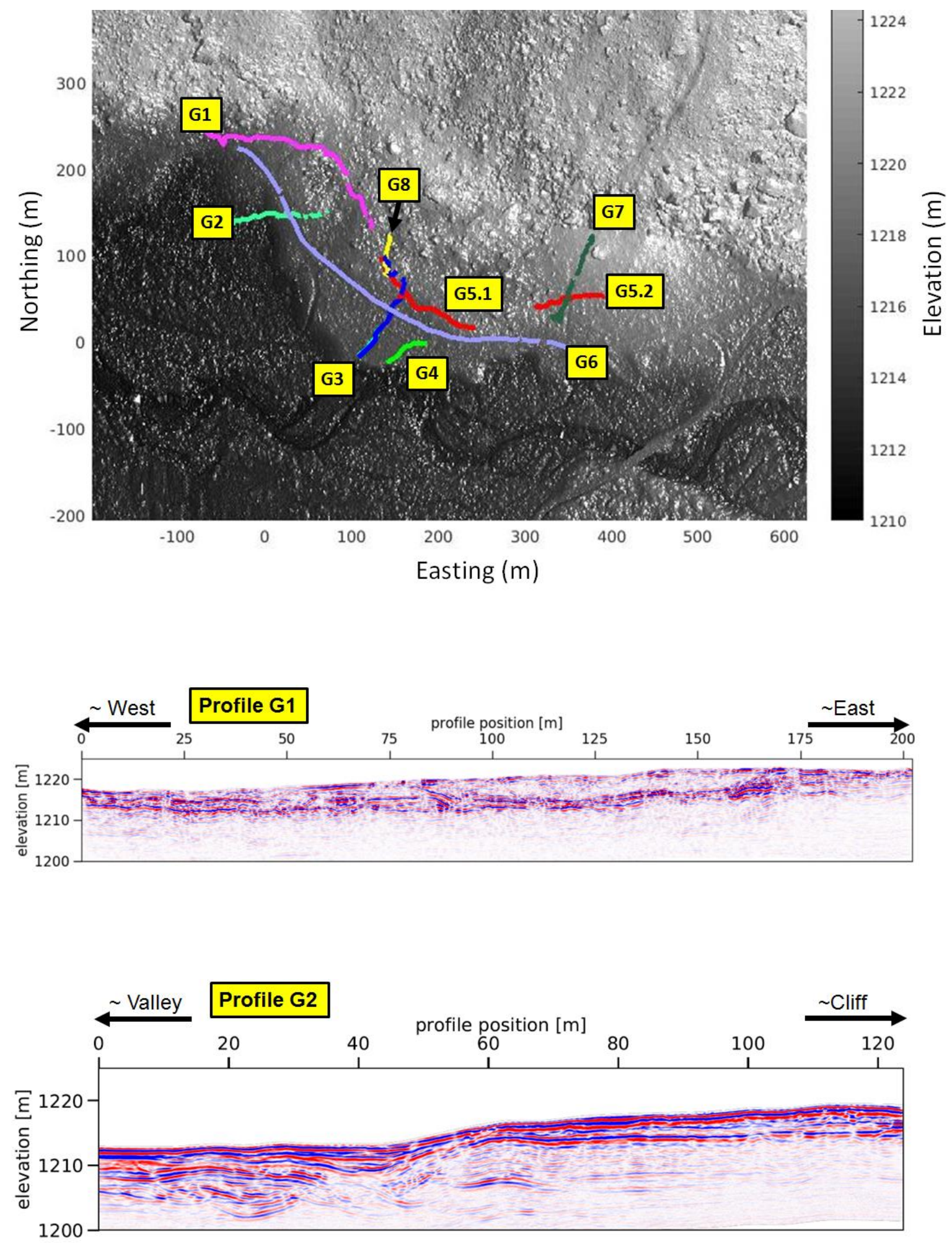

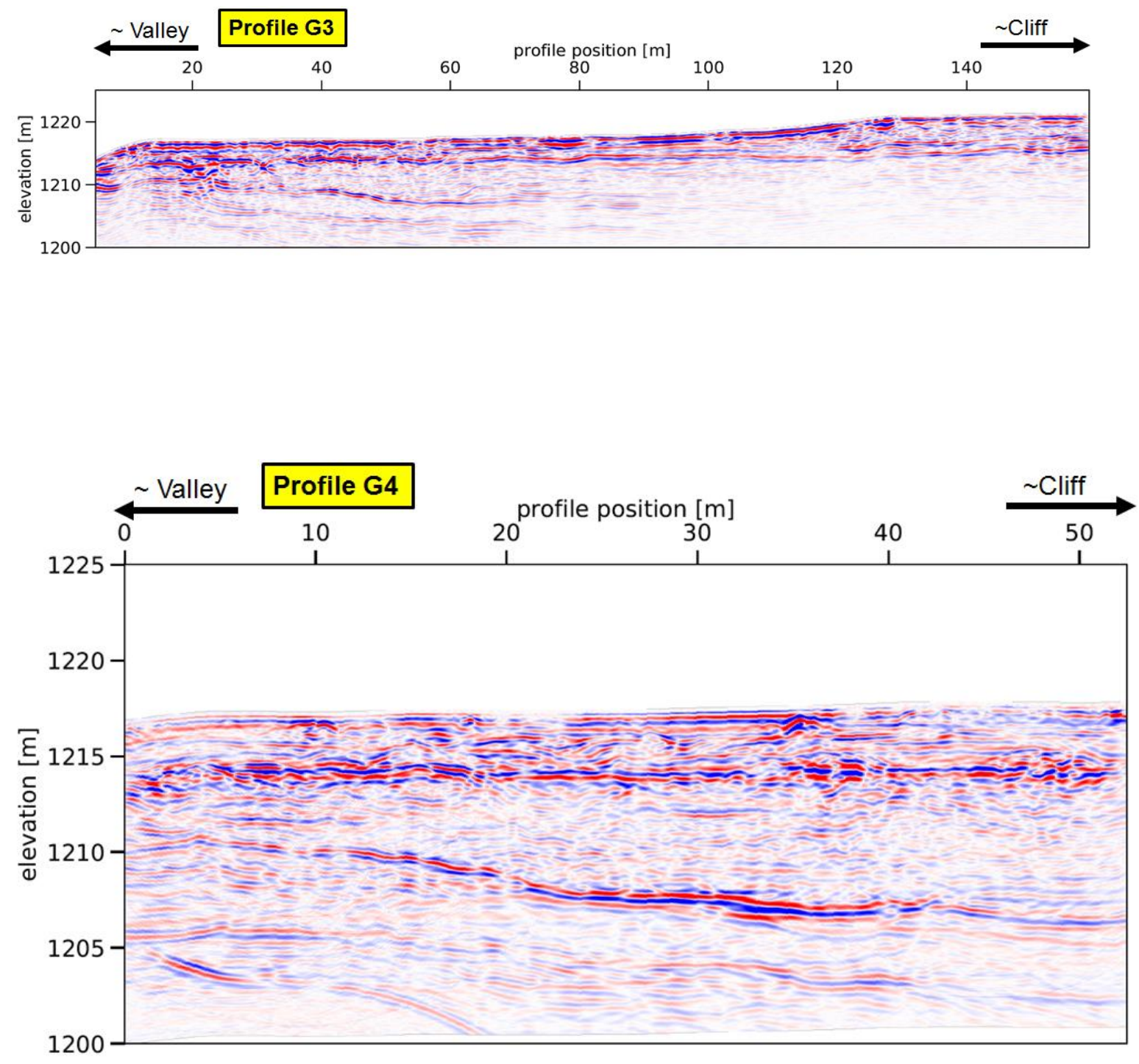

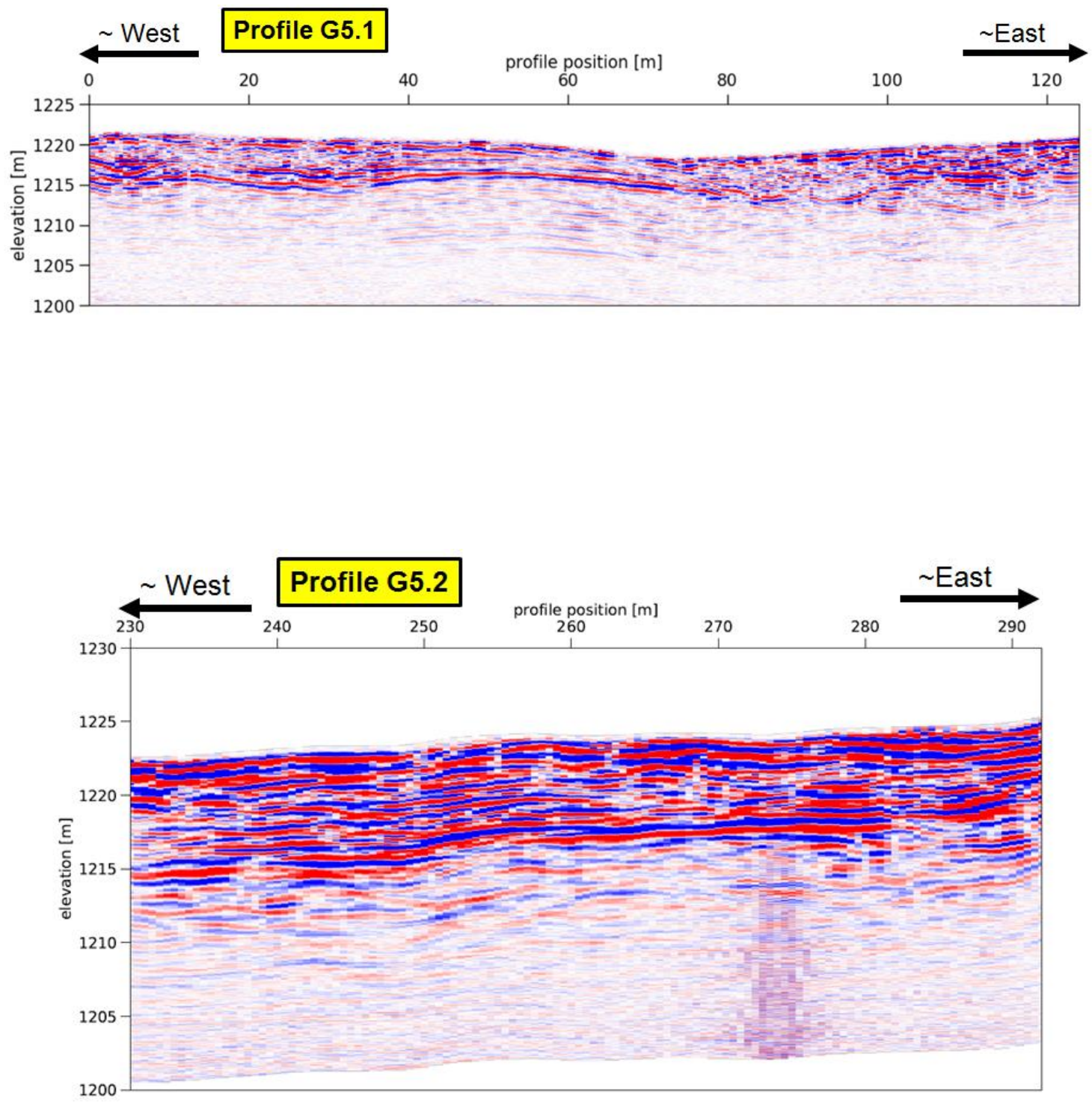

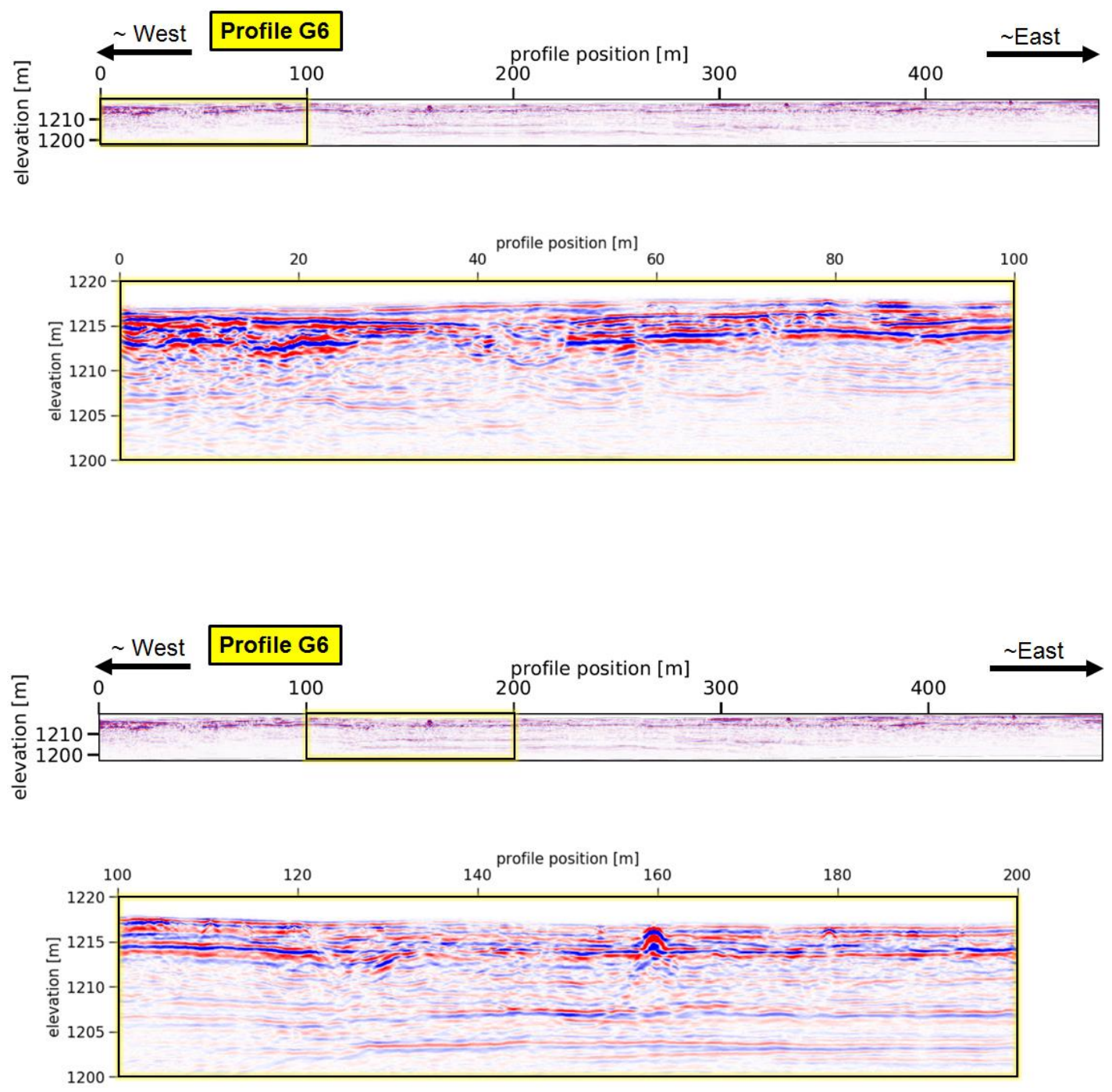

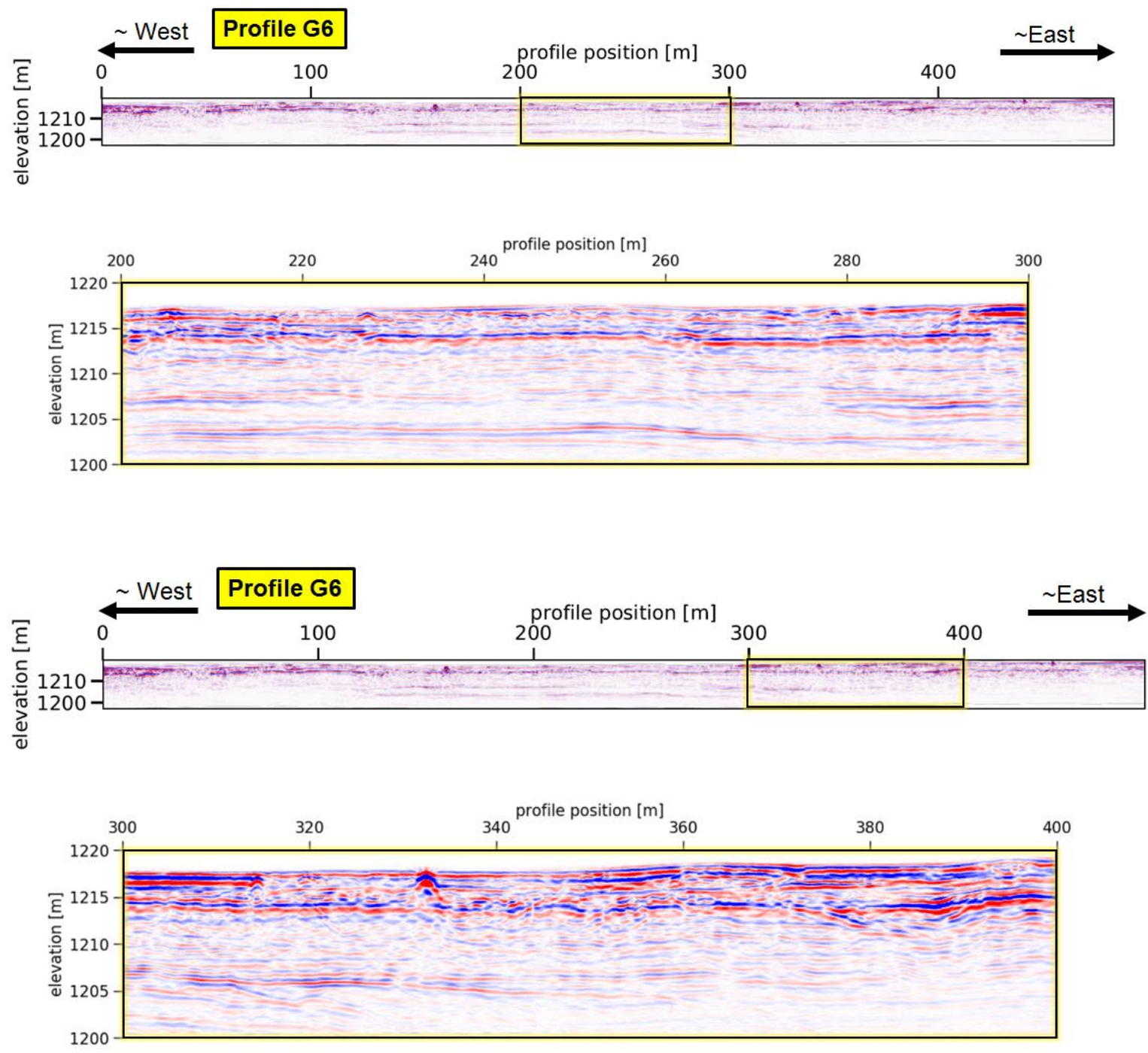

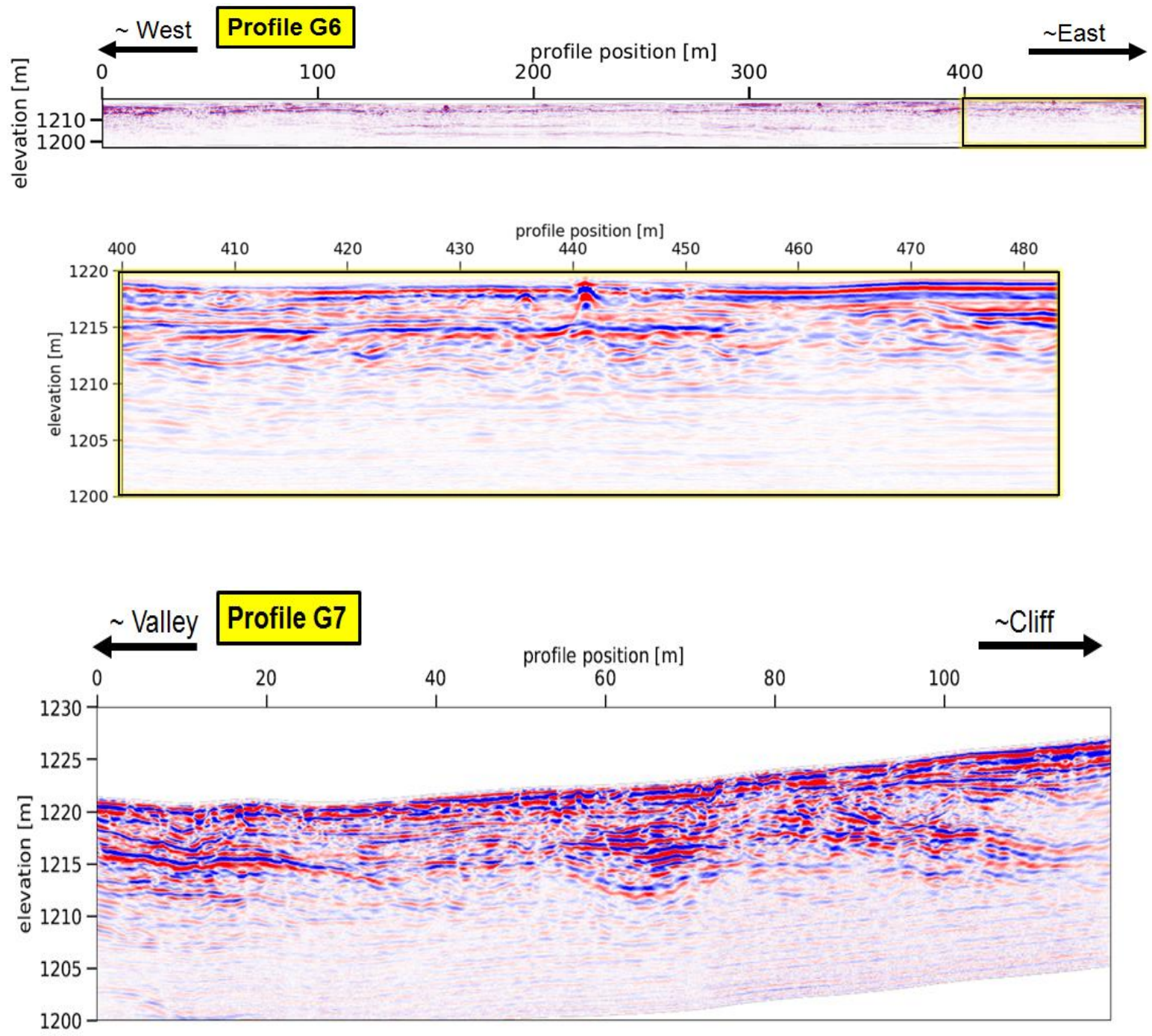


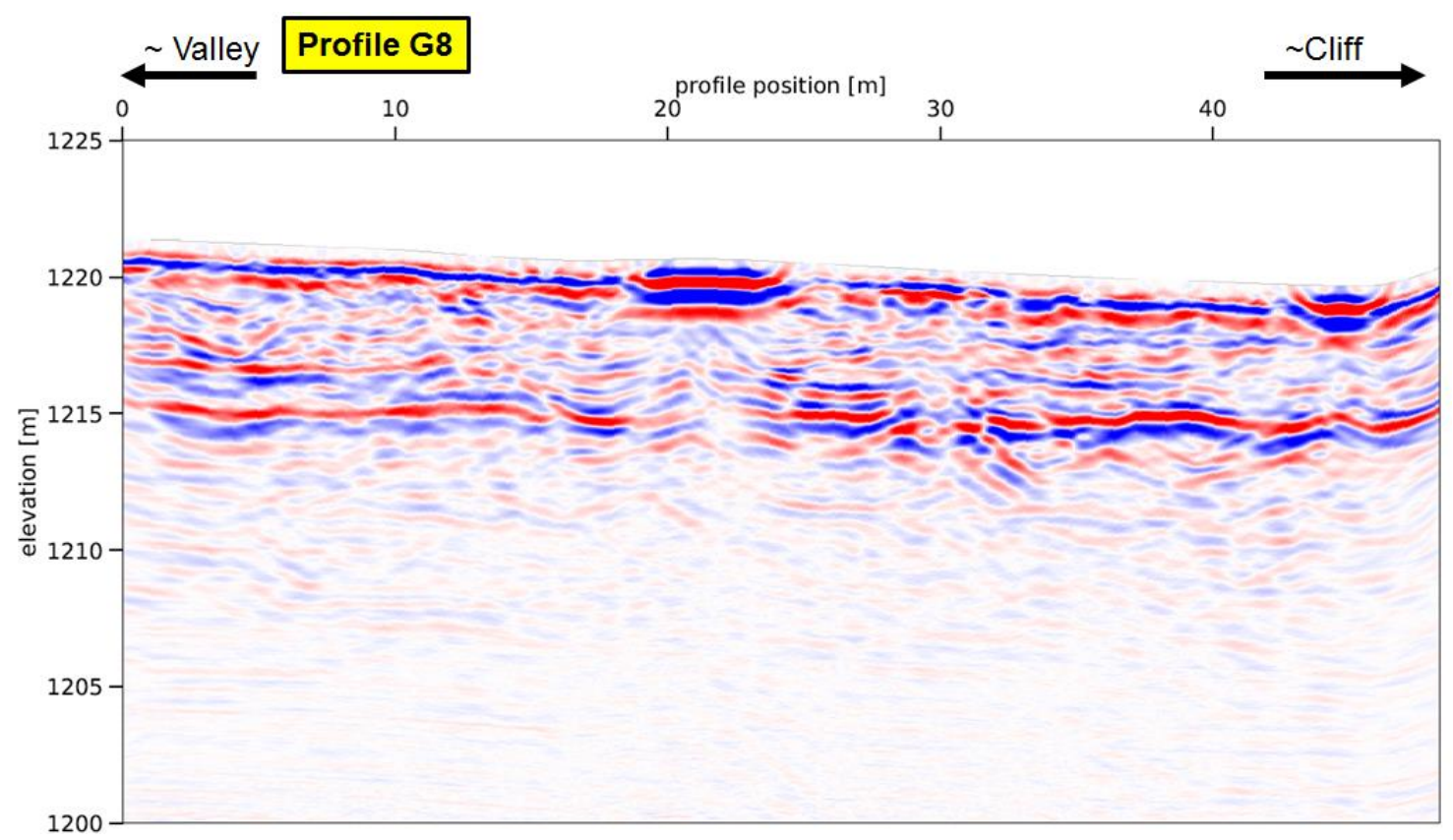


APPENDIX B: ELECTRO RESISTIVITY TOMOGRAPHY PROFILES AND MAP 


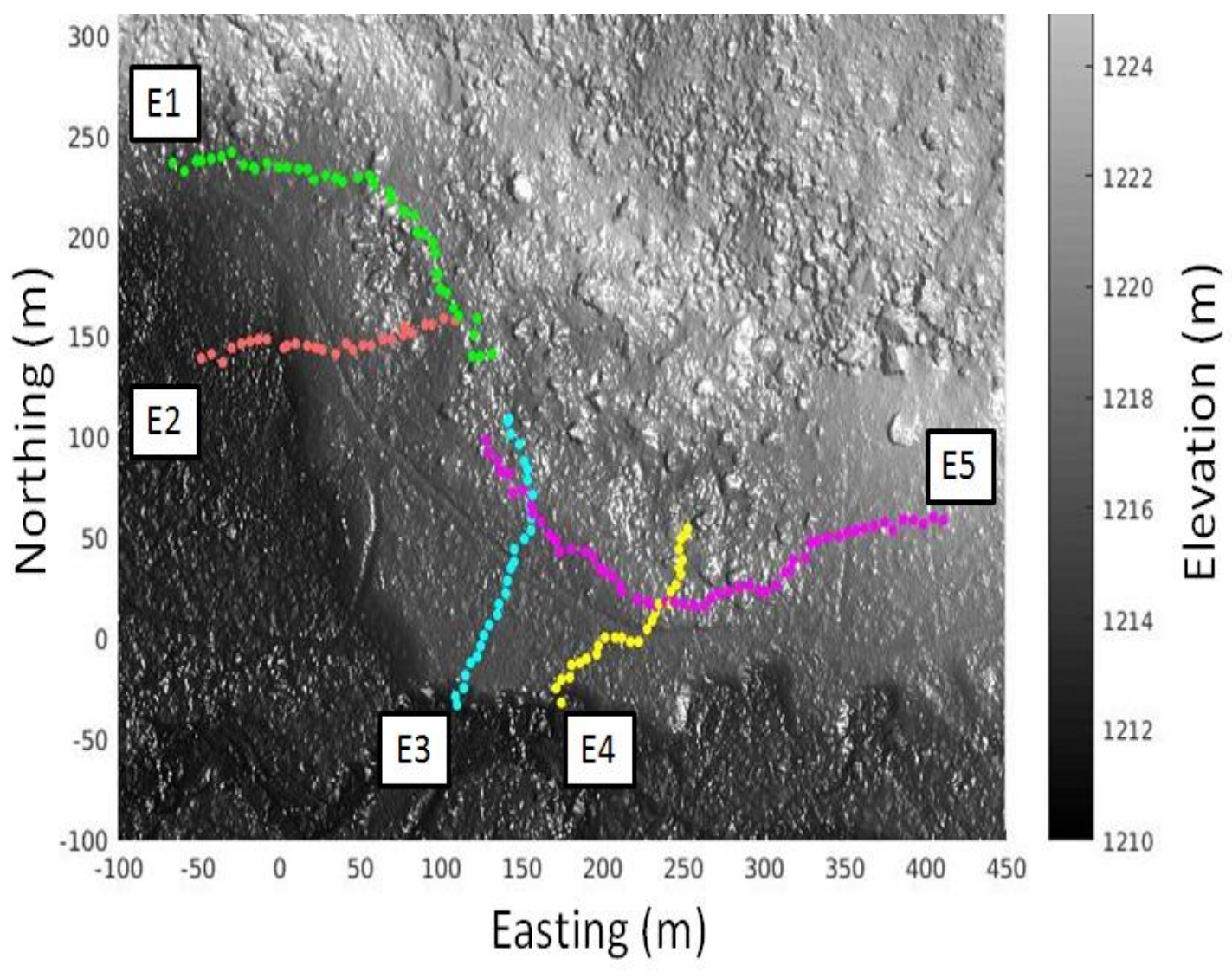



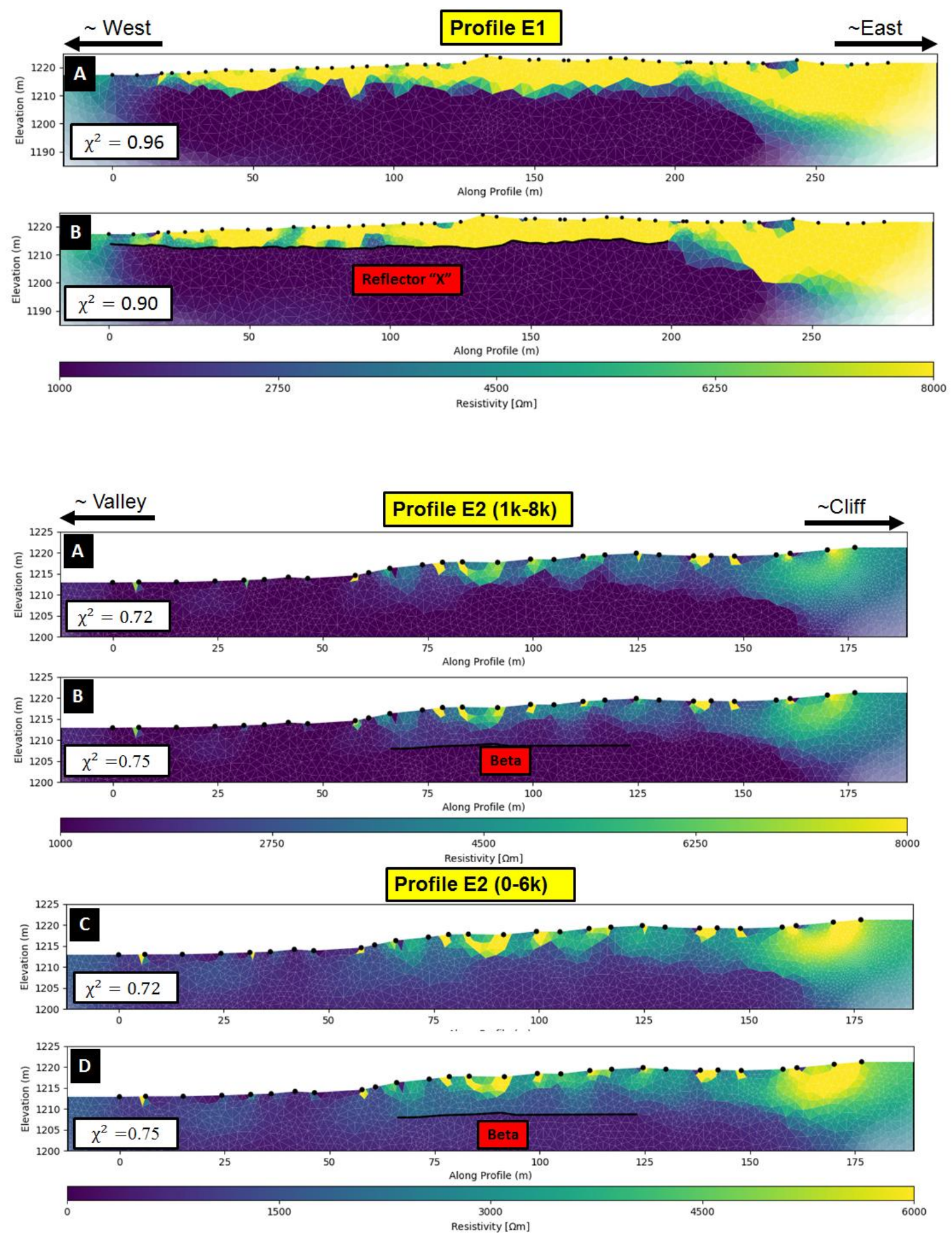

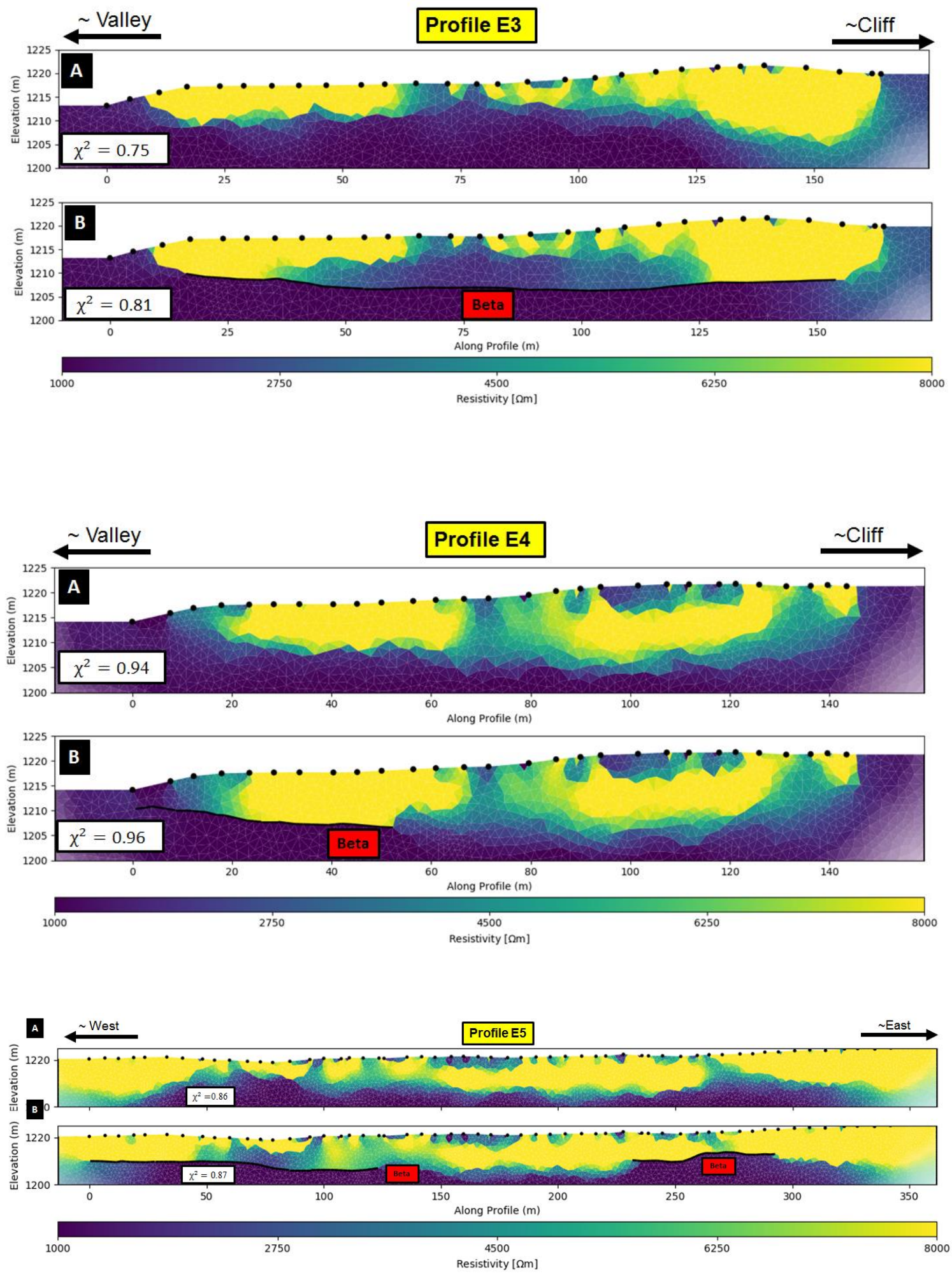